\title{
Liquid scintillation counting for determination of radionuclides in environmental and nuclear application
}

\author{
Hou, Xiaolin
}

Published in:

Journal of Radioanalytical and Nuclear Chemistry

Link to article, DOI:

$10.1007 / \mathrm{s} 10967-018-6258-6$

Publication date:

2018

Document Version

Peer reviewed version

Link back to DTU Orbit

Citation (APA):

Hou, X. (2018). Liquid scintillation counting for determination of radionuclides in environmental and nuclear application. Journal of Radioanalytical and Nuclear Chemistry, 318, 1597-1628. https://doi.org/10.1007/s10967018-6258-6

\section{General rights}

Copyright and moral rights for the publications made accessible in the public portal are retained by the authors and/or other copyright owners and it is a condition of accessing publications that users recognise and abide by the legal requirements associated with these rights.

- Users may download and print one copy of any publication from the public portal for the purpose of private study or research.

- You may not further distribute the material or use it for any profit-making activity or commercial gain

- You may freely distribute the URL identifying the publication in the public portal

If you believe that this document breaches copyright please contact us providing details, and we will remove access to the work immediately and investigate your claim. 


\section{Title page}

2 Names of the authors: Xiaolin Hou

3 Title: Liquid Scintillation Counting for Determination of Radionuclides in Environmental

4 and Nuclear Application

5 Affiliation(s) and address(es) of the author(s):

6 1) Center for Nuclear Technologies, Technical University of Denmark, DK-4000

$7 \quad$ Roskilde, Denmark

8 2) School for Nuclear Science and Technology, Lanzhou University, 730000

9 Lanzhou, China

10 E-mail address of the corresponding author: xiho@dtu.dk

11 


\title{
Liquid Scintillation Counting for Determination of
} Radionuclides in Environmental and Nuclear

\section{Application}

\author{
Xiaolin Hou ${ }^{1,2}$ \\ ${ }^{I}$ Center for Nuclear Technologies, Technical University of Denmark, DK-4000 Roskilde, \\ Denmark \\ ${ }^{2}$ School for Nuclear Science and Technology, Lanzhou University, 730000 Lanzhou, \\ China
}

\begin{abstract}
Liquid scintillation counting (LSC) is a major technique not only for measurement of pure beta emitting radionuclides, but also radionuclides decay by electron capture and alpha emission. Although it is a conventional radiometric technique, but still a competitive techniques for the measurement of many radionuclides. This paper summaries the major development of this measurement technique in instrumentation, methodology and applications in the past decades. The progresses in the instrumentation and methodology mainly focus on the commercialization of triple-to-double coincidence ratio based LSC techniques and its application in the determination of different types of radionuclides. An overall review and discussion on the LSC based analytical methods for the determination of major radionuclides in environmental researches, decommissioning of nuclear faculties and nuclear application are presented, in both measurement techniques and sample preparation using radiochemical separation. Meanwhile the problems and challenges in the development and application of the LSC are also discussed.
\end{abstract}




\section{Keywords}

37 Liquid scintillation counting, triple-to-double coincidence ratio, Cerenkov counting,

38 alpha-beta discrimination, characterization of decommissioning samples, measurement of

39 radionuclides

\section{Introduction}

41 Liquid scintillation counting (LSC) is a conventional radiometric method for 42 measurement of beta emitting radionuclides including those decay by electron capture.

43 With the application of alpha-beta discrimination using pulse shape analyzer (PSA), alpha

44 emitting radionuclides can be also measured by LSC in the presence of beta emitting 45 radionuclides. The major advantages of LSC are high counting efficiency (up to 100\%), 46 relative simple procedure for target preparation, and the feature to obtain beta spectrum of 47 the samples. This measurement technique is still a major radiometric method in the 48 determination of beta emitting radionuclides, especially those emitting low energy beta

49 particles and decaying by electron capture, and still a competitive method compared to 50 mass spectrometry for the short-lived radionuclides $(\mathrm{t} t / 2<100$ years).

51 Although the LSC techniques has been developed and applied for more than 60 years 52 since its first application in the 1950's and was considered as a mature measurement 53 methods, further development in the methodology and new applications continue in the 54 past decades. A series of international conferences dedicated to this technique have been 55 organized for 23 editions since 1957, and the last conference (LSC 2017) was organized 56 in 2017 in Copenhagen (http://lsc2017.nutech.dtu.dk). In the instrumentation and 57 methodology aspects, the major progresses in the past decades are the commercialization 58 of triple-to-double coincidence ratio (TDCR) based instrument, which can implement so59 called absolute measurement without the quench curve or standard addition for efficiency 60 calibration [1-4]. The determination of radionuclides using plastic scintillation resin and 61 conventional LSC instrument has being proposed and shown a promising application, 62 especially for the rapid analysis, which can avoid the utilization of the organic scintillator, 63 therefore reduce the organic radioactive waste [5-8]. In the past years, an increased 
64 application of LSC occurred in the measurement of radionuclides for decommissioning of 65 nuclear facilities, such as ${ }^{36} \mathrm{Cl},{ }^{41} \mathrm{Ca},{ }^{55} \mathrm{Fe},{ }^{63} \mathrm{Ni},{ }^{93} \mathrm{Zr}$, ${ }^{99} \mathrm{Tc}$ and ${ }^{129} \mathrm{I}[9-16]$. The LSC has

66 also shown a competitive application in the rapid analysis of radionuclides for emergency

67 preparedness and homeland security purposes due to its relative short measurement time 68 and simple target preparation [17-20]. In the studies of environmental process using 69 radionuclides, which are naturally occurred and released from human nuclear activities, 70 LSC is also a major technique, especially in the measurement of ${ }^{14} \mathrm{C},{ }^{3} \mathrm{H},{ }^{234} \mathrm{Th}$ and $71{ }^{210} \mathrm{~Pb} /{ }^{210} \mathrm{Bi} /{ }^{210} \mathrm{Po}[21-26]$. LSC is still a common used measurement method in the routine 72 monitoring work in the nuclear facilities and medical researches. Besides the 73 anthropogenic radionuclides, the LSC is a key measurement technique for the

74 measurement of natural occurred radionuclides, such as ${ }^{210} \mathrm{~Pb},{ }^{226} \mathrm{Ra},{ }^{228} \mathrm{Ra},{ }^{222} \mathrm{Rn}[27-28]$ 75 due to its high availability in radioanalytical laboratory and simple sample preparation.

76 The LSC is also widely used for the measurement of gross alpha and gross beta in water 77 samples for screen purpose due to its simple sample preparation.

78 This paper aims present the major progresses in the LSC methodology and new 79 applications of LSC in the determination of radionuclides in different fields, the basic 80 principles and main features of the LSC can be find in many books and papers [29-32].

\section{Progress on the instrumentation and methodology of LSC}

82 The major progress on the instrumentation of LSC in the past decades is the 83 commercialization of triple-to-double coincidence ratio (TDCR) LSC technique, which 84 makes this technique become a routine method for measurement of beta emitting 85 radionuclides.

\section{TDCR liquid scintillation counting}

88 The TDCR method is considered as an absolute measurement technique of LSC for 89 the measurement of the activity of pure $\beta$-emitting and pure electron capture (EC) 90 nuclides. In the liquid scintillation analyzer (LSA) based on TDCR technique, three 
91 photomultiplier tubes (PMTs) and two different coincident outputs are equipped (Fig. 1).

92 The integration of theoretical calculation of counting efficiency (TDCR value) is based

93 on a physical and statistical model of the distribution of scintillation photons and their

94 detection probability by the LSA. When a relationship between TDCR values and the real

95 counting efficiency obtained by measurement of a standard solution with different quench

96 level is established, the radioactivity of the target radionuclides can be obtained without

97 the quench curve or standard addition. The detailed principle of the TDCR method, the

98 configuration of the TDCR detector system, and the TDCR efficiency calculation

99 technique have been reported in many literatures [30-32.

100 In TDCR based LSC, both triple and double coincidences are measured to obtain the 101 TDCR value for efficiency calculation. Triple coincidences are more sensitive to quench 102 compared to double coincidences, a correlation between the quench level (or counting 103 efficiency) and the measured TDCR value can be established for quench correction.

104 Unlike external standard methods, TDCR is a universal method applicable for both 105 chemical and color quenching, for aqueous and organic samples and for different 106 cocktails and range of isotopes. In TDCR based LSA, an external standard for monitoring 107 quench level is not needed. The TDCR efficiency calculation technique enables the 108 determination of pure beta-emitting and pure electron capture nuclides in samples of 109 various states of quench. Alternatively, quench correction can also be made with a curve 110 fit option. Using a set of quench standard samples for the analyte nuclide, a standard 111 quench curve of counting efficiency vs. the TDCR value is first established, and the 112 counting efficiency of an unknown sample can then be determined from the measured 113 TDCR value of the sample. Once established, the TDCR quench curves are quite generic 114 and do not need to be redone. For pure beta emitting radionuclides, the TDCR values 115 usually approximate the overall counting efficiencies. In the Hidex 300SL LSA, a 116 standard quench curve can be stored with the curve fit option, which can be automatically 117 employed to determine the real counting efficiency based on the TDCR value of the 118 sample. The TDCR efficiency calculation technique has been approved to be suitable for 119 routine analysis of beta-emitting nuclides in samples with different quench levels [30-32]. 


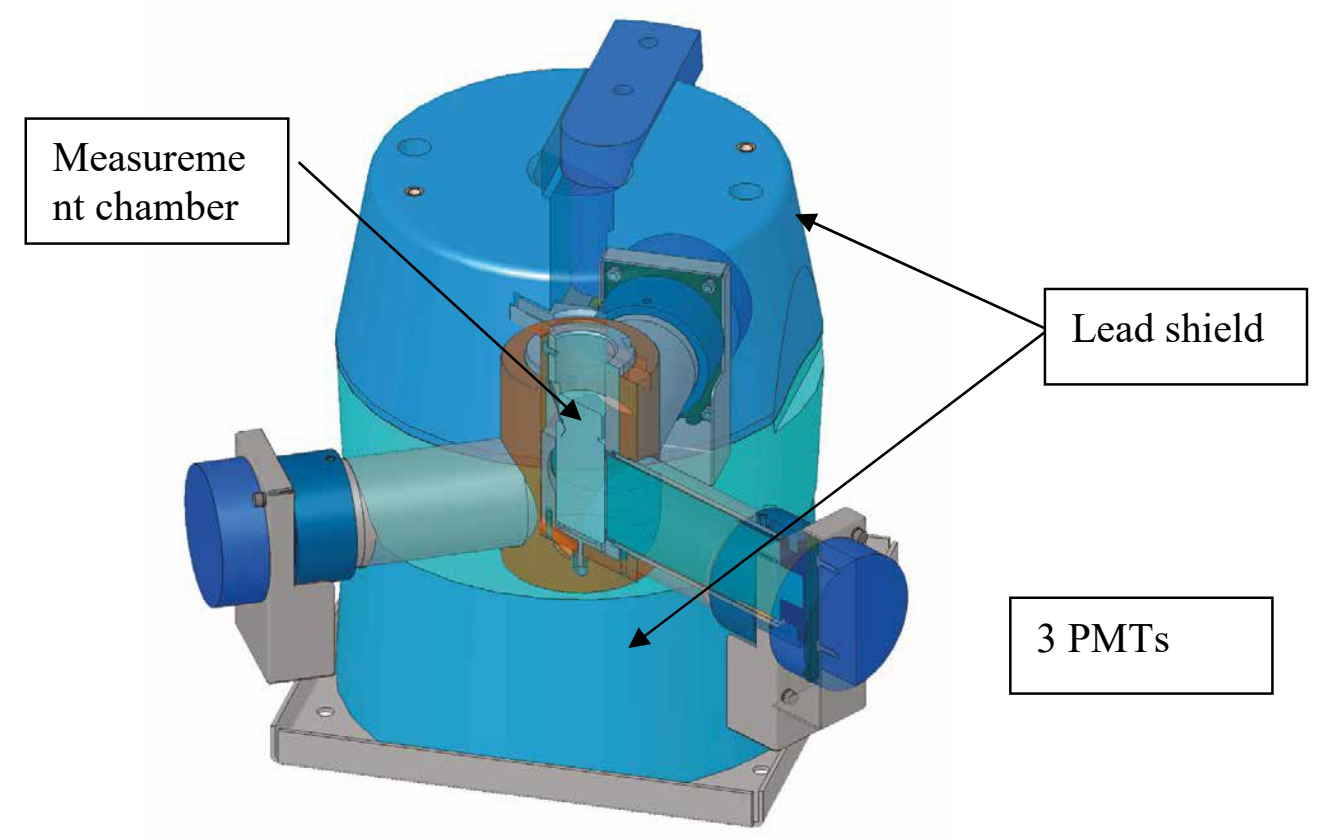

120

121

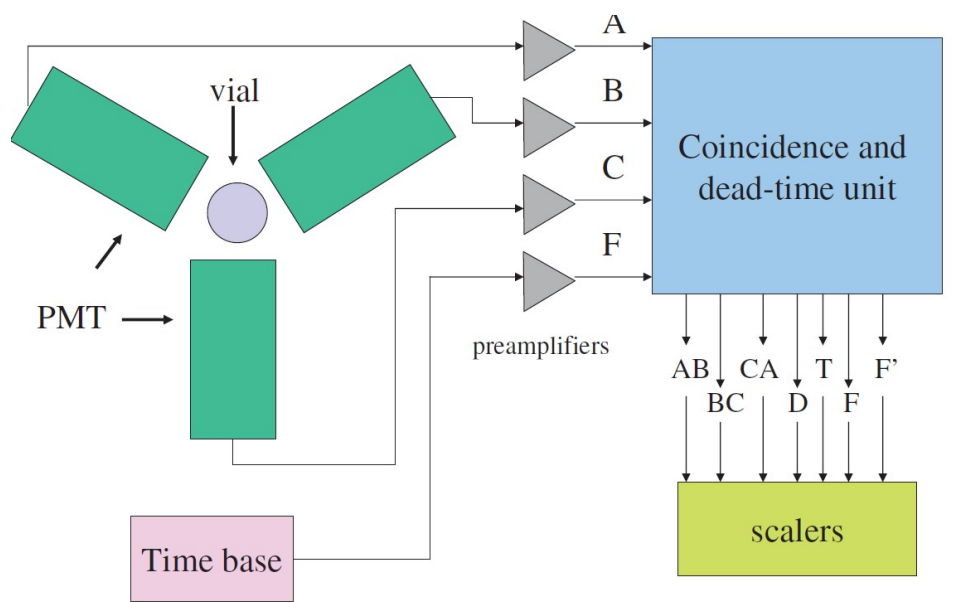

124 Fig. 1 Diagram of principle of TDCR system in LSC instrument and the Hidex 300SL detector structure

127 The TDCR based LSC method has been reported in the 1980's [33], since then many 128 laboratories have built their own TDCR system for LSC measurement. However, these 129 early applications of the TDCR method was exclusively employed in metrological 130 laboratories for radionuclide standardization [31, 32, 34-37]. The first commercial TDCR 
131 LSA (Hidex $300 \mathrm{SL}$ ) was introduced by Hidex Oy in 2008. Recently, two more types of 132 TDCR LSAs, the Hidex 300SL Super Low level and Hidex 600SL were introduced to the 133 market by Hidex Oy. By equipped with additional lead shielding, low level PMT 134 detectors and an active guard detector in the Hidex 300SL super Low Level instrument 135 for further background reduction, the detection limit is significantly improved to be used 136 for environmental monitoring, radiocarbon dating and biofuel verification applications. 137 By extending sample load capacity and queuing, Hidex 600SL TDCR LSA can hold over 138500 small vials or 210 large vials, and can automatic determination large number of 139 samples. Pulse shape analyzer is also equipped in the Hidex TDCR LSAs, so the alpha 140 emitting radionuclides can be also measured in the presence of beta emitters using alpha141 beta discrimination setup. In the past 5 years, many Hidex TDCR LSAs have been 142 installed and applied in many laboratories, which makes the TDCR LSC method has 143 becoming a widely used LSC method for measurement of radionuclide for many 144 applications such as environmental monitoring, radiological protection, and biomedical 145 studies.

146 By compared with conventional LSC method using TriCarb 2200/2500, it was 147 demonstrated that Hidex 300SL performed a good measurement for ${ }^{90} \mathrm{Sr}$ and ${ }^{241} \mathrm{Pu}$ in soil 148 and radioactive slurry samples [38]. A comparison of the Hidex 300SL with Quantulus 1491414 and TriCarb 2800 in different labs by measurement of ${ }^{89} \mathrm{Sr}$ standard solution has 150 also demonstrated a good performance of this method [1]. Hidex TDCR LSA has also 151 been successfully applied for the measurement of ${ }^{3} \mathrm{H},{ }^{63} \mathrm{Ni},{ }^{68} \mathrm{Ga},{ }^{99} \mathrm{Tc}$ and ${ }^{228} \mathrm{Ra}$ and ${ }^{210} \mathrm{~Pb}$ 152 in environmental and waste samples [3, 17, 39-41], it was also used for the determination $153{ }^{68} \mathrm{Ga}{ }^{51} \mathrm{Cr},{ }^{90} \mathrm{Sr}$ and ${ }^{32} \mathrm{P}$ in various biological samples [20, 42-43].

154 The TDCR LSC has also been investigated for measurement of ${ }^{14} \mathrm{C}$ samples using 155 Hidex 300SL instrument, it was found that the TDCR quench correction worked well for 156 measuring the activity of ${ }^{14} \mathrm{C}$ in quench standards with high activity levels, it may not be 157 preferred for the correction of benzene impurities in very low activity samples for 158 radiocarbon dating. Thus, based on the observed position of the right slope of the ${ }^{14} \mathrm{C}$ or 159 muons spectrum, a quench correction method was proposed and seemed to be more 160 optimal for ${ }^{14} \mathrm{C}$ dating. However, a relative high background level of $13.7 \mathrm{CPM}$ was 
161 observed in triple coincidence model, it prevents from the precise measurement of ultra162 low-level samples for ${ }^{14} \mathrm{C}$ dating purpose [44]. The introduction of the Hidex 300SL 163 Super Low Level instrument in the recent years can significantly suppress the 164 background level, which will makes it comparable to the conventional Quantulus 1220 165 instrument and enable to be applied for ${ }^{14} \mathrm{C}$ dating.

166 With the feature of PSA, alpha-beta discrimination can be applied and alpha emitting 167 radionuclides have been measured by Hidex TDCR LSA, e.g. ${ }^{226} \mathrm{Ra}$ a solution containing $168{ }^{210} \mathrm{~Pb},{ }^{210} \mathrm{Bi}$, and ${ }^{228} \mathrm{Ra}$ [3]. Meanwhile Hedix TDCR LSA was also used for measurement 169 of gross alpha/gross beta in water samples [45].

170 For electron capture nuclides, such as ${ }^{55} \mathrm{Fe},{ }^{41} \mathrm{Ca}$ and ${ }^{139} \mathrm{Ce}$, there can be more than one 171 counting efficiencies corresponding to a given TDCR value, as the decay spectra are not 172 continuous due to the contribution of two or more separated group of scintillation energy 173 from conversion electrons and gammas. Thus, the introduction of a new parameter into 174 the algorithm of counting efficiency determination would be required to yield a single175 valued efficiency vs. TDCR curve [46]. Hidex TDCR LSA has been used for the 176 measurement of ${ }^{55} \mathrm{Fe}$ in radioactive waste, irradiated steel and urine samples [4, 47-48]. 177 An obvious discrepancy was observed between the measured TDCR value and the 178 counting efficiency of ${ }^{55} \mathrm{Fe}$. Therefore, a quench correction needs to be conducted by 179 fitting with a quench calibration curve, especially for the solution with high color quench 180 due to the ferric ion in $\mathrm{HCl}$ or water solution. By obtaining a simple power function of 181 counting efficiency vs. the TDCR value with a set of quench standards, satisfactory 182 results of quench correction for ${ }^{55} \mathrm{Fe}$ has been achieved [47]. To reduce the color quench 183 in the measurement of ${ }^{55} \mathrm{Fe}, \mathrm{H}_{3} \mathrm{PO}_{4}$ can be used to dissolve the separated iron in 184 precipitate, a colorless solution can be obtained by formation of an iron complex with $185 \mathrm{H}_{3} \mathrm{PO}_{4}[12]$.

\section{Cerenkov counting using TDCR LSA}


Besides the typical beta-emitting radionuclides by counting the electrons produced in their radioactive decay, the TDCR LSA can be also used for the measurement of highenergy beta emitting nuclides (e.g., ${ }^{89} \mathrm{Sr},{ }^{90} \mathrm{Y},{ }^{32} \mathrm{P},{ }^{106} \mathrm{Rh},{ }^{204} \mathrm{Tl}$ ) by Cerenkov counting [2].

191 In the Cerenkov counting, the samples are measured by directly counting Cerenkov

192 photon/s without addition of the scintillation cocktail. Since Cerenkov photons are

193 produced directly in sample solutions, no inhibition of the photon emission process due to

194 fluorescence is involved; thus, Cerenkov counting is free of chemical quenching.

195 However, Cerenkov counting efficiency could be affected strongly by color quenching.

196 Even very light color can produce a significant quench effect with a noticeable reduction

197 in counting efficiency.

198 The color quench for Cerenkov counting is usually corrected by internal standard method or quench curve method using an external gamma source in the ordination LSC method. In the TDCR LSC, constructing of quench correction curves is not needed, the

201 effects of color quenching on Cerenkov efficiency can be automatically corrected based 202 on the measured TDCR values. A free parameter model has been proposed for 203 standardization with the TDCR LSC [2, 49]. A stochastic TDCR model based on the 204 Monte Carlo code Geant4, has also constructed to determine the Cerenkov efficiency 205 using the experimental TDCR value [50]. These TDCR Cerenkov models have been 206 successfully tested for the activity standardizations of ${ }^{90} \mathrm{Y},{ }^{89} \mathrm{Sr}$ and ${ }^{68} \mathrm{Ge}$ in nuclear 207 medicine applications [4, 51]. The TDCR Cerenkov method would allow for calculating 208 the counting efficiency without an external or internal standard source.

209 Using a TDCR LSA (Hidex 300SL), the TDCR Cerenkov method has been 210 successfully used for quantitative determination of high-energy beta emitters in 211 environmental samples. An empirical correlation between the Cerenkov counting 212 efficiency for ${ }^{90} \mathrm{Y}$ and the measured TDCR value was established for the correction of 213 color quench effect on the determination of ${ }^{90} \mathrm{Sr} /{ }^{90} \mathrm{Y}$ in aqueous samples [18-19]. The 214 direct TDCR Cerenkov counting can serve as a rapid screening method for high-energy 215 beta-emitting radionuclides in environmental water samples without any radiochemical 216 separation procedure. TDCR Cerenkov counting without chemical separation has been 217 compared with ordinary LSC following radiochemical separation for the measurements 
218 of ${ }^{90} \mathrm{Sr}^{90} \mathrm{Y}$ in groundwater samples collected in a contaminated riverbed, and found a 219 good agreement between two methods [52]. Using three commercial liquid scintillation 220 analyzers (Triathler, Tri-Carb 3180 and Hidex 300 SL) with one-, two- and three PMTs, 221 the effects of measurement conditions for Cerenkov counting efficiency has been 222 investigated, it was found that the TDCR Cerenkov counting would be well suited for 223 routine quantitative determination of high energetic beta-emitting radionuclides in low 224 level environmental samples [53]. However, to date, the TDCR Cerenkov counting is still 225 not yet widely applied for measurement of high-energy beta-emitting radionuclides with 226 only few publications focusing on the determination of ${ }^{90} \mathrm{Sr}^{90} \mathrm{Y}$ in environmental samples $227 \quad[18,52,54-55]$.

\section{Determination of anthropogenic radionuclides}

229 LSC is the major technique for measurement of pure beta-emitting radionuclides, 230 including the radionuclides decay by electron capture. The most important anthropogenic 231 radionuclides in view of environmental radioactivity, tracer application in various 232 disciplines and nuclear waste management are ${ }^{3} \mathrm{H},{ }^{14} \mathrm{C},{ }^{36} \mathrm{Cl},{ }^{41} \mathrm{Ca},{ }^{55} \mathrm{Fe},{ }^{63} \mathrm{Ni},{ }^{89} \mathrm{Sr},{ }^{90} \mathrm{Sr}$,

$233{ }^{129} \mathrm{I}$ and ${ }^{241} \mathrm{Pu}$. Large efforts have been given in the past decades in the establishment and 234 improvement of the analytical method for these radionuclides, especially with the rapidly 235 increased requirement in the characterisation analysis of decommissioning waste in the 236 past years. The progress on the analytical methods for these radionuclides using LSC are 237 presented below.

\section{Tritium $\left({ }^{3} \mathbf{H}\right)$}

240 Tritium is a low-energy $\left(E_{\max }=18.6 \mathrm{KeV}\right)$ pure beta emitter with a half-life of 12.32 years, the 241 LSC is the most often used method for its measurement. Ionization chamber and proportional 242 counter methods can be also used for the measurement of tritium, but often used for measure 243 relative high-level tritium because of high detection limit. In these methods, gas tritium (HT, $\mathrm{T}_{2}$ ) 244 and ${ }^{14} \mathrm{C}\left({ }^{14} \mathrm{CO}_{2}, \mathrm{CH}_{4}\right)$ are direct introduced to detector chamber and measured for on-line 245 monitoring for tritium level [56].

246 Besides the production in the upper atmosphere through cosmic ray reactions of nitrogen and 247 oxygen, tritium in the present environment is mainly from atmospheric nuclear weapons testing 
248 and on-going nuclear fuel cycle operations. Since the partial atmospheric nuclear test ban treaty

249 in 1963, the worldwide levels of tritium in the environment have been decreasing at a rate

250 approximately equal to its half-life. Generally, nuclear fuel cycle operations are of concern to the

251 immediate locale only, with relatively minor contributions to more general environmental tritium

252 levels. Regulated monitoring of specific sites and hydrological studies are the principal

253 applications of environmental tritium analysis.

254 Tritium in water form is normally prepared as purified water for measurement using LSC. To

255 improve the counting efficiency, water is filtered, neutralized and distilled to remove the particles

256 and chemicals (including salts) to reduce the quench effect. To overcome the color quench (e.g.

257 urine sample), charcoal adsorption is often utilized to remove the colorful organics before further

258 neutralization and distillation. A commercial available tritium column (Tritium resin, Triskem

259 International) is dedicated to purify water sample for tritium (tritated water)

260 determination using LSC, this column is filled with cation and anion exchange resins for

261 removal of ions and a prefilter for removal of organics. A scintillation cocktail is mixed

262 with the purified water for LSC measurement, a better compatible cocktail is normally

263 selected to use bigger volume of water and to obtain a better counting efficiency, and

264 finally a good detection limit. For determination of tritium in environment, $10 \mathrm{ml}$ water

265 sample is often used and mixed with $10 \mathrm{ml}$ scintillation cocktail for LSC measurement. In

266 this case, a detection limit of 1-2 Bq/L can be obtained using ultra-low level LSA (e.g.

267 Quantulus 1220, PerkinElmer, USA). For improvement of detection limit, a high capacity

268 LSA (e.g. AccuFLEX LSC-LB7, HITACHI ALOKA, Japan) with $145 \mathrm{ml}$ vial can be

269 used. In this case, up to $70 \mathrm{ml}$ water sample can be used, and a detection limit down to

$270 \quad 0.3 \mathrm{~Bq} / \mathrm{L}$ can be reached.

271 Since tritium in the present environmental water samples is already declined to $<2 \mathrm{~Bq} / \mathrm{L}$,

272 the direct measurement using LSC is not sufficient sensitive for its reliable determination.

273 Electrolysis method is therefore often applied for the enrichment of tritium in water. This

274 method is based on the slightly higher binding energies of tritium with oxygen in tritated

275 water compared to hydrogen, and molecules of THO are not decomposed to form HT and

$276 \mathrm{O}_{2}$ as readily as $\mathrm{H}_{2} \mathrm{O}$ or DHO $(\mathrm{T}=$ tritium, $\mathrm{D}=$ deuterium $)$. With this method, tritium can

277 be enriched by a factor of 15-40, depending on the volume of the electrolysis cell and

278 final volume of the enriched tritiated water. It should be mentioned that the electrolysis

279 process is quite slow; 5-10 days are normally needed for treatment of 100-500 ml water 
280 in each cell. Combined the electrolysis enrichment, the detection limit of LSC for tritium

281 can be improved to be lower than $0.1 \mathrm{~Bq} / \mathrm{L}$. Noble gas mass spectrometry is the most 282 sensitive technique for measurement of tritium in very low-levels $(<1 \mathrm{mBq})$, which is 283 based on the measurement of ${ }^{3} \mathrm{He}$, the decay daughter of tritium. Helium in the sample is 284 first removed by vacuum, and the sample in a tight container is kept for a few months for 285 ingrowth of helium from tritium decay, the produced ${ }^{3} \mathrm{He}$ is separated and measured 286 using noble gas mass spectrometry [57]. The major drawback of this method is its long 287 analytical time of a few month to years due to the ingrowth of ${ }^{3} \mathrm{He}$, and LSC is still the 288 dominant method for measurement of tritium.

289 Tritium in solid sample such as biological and soil samples needs to be separated first 290 from the solid matrices. Tritium exist in biological samples as part of the water 291 component (FWT, free water tritium) or as part of the organic structure (BT, bound 292 tritium). The free water tritium is often separated from the sample by freeze drying and 293 collecting the evaporated water. To analyze the bound tritium, the sample is dried first 294 (freeze drying or low-temperature oven drying at $\sim 60-80^{\circ} \mathrm{C}$ ) and then combusted to 295 separate the bound tritium. The water of combustion is collected, purified as required and 296 measured using LSC.

297 Azeotropic distillation is also used for extraction of free water tritium, and cyclohexane is 298 the most often used azeotrope for extracting water from various biological samples, such 299 as honey, milk, vegetation, soil, and fish for tritium measurement using LSC. The organic 300 bound tritium in biological samples and firming binding tritium inside of the crystal of 301 grains of soil and sediment are often separated using combustion with oxygen flow at 302 high temperature. In this case, tritium in organic substance is converted to water vapor 303 and collected by condensing [58-59], and the firmly binding tritium in the crystal of soil 304 and sediment grains and metals can be also separated by converting it into water vapor by 305 combustion with oxygen flow [60-62]. The converted tritium in water vapor form is 306 condensed and collected as liquid water and finally measured using LSC.

307 In the past decades, the major progress on the determination of tritium focus on the 308 analysis of various decommissioning samples because of the increased requirement in the 309 characterization of decommissioning waste, and highly present of tritium in all types of 310 samples in the nuclear facilities and the high mobility of tritium [10, 61-65 ]. Hou [10, 61] 
311 has reported a combustion method for separation of tritium from decommissioning 312 samples, such as concrete, graphite, steel, aluminum for its determination using LSC. A 313 Sample Oxidizer (PerkinElmer) was used for the separation of tritium in all species. The 314 solid sample was ground/cut to fine powder/small pieces and mixed with combustible 315 materials (e.g. cellulous powder), all tritium in the samples is converted to THO by 316 combustion with an oxygen flow and at temperature of more than $1000{ }^{\circ} \mathrm{C}$. The formed 317 water vapor is converted to liquid water in an air condenser and is directly collected in a 318 LSC vial; scintillation cocktail is flow into the vial through the tube for rinsing. After 319 mixing, tritium is then measured using LSC. The entire process only takes less than two 320 minutes, and therefore very suitable for the rapid analysis of large number of 321 decommissioning sample. An attention should be given in the sampling and sample

322 preparation steps to avoid the loss and contamination of tritium because of high volatility 323 and mobile property of tritium. Warwick et al. [61] investigated the release feature of 324 different species of tritium from solid samples using a programmable combustion system 325 (Fig. 2), and demonstrated that combustion method can be used not only for separation of 326 total tritium, but also for speciation analysis of tritium [61,63 ].

\section{Carbon-14}

329 Carbon-14 has a half-life of 5730 years and decays by pure beta emission $\left(E_{\max }=156\right.$ $330 \mathrm{keV})$. In the environment, ${ }^{14} \mathrm{C}$ is produced by the interaction of cosmically produced 331 neutrons with atmospheric nitrogen in the upper atmosphere, which provides a 332 continuous and constant source of ${ }^{14} \mathrm{C}$ in the atmosphere. The uniform uptake as ${ }^{14} \mathrm{CO}_{2}$ 333 into living plant material, conversion to plant carbohydrates, and subsequent transfer 334 through the food chain are the basis of the radiocarbon dating technique. ${ }^{14} \mathrm{C}$ dating is 335 used in a wide range of scientific disciplines including archaeology, geology, soil science, 336 climate reconstruction, and oceanography, and LSC has been the widely used 337 measurement technique for ${ }^{14} \mathrm{C}$ dating. Human nuclear activity such as atmospheric 338 nuclear weapons tests (principally during the 1950s and 1960s) has injected huge amount 339 of ${ }^{14} \mathrm{C}\left(1.2 \times 10^{8} \mathrm{GBq}\right)$ to the atmosphere, which increased ${ }^{14} \mathrm{C}$ level in the atmosphere by

340 a factor of two. With the exchange of ${ }^{14} \mathrm{C}$ in the ecosystem, the ${ }^{14} \mathrm{C}$ level in the 341 environment decreased gradually, but still higher than the pre-nuclear level at present 
342 environment. Discharges from facilities associated with the nuclear fuel cycle (principally

343 nuclear power plants and fuel reprocessing plants) have also releases ${ }^{14} \mathrm{C}$ to the

344 environment. Although ${ }^{14} \mathrm{C}$ is not the most abundant anthropogenic radionuclides

345 released to the environment, its long half-life, high environmental mobility, and ability to

346 enter the food chain mean that it delivers one of the highest collective effective dose

347 equivalents to the global population, hence the level of ${ }^{14} \mathrm{C}$ in the environment is critical

348 for environmental monitoring of the nuclear facilities [66]. Petroleum derivatives are

349 occasionally used to adulterate natural food and drink products (e.g. wines, spirits, or

350 cider vinegars) without the buyer's knowledge. Because petroleum-based products are

351 sufficiently old that they contain no ${ }^{14} \mathrm{C}$, depletions in ${ }^{14} \mathrm{C}$ content are normally indicative

352 of adulteration. Carbon dioxide is the main greenhouse gas released to the atmosphere as

353 a result of human activities. A $30 \%$ rise in $\mathrm{CO}_{2}$ concentration has been observed since

354 the start of the industrial revolution, this is mainly attributed to the increased use of fossil

355 based fuel for energy production and transportation. Since the ${ }^{14} \mathrm{C}$ in the fossil fuel is

356 absent, measurement of atmospheric ${ }^{14} \mathrm{C}$ level and its distribution can be used for directly

357 estimating the amount of fossil $\mathrm{CO}_{2}$ releases, and has been widely applied in the past

358 years [22-23].

359 Carbon-14 is often measured by LSC after separation from the sample matrices and other

360 radionuclides. Combustion is the most effective method for separation of ${ }^{14} \mathrm{C}$ from solid

361 samples, Acid digestion is also used for water and solid sample by converting carbon

362 species to $\mathrm{CO}_{2}$. The released $\mathrm{CO}_{2}$ can be absorbed using $\mathrm{NaOH}$ or quaternary amines for

363 the LSC measurement of ${ }^{14} \mathrm{C}$. Carbo-Sorb E (PerkinElmer, Inc.) and Solusol (National

364 Diagnostics) are examples of high-capacity carbon dioxide absorbers that are compatible

365 with LSC cocktails. Due to strong quenching, less trapping capacities and severe

366 chemiluminescence, ${ }^{14} \mathrm{CO}_{2}$ absorbed in $\mathrm{NaOH}$ solution is not often directly used for LSC,

367 but for further purification.

368 The combustion and direct absorption of $\mathrm{CO}_{2}$ in quaternary amine is simple and effective

369 method for the separation and measurement of ${ }^{14} \mathrm{C}$. The major disadvantage of the $\mathrm{CO}_{2}$

370 absorption technique is the relative small amount of carbon that can be absorbed,

371 therefore often applied for analysis of samples from nuclear facilities or surrounding

372 environment, which have a relative high ${ }^{14} \mathrm{C}$ concentration. Hou $[10,61]$ have reported a 
373 method for the determination of ${ }^{14} \mathrm{C}$ in samples from nuclear decommissioning, such as 374 graphite, concrete and metals. ${ }^{14} \mathrm{C}$ was released from the sample matrix as $\mathrm{CO}_{2}$ by 375 oxidation combustion with $\mathrm{O}_{2}$ flow at a temperature higher than $1000^{\circ} \mathrm{C}$ with $\mathrm{Pt}$ as 376 catalyzer to convert all $\mathrm{CO}$ to $\mathrm{CO}_{2}$. It was also confirmed that both organic and inorganic 377 carbon in the samples can be completely converted to $\mathrm{CO}_{2}$ in this condition. The released $378{ }^{14} \mathrm{CO}_{2}$ is trapped using 8-12 $\mathrm{ml}$ of Carb-Sorb E solution filled into a trapping column to 379 ensure a high absorption efficiency. The trap solution was then mixed with Permafluor 380 E+ scintillation cocktail for LSC measurement. The entire separation was implemented 381 with a Sample Oxidizer (PerkinElmer Inc.), which makes the separation to be completed 382 within 2 minutes. The major disadvantage of this method is that the sample amount can 383 be treated is relative small $(0.2-1.0 \mathrm{~g})$, which limits the analysis of big sample and the 384 detection limit of the method. A tube furnace was also reported for separation of ${ }^{14} \mathrm{C}$ from 385 solid sample using combustion. In this case, the sample amount can be increased to $20 \mathrm{~g}$, 386 therefore improve the detection limit [67]. Fig. 2 shows diagrams of these two systems 387 for ${ }^{14} \mathrm{C}$ analysis. This method was also confirmed to be applicable for other solid samples, 388 such as soil, sediment, vegetation, tissues, exchange resin, filter, and plastic materials [62, $38967]$.

390 A method for the determination of ${ }^{14} \mathrm{C}$ in water samples was reported using 391 evaporation and combustion for carbon separation and LSC for ${ }^{14} \mathrm{C}$ measurement [10]. In 392 environmental water samples, ${ }^{14} \mathrm{C}$ presents as both inorganic (carbonate) and organic 393 associated form, evaporation with addition of stable carbonate as carrier is first used to 394 concentrate ${ }^{14} \mathrm{C}$ and convert to solid. The residue with concentrated ${ }^{14} \mathrm{C}$ was used for the 395 analysis using the same procedure as other solid sample described above.

396 Wet oxidation using strong oxidative reagents $\left(\mathrm{K}_{2} \mathrm{~S}_{2} \mathrm{O}_{8}\right.$ with $\mathrm{AgNO}_{3}$ in acidic media or $397 \mathrm{CrO}_{3}$ and $\left.\mathrm{H}_{2} \mathrm{SO}_{4}\right)$ and acid digestion $\left(\mathrm{H}_{2} \mathrm{SO}_{4}\right)$ has also been applied for separation ${ }^{14} \mathrm{C}$ in 398 water and ion exchange resin samples. Acid digestion is used to separate ${ }^{14} \mathrm{C}$ in 399 carbonate/bicarbonate form, while wet oxidation in acidic media for decomposing 400 organic compounds is used for separation of ${ }^{14} \mathrm{C}$ in both organic and carbonate forms. 401 The released ${ }^{14} \mathrm{C}$ is adsorbed in alkaline solution for LSC measurement of ${ }^{14} \mathrm{C}[68]$. In the 402 combustion and wet digestion process, other volatile radionuclides such as tritium, ${ }^{36} \mathrm{Cl}$ 403 and ${ }^{99} \mathrm{Tc}$ might be also released from sample with ${ }^{14} \mathrm{C}$ and interfering the measurement of 
$404{ }^{14} \mathrm{C}$. A pre-condensing or pre-absorption with diluted acid $\left(\mathrm{H}_{2} \mathrm{SO}_{4}\right)$ is often applied for 405 removal of these interferences. In this case, $\mathrm{CO}_{2}$ can pass through the condenser or the 406 acidic solution and absorbed in the alkaline solution, but all other radionuclides deposited 407 on the condenser or absorbed in the acidic solution and removed from ${ }^{14} \mathrm{C}$. 408

a)

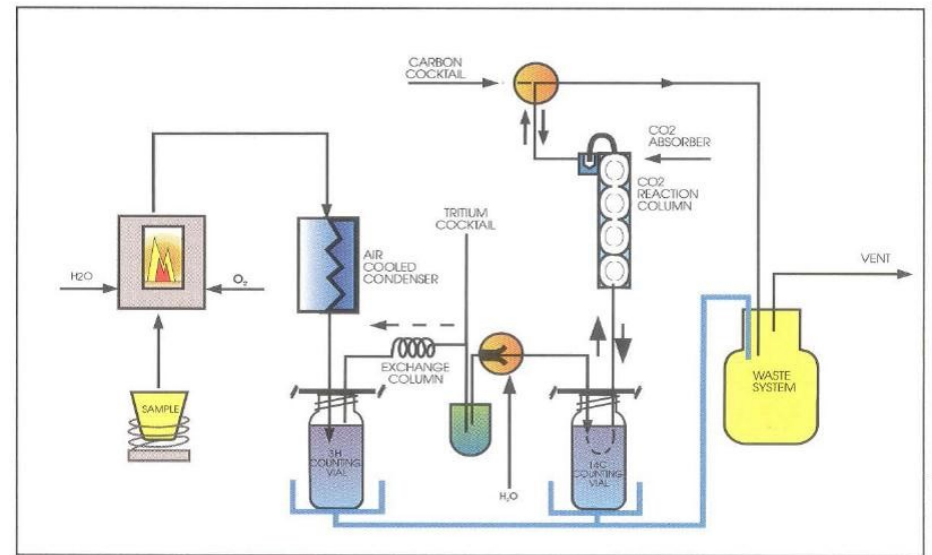

b)

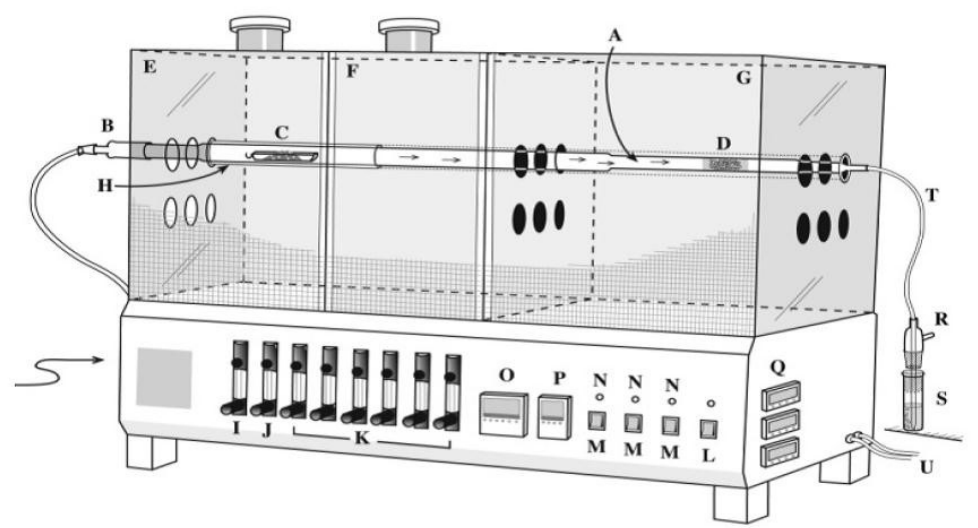

409

410

411 Fig. 2 Diagram of two combustion system for separation ${ }^{14} \mathrm{C}$ and tritium from solid 412 samples.

415 The absorption capacity of alkaline solution for ${ }^{14} \mathrm{CO}_{2}$ is relative low, $10 \mathrm{~mL}$ of Carbo416 Sorb can only absorb $58 \mathrm{mmol}$ of $\mathrm{CO}_{2}$, which is equivalent to $0.7 \mathrm{~g}$ of carbon. Therefore, 417 the combustion and direct absorption of ${ }^{14} \mathrm{CO}_{2}$ in alkaline solution for ${ }^{14} \mathrm{C}$ measurement 
418 using LSC is not sufficient good for determination of low-level ${ }^{14} \mathrm{C}$ in environmental 419 samples, especially for the ${ }^{14} \mathrm{C}$ dating and application in the estimation of fossil $\mathrm{CO}_{2}$ 420 emission. The conventional benzene synthesis method is still used, which enable to use $42119 \mathrm{~g}$ of carbon in maximum for ${ }^{14} \mathrm{C}$ measurement [69]. In this method, all species carbon 422 is first converted to $\mathrm{CO}_{2}$ by combustion or acid hydrolysis. The collected $\mathrm{CO}_{2}$ is 423 subsequently converted to lithium carbide by reaction with molten lithium, and on

424 cooling, the addition of water to $\mathrm{C}_{2} \mathrm{H}_{4}$ causes the production of acetylene $\left(\mathrm{C}_{2} \mathrm{H}_{4}\right)$. The 425 acetylene is then cyclotrimerized to benzene using a chromium- or vanadium-based 426 catalyst. Duo to high carbon content (92.3\%), a clear aromatic solvent capable of 427 dissolving sufficient Fluor, excellent energy transmission properties, benzene is an ideal 428 counting medium for ${ }^{14} \mathrm{C}$. In most instances, solid flours would be added directly, rather 429 than a scintillation cocktail. This minimizes volume additions and therefore any increase 430 in quenchable background, meanwhile highest volume of sample for measurement. 431 However, compared to the direct alkaline absorption and LSC measurement, this method 432 is tedious and more expensive, therefore mainly applied for the ${ }^{14} \mathrm{C}$ dating or precise 433 measurement of ${ }^{14} \mathrm{C}$ in low level or background level environmental samples. With the 434 rapid development of accelerator mass spectrometry (AMS) and its wide application, ${ }^{14} \mathrm{C}$ 435 measurement for dating purpose is now mainly carried out by AMS technique.

\section{Chloride-36}

$438{ }^{36} \mathrm{Cl}$ is a long-lived $\left(\mathrm{t}_{1 / 2}=301 \mathrm{ky}\right)$ pure beta-emitter $\left(\mathrm{E}_{\max }=709 \mathrm{keV}\right)$, formed by neutron 439 activation reaction of stable chlorine ${ }^{35} \mathrm{Cl}(\mathrm{n}, \gamma){ }^{36} \mathrm{Cl}$ in nuclear reactor. Less important 440 sources are nuclear reactions induced by cosmic radiation in atmosphere, water and 441 bedrock. Because of its low specific activity, ${ }^{36} \mathrm{Cl}$ is not considered substantial danger to 442 humans at present environmental level. However, since the high mobility of chlorine and 443 long half-live, ${ }^{36} \mathrm{Cl}$ is a useful tracer in interpreting environmental processes [70-72] and 444 important for waste depository.

445 Many methods have been reported for the determination of ${ }^{36} \mathrm{Cl}$ in environmental and 446 waste samples [11, 73-76]. For soil, concrete and other solid materials, chlorine is 447 separated from the sample in one of two ways: vaporizing chlorine to $\mathrm{Cl}_{2}$ gas by 448 subjecting the sample to high temperature or by boiling the sample in strong oxidizing 
449 acids. The released chlorine gas from the samples is captured in a $\mathrm{NaOH}$ solution. The 450 sample can also be dissolved so that the chlorine remains in solution as chloride ions. It 451 should be mentioned that no (or very small amount of) $\mathrm{HCl}$ or $\mathrm{HClO} 4$ should be added 452 for sample decomposition, otherwise a huge amount of $\mathrm{Cl}$ from the acid will be transfer 453 to the final sample, make it impossible to be measured. In all three cases, a known 454 amount of chlorine carrier, in the form of $\mathrm{NaCl}$ or $\mathrm{NaClO}_{3}$ is added to the sample. 455 Chlorine gas trapped in the $\mathrm{NaOH}$ solution is reduced to chloride with $\mathrm{NaNO}_{2}$, and the 456 chloride is precipitated as silver chloride $(\mathrm{AgCl})$ by adding $\mathrm{AgNO}_{3}$ after acidifying the 457 solution to a weakly acidic medium using $\mathrm{HNO}_{3}$. Iodine can be removed by dissolving 458 the precipitate with $\mathrm{NH}_{4} \mathrm{OH}$, in which $\mathrm{AgCl}$ is dissolved but $\mathrm{AgI}$ does not. The $\mathrm{AgI}$ 459 precipitate is discarded and the chloride in the $\mathrm{NH}_{4} \mathrm{OH}$ solution is again precipitated by 460 acidification to $\mathrm{pH}<2$. The chemical yield of the separation is determined by measuring 461 the amount of chlorine using ICP-MS or ion chromatography. Finally, ${ }^{36} \mathrm{Cl}$ in the purified $462 \mathrm{AgCl}$ precipitate is counted by LSC after dissolving the precipitate with ammonium and 463 adding scintillation cocktail. Because of the relative high beta energy of ${ }^{36} \mathrm{Cl}$, the 464 counting efficiency of ${ }^{36} \mathrm{Cl}$ is normally higher than $85 \%$ depending on the quench level, 465 and need to be corrected using quench curve or standard addition method. Because $\mathrm{AgCl}$ 466 dissolved in ammonia solution is not stable, $\mathrm{Ag}^{+}$can be gradually oxidized to $\mathrm{Ag}_{2} \mathrm{O}$, 467 worsen the quench level of the sample, making the analytical results not precise.

468 Hou et al. [11] reported a method for the determination of ${ }^{36} \mathrm{Cl}$ in decommissioning 469 samples, including graphite, concrete and metals. Fig. 3 shows an analytical procedure 470 for the determination of ${ }^{36} \mathrm{Cl}$ in waste samples. In this method, the sample is first 471 decomposed. Graphite sample is decomposed by acid dissolution with a mixed acids $472 \quad\left(\mathrm{H}_{2} \mathrm{SO}_{4}: \mathrm{HNO}_{3}: \mathrm{HClO}_{4}=15: 4: 1\right)$; the metals such as lead, aluminum and stainless steel are 473 dissolved with $5 \mathrm{M} \mathrm{HNO}_{3}, 5 \mathrm{M} \mathrm{H}_{2} \mathrm{SO}_{4}$, and $\mathrm{H}_{2} \mathrm{SO}_{4}-\mathrm{H}_{3} \mathrm{PO}_{4}$, respectively. During the 474 decomposition by heating, the solution is bubbled with nitrogen gas, and the released 475 gas (including $\mathrm{Cl}_{2}$ ) is trapped in 3 sequential trapping solutions: one $\mathrm{H}_{2} \mathrm{O}$, two $0.4 \mathrm{M}$ $476 \mathrm{NaOH}$. The concrete sample is decomposed by alkaline fusion by mixing sample with $477 \mathrm{NaOH}-\mathrm{Na}_{2} \mathrm{CO}_{3}$ and fused at $500{ }^{\circ} \mathrm{C}$ for $3-4 \mathrm{~h}$, the fused cake is dissolved with $\mathrm{H}_{2} \mathrm{O}$, and 478 the leachate is used for the determination of ${ }^{36} \mathrm{Cl}$. Before sample decomposition, stable 479 chloride as carrier and other stable elements as hold back carriers are added. The 
480 decomposed sample solution is then transferred to a separation funnel. $\mathrm{NaHSO}_{3}$ solution

481 is added to convert all iodine to iodide, $\mathrm{HNO}_{3}$ is then added to adjust $\mathrm{pH}<2$. After 482 addition of $\mathrm{CCl}_{4}, \mathrm{NaNO}_{2}$ solution is added to oxidize iodine to $\mathrm{I}_{2}$, and chlorine is 483 reduced to $\mathrm{Cl}^{-}, \mathrm{I}_{2}$ is then extracted to $\mathrm{CCl}_{4}$ phase by shaking. $\mathrm{AgNO}_{3}$ solution is then 484 added to the aqueous phase after extraction of iodine, stirring the solution to aggregate 485 the $\mathrm{AgCl}$ precipitate. The $\mathrm{AgCl}$ precipitate is separated by centrifuge, and washed with $4861 \mathrm{M} \mathrm{HNO}_{3}$ to remove the interfering metal radionuclides. The precipitate is dissolved 487 with $25 \% \mathrm{NH}_{3}, \mathrm{HNO}_{3}$ is then added to the solution to $\mathrm{pH}<2$ to re-precipitate $\mathrm{AgCl}$. The $488 \mathrm{AgCl}$ precipitate separated by centrifuge is dissolved in $25 \% \mathrm{NH}_{3}$ solution. The solution 489 is loaded to an anion exchange column, which is converted to $\mathrm{OH}^{-}$form and conditioned 490 with $25 \% \mathrm{NH}_{4} \mathrm{OH}$. The column is washed with $25 \% \mathrm{NH}_{3}$ until no $\mathrm{Ag}^{+}$in the rinsed 491 solution. Chloride on the column is then eluted with $0.2 \mathrm{~mol} / \mathrm{L} \mathrm{NH}_{4} \mathrm{NO}_{3}-0.6 \mathrm{~mol} / \mathrm{L}$ $492 \mathrm{NH}_{4} \mathrm{OH}$. The eluate is evaporated to dryness on a hotplate; the residue is dissolved with $4932 \mathrm{ml}$ water and transferred to a LSC vial. $0.1 \mathrm{ml}$ of the solution is taken to measure 494 stable chlorine by ICP-MS for chemical yield monitor. $15 \mathrm{ml}$ of cocktail is added to the 495 remaining solution, ${ }^{36} \mathrm{Cl}$ in the solution is measured by LSC. The decontamination 496 factors for all interfering radionuclides are higher than $10^{6}$, and recovery of $\mathrm{Cl}$ is higher 497 than $90 \%$. Since the final solution of ${ }^{36} \mathrm{Cl}$ is prepared in $2 \mathrm{ml}$ of water, the quench level 498 is very low and the counting efficiency is higher than $>98 \%$. 


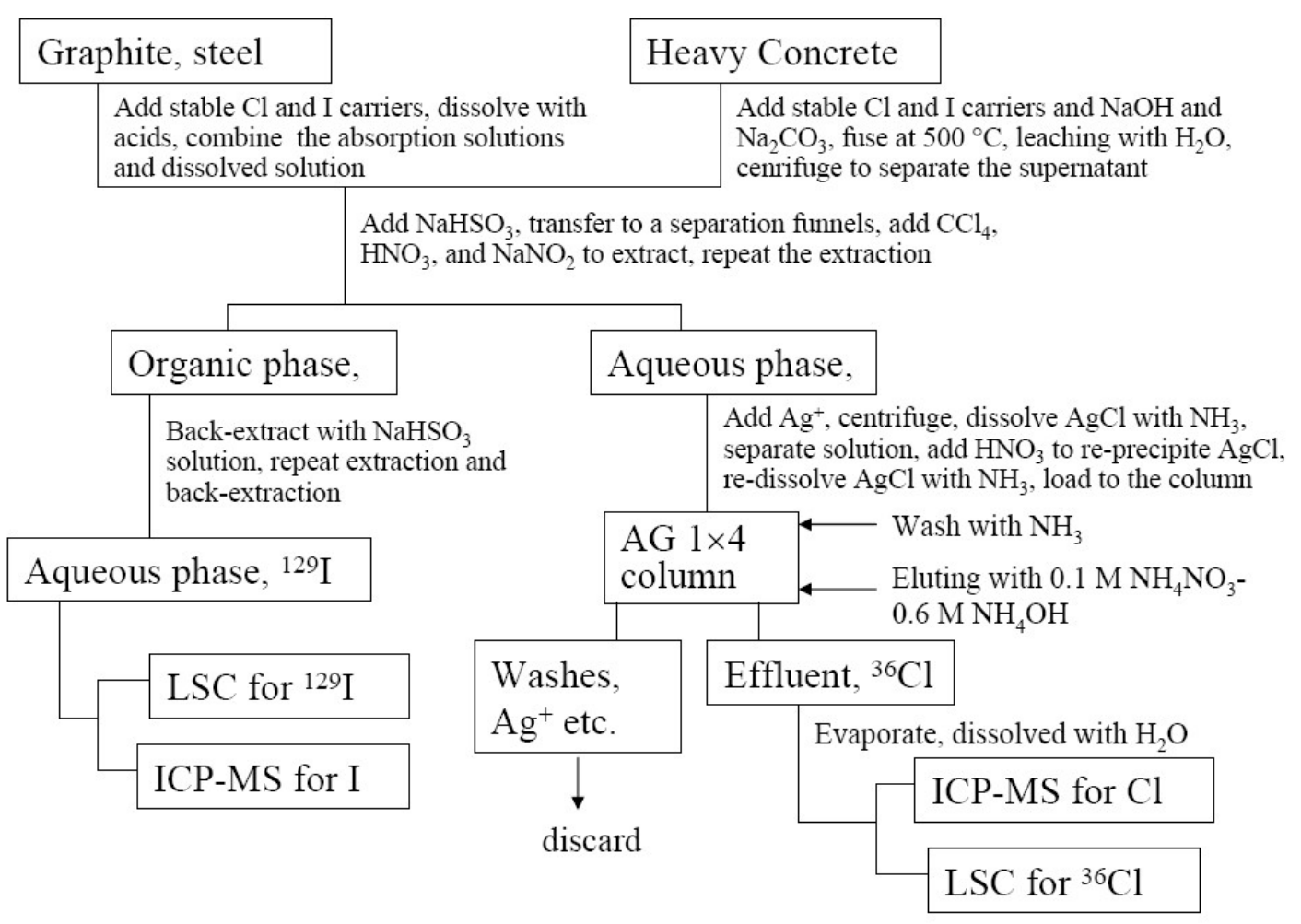

Fig. 3 Analytical procedure for the determination of ${ }^{36} \mathrm{Cl}$ in nuclear waste samples [11]

502 For the nuclear waste samples, ${ }^{36} \mathrm{Cl}$ level is normally relative high to be measured by

503 LSC. While, for most of environmental samples, especially the sample with natural 504 originated ${ }^{36} \mathrm{Cl}\left({ }^{36} \mathrm{Cl} / \mathrm{Cl}<10^{-11}\right)$, LSC is not sensitive enough to measure such a low level $505{ }^{36} \mathrm{Cl}\left(<1 \mathrm{mBq}\right.$ or ${ }^{36} \mathrm{Cl} / \mathrm{Cl}<10^{-10}$ for $10 \mathrm{mg} \mathrm{Cl}$ in the sample $)$. The most sensitive 506 accelerator mass spectrometry (AMS) is needed, which can measure ${ }^{36} \mathrm{Cl}$ in the sample target with ${ }^{36} \mathrm{Cl} /{ }^{35} \mathrm{Cl}$ atomic ratio of $10^{-15}$.

\section{Calcium-41}

${ }^{41} \mathrm{Ca}\left(\mathrm{t}^{1} / 2=1.03 \times 10^{5}\right.$ years $)$ is mainly produced by neutron activation reaction of

512 stable calcium $\left({ }^{40} \mathrm{Ca}\right)$ of the earth with neutrons from the cosmic rays and fission of 513 uranium. Human nuclear activities including atmospheric nuclear weapons testing and 514 operation of nuclear facilities have also released some ${ }^{41} \mathrm{Ca}$ to the environment. In the 515 nuclear reactor, ${ }^{41} \mathrm{Ca}$ is mainly produced in the concrete shielding because of its high 516 calcium content and its exposure to the neutrons from the reactor. ${ }^{41} \mathrm{Ca}$ is an important 
517 radionuclide in the disposal of radioactive waste, because of its long half-life and high 518 mobility in the environment and high bioavailability.

$519 \quad{ }^{41} \mathrm{Ca}$ decays to the ground state of ${ }^{41} \mathrm{~K}$ by pure electron capture, emitting X-rays and 520 Auger electrons of very low energy (0.3-3.6 keV). It can thus be measured by X-ray 521 spectrometry and LSC, but the LSC is much more sensitive [9, 77-80] compared with X522 ray spectrometry because of its low counting efficiency $(<0.08 \%)$ and low abundance of 523 X-ray of ${ }^{41} \mathrm{Ca}(11.4 \%$ for $3.31 \mathrm{keV} \mathrm{X-ray).}$

524 Due to the pure electron capture decay of ${ }^{41} \mathrm{Ca}$, chemical separation from the sample 525 matrices and purification from all other radionuclides are necessary before measurement 526 of ${ }^{41} \mathrm{Ca}$ using LSC or other techniques. Suárez et al. [77] reported a radiochemical 527 separation procedure for separation of calcium from other radionuclides, which is based 528 on the hydroxides precipitation of transition metals and chromate precipitation of $\mathrm{Ba}, \mathrm{Sr}$ 529 and Ra with a chemical recovery of $40 \%$. In this procedure, the separation of $\mathrm{Ba}, \mathrm{Sr}$ and $530 \mathrm{Ra}$ by chromate precipitation is very critical because of very restrict control of $\mathrm{pH}$ value. 531 Ion exchange and extraction chromatography have also been used for separation of 532 calcium [78, 80]. Anion exchange chromatography was used to remove all radionuclides 533 presenting as anion in high concentration $\mathrm{HCl}$ media, and extraction chromatography 534 using TRU resin was applied to remove actinides and lanthanides. However, this 535 procedure is not well suitable for removal of earth alkaline radionuclides such as 536 radiostrontium, radium and barium. An tertbutylmethylether/ethanol extraction step was 537 proposed to extract calcium and to remove $\mathrm{Sr}, \mathrm{Ba}$ and $\mathrm{Ra}$ [80]. With all these steps, a 538 recovery of more than $65 \%$ and decontamination factor of $<10^{3}$ for most of interfering 539 radionuclides were obtained. Hou [9] reported a simple and effective method for 540 determination of ${ }^{41} \mathrm{Ca}$ in ordinary and heavy concrete (containing more than $75 \%$ of $\left.541 \mathrm{BaSO}_{4}\right)$ based on the relative low solubility production of $\mathrm{Ca}(\mathrm{OH})_{2}$ compared to the 542 hydroxides of $\mathrm{Sr}, \mathrm{Ba}$ and $\mathrm{Ra}$ in $\mathrm{NaOH}$ solution. Calcium (mainly as calcium carbonate) is 543 first leached using aqua regia, and the experiment shows that more than $95 \%$ of Ca can 544 be leached out from the concrete sample in this step. There are 3 main steps for the 545 separation of $\mathrm{Ca}$ from the interfering radionuclides. $\mathrm{Ca}$ is first separated from the 546 transition metals, such as $\mathrm{Co}, \mathrm{Eu}, \mathrm{Fe}, \mathrm{Ni}$ and transuranic by precipitation at $\mathrm{pH} 9 \mathrm{using}$ $547 \mathrm{NaOH}$. In this step, the interfering radioisotopes of these elements are precipitated, while 
$548 \mathrm{Ca}$ remains in the solution with $\mathrm{Sr}$, as well as $\mathrm{Ba}, \mathrm{Ra}, \mathrm{Cs}$, etc. $\mathrm{Ca}$ and $\mathrm{Sr}$ in the 549 supernatant are then precipitated as carbonates with $\mathrm{Ba}$ and $\mathrm{Ra}$ by adding $\mathrm{Na}_{2} \mathrm{CO}_{3}$ and 550 separated from alkali metals and non-metal elements. $\mathrm{Ca}$ is then separated from $\mathrm{Sr}, \mathrm{Ba}$ 551 and $\mathrm{Ra}$ by precipitation of $\mathrm{Ca}$ as $\mathrm{Ca}(\mathrm{OH})_{2}$ in $0.5 \mathrm{~mol} / \mathrm{L} \mathrm{NaOH}$ solution after dissolution 552 of the carbonate precipitates. This is based on the low solubility of $\mathrm{Ca}(\mathrm{OH})_{2}$ in high 553 concentration of $\mathrm{NaOH}$ (higher than $0.5 \mathrm{~mol} / \mathrm{L}$ ) compared with $\mathrm{Sr}, \mathrm{Ba}$, and $\mathrm{Ra}$. This step 554 is repeated and the separated $\mathrm{Ca}(\mathrm{OH})_{2}$ is dissolved with $\mathrm{HCl}$ for measurement using LSC 555 after neutralizing to $\mathrm{pH} 6-8$. The chemical yield of $80-90 \%$ for ${ }^{41} \mathrm{Ca}$ was obtained by 556 measurement of $\mathrm{Ca}$ before and after chemical separation using ICP-OES. The 557 decontamination factor for the interfering radionuclides such as ${ }^{60} \mathrm{Co},{ }^{152} \mathrm{Eu},{ }^{133} \mathrm{Ba},{ }^{85} \mathrm{Sr}$, $558{ }^{137} \mathrm{Cs},{ }^{55} \mathrm{Fe}$, and ${ }^{63} \mathrm{Ni}$ are higher than $10^{5}$. The detection limit of $20 \mathrm{mBq}$ for ${ }^{41} \mathrm{Ca}$ was 559 achieved by using low background LSC instrument (Quantulus 1220) [9].

560 However, this method could not separate ${ }^{45} \mathrm{Ca}$ from ${ }^{41} \mathrm{Ca}$. If both isotopes exist in the 561 sample, interference of ${ }^{45} \mathrm{Ca}$ to the measurement of ${ }^{41} \mathrm{Ca}$ has to be corrected, which can be 562 carried out by measurement of the contribution of ${ }^{45} \mathrm{Ca}$ to the window of ${ }^{41} \mathrm{Ca}$ at lower 563 channel. Due to the low energy of Auger electrons (0.3-3.6 keV) used for measurement of $564{ }^{41} \mathrm{Ca}$ by LSC, the counting efficiency is relatively low $(<25 \%)$, and highly influenced by 565 quench. The separated calcium sample is normally prepared in a neutral solution of $\mathrm{CaCl}_{2}$ 566 and all other element (especially iron) has to be completely removed. The major quench 567 effect is the amount of calcium in the samples. In addition, luminesce is also an 568 interference for the measurement of ${ }^{41} \mathrm{Ca}$, which has to be considered in the measurement 569 of ${ }^{41} \mathrm{Ca}$ using LSC.

$570 \quad$ For measurement of ${ }^{41} \mathrm{Ca}$ in natural environmental level $(<1 \mathrm{mBq})$, more sensitive 571 mass spectrometry techniques such as AMS [81] and resonance ionization mass 572 spectrometry (RIMS) [82] are needed, a ${ }^{41} \mathrm{Ca} /{ }^{40} \mathrm{Ca}$ atomic ratio as low as $10^{-15}$ can be 573 measured by AMS.

$576 \quad{ }^{55} \mathrm{Fe}\left(\mathrm{t}_{1 / 2}=2.7\right.$ years $)$ decays via electron capture with the emission of Auger 577 electrons and low energy X-rays $(5.89 \mathrm{keV}, 16.9 \%) .{ }^{55} \mathrm{Fe}$ is mainly measured by LSC 578 although X-ray spectrometry and gas flow proportional counter can be also used, but very 
579 low counting efficiencies $(<1 \%) .{ }^{55} \mathrm{Fe}$ is produced by neutron activation reactions of two 580 major stable iron isotopes: ${ }^{54} \mathrm{Fe}(\mathrm{n}, \gamma){ }^{55} \mathrm{Fe}$ and ${ }^{56} \mathrm{Fe}(\mathrm{n}, 2 \mathrm{n}){ }^{55} \mathrm{Fe}$. Since iron is the main 581 component of construction materials in nuclear reactors, huge amounts of ${ }^{55} \mathrm{Fe}$ were 582 produced in nuclear reactors and other nuclear facilities/devices with neutron production. $583{ }^{55} \mathrm{Fe}$ enters into the environment mainly through the release of radioactive effluents of 584 nuclear reactors, as well as atmospheric nuclear weapons tests in 1945-1980. 585 Determination of ${ }^{55} \mathrm{Fe}$ is often required for monitoring the radioactivity in the nuclear 586 facilities and their discharges, as well as characterisation and depository of nuclear 587 wastes. Iron has to be separated from the sample matrices and then completely purified 588 from other radionuclides prior to the measurement of ${ }^{55} \mathrm{Fe}$.

Most of work on the determination of ${ }^{55} \mathrm{Fe}$ is addressed to the analysis of decommissioning waste, and the key issue on the analytical method is the separation of iron from other radionuclides and its high efficient measurement.

The separation of iron from the sample matrices (solution) is often carried out by hydroxide precipitation based on the formation of $\mathrm{Fe}(\mathrm{OH})_{3}$ and $\mathrm{Fe}(\mathrm{OH})_{2}$. However, for 594 some special samples, the matrix component need to be first removed. For instance, in 595 acid-dissolved lead sample, lead has to be removed by $\mathrm{PbSO}_{4}$ precipitation to avoid the 596 formation of a large amount of $\mathrm{Pb}(\mathrm{OH})_{2}$ during the $\mathrm{Fe}(\mathrm{OH})_{3}$ precipitation step. For 597 aluminium sample, the bulk $\mathrm{Al}(\mathrm{OH})_{3}$ in the $\mathrm{Fe}(\mathrm{OH})_{3}$ precipitation step can be removed 598 by adding more $\mathrm{NaOH}$ to a concentration $0.2 \mathrm{M}$ for converting $\mathrm{Al}(\mathrm{OH})_{3}$ precipitate to soluble $\mathrm{NaAlO}_{2}[12]$.

600 All transition metals can be co-precipitated with $\mathrm{Fe}(\mathrm{OH})_{3}$ in alkali solution, among 601 them the most important radionuclides are ${ }^{60} \mathrm{Co},{ }^{63} \mathrm{Ni},{ }^{54} \mathrm{Mn},{ }^{152} \mathrm{Eu}$ and ${ }^{154} \mathrm{Eu}$ in 602 decommissioning waste and further chemical separation is necessary to isolate iron from 603 these interfering radionuclides. Chelating and anion exchange chromatography combined 604 with solvent extraction have been used to separate iron from other nuclides [83, 84]. The 605 commonly used extraction reagents include ethyl acetate, isobutyl ketone and isopropyl 606 ether, particularly iron has a high partition coefficient in ethyl acetate [85]. However, as 607 solvent extraction is not very specific for iron, the decontamination of interfering 608 radionuclides is not sufficient with one extraction. To improve the separation efficiency 609 of iron from other radionuclides, an extraction chromatography based on di-isobutyl- 
610 ketone has been proposed [85]. A commercial solid phase extraction chromatographic 611 resin, TRU resin, has also been applied to separate iron for the determination of ${ }^{55} \mathrm{Fe}[86$,

612 87]. One limitation of this resin is the low capacity for a small extraction 613 chromatographic column $(2 \mathrm{ml})$, which can only allow for upload of sample solution with 614 less than $2 \mathrm{mg}$ iron. For sample with high iron content, such as soil, sediment and steel, 615 anion exchange chromatography using strong basic anion resin (e.g., AG1×-4) has been 616 confirmed to be an effective method for separation iron from other interfering 617 radionuclides with a high recovery $(>95 \%)$ and a high decontamination factor $\left(>10^{4}\right)$ for 618 most of interfering radionuclides (e.g. ${ }^{60} \mathrm{Co},{ }^{58} \mathrm{Co},{ }^{152} \mathrm{Eu},{ }^{154} \mathrm{Eu},{ }^{63} \mathrm{Ni},{ }^{137} \mathrm{Cs},{ }^{90} \mathrm{Sr}$ ). This is 619 mainly due to the high distribution coefficient of $\mathrm{FeCl}_{4}^{-}$on the anion resin in high 620 concentration of $\mathrm{HCl}$ solution. Fig. 4 shows a separation procedure of iron from the most 621 important interfering radionuclides using a strong basic anion exchange chromatography. 622 By this way, ${ }^{55} \mathrm{Fe}$ can be completely separated from ${ }^{58,60} \mathrm{Co},{ }^{63} \mathrm{Ni},{ }^{152,154} \mathrm{Eu}$ and ${ }^{65} \mathrm{Zn}$. 623 Other radionuclides, including all alkali and alkaline earth metals, could not form anion 624 complex with chloride and would be removed. In combination with hydroxides 625 precipitation, a chemical separation procedure has been successfully applied for 626 separation of iron from different waste samples for ${ }^{55} \mathrm{Fe}$ determination. This method has 627 also been used to investigate the distribution of ${ }^{55} \mathrm{Fe}$ in the environment surrounding 628 nuclear power plant [88]. For samples with high iron content (>50 mg) and high ${ }^{60} \mathrm{Co}$ 629 radioactivity, a repeated anion exchange chromatographic separation can effectively 630 remove ${ }^{60} \mathrm{Co}$ with a high recovery of iron (Fig. 5).

631 A modified procedure using hydroxide precipitation followed by anion exchange 632 chromatographic separation and LSC measurement has also been applied to 633 determination of ${ }^{55} \mathrm{Fe}$ in urine samples [47]. Due to complicated matrix component in 634 urine, the concentration of $\mathrm{NaOH}$ in the sample solution needs to be increased to $2 \mathrm{M}$ to 635 get a high recovery of iron in the hydroxide precipitation step. 


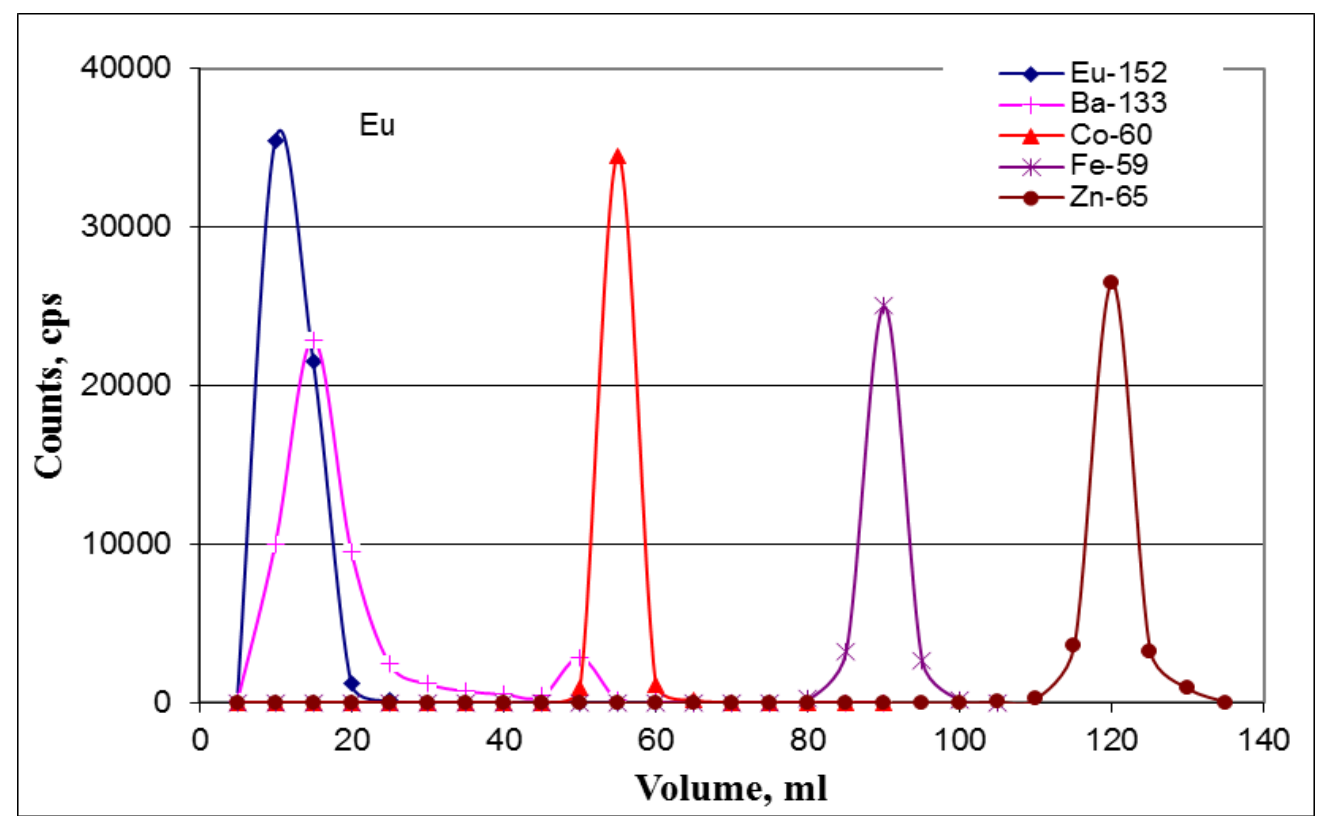

638 Fig. 4 Separation of $\mathrm{Eu}, \mathrm{Ba}, \mathrm{Co}, \mathrm{Cu}, \mathrm{Fe}$ and $\mathrm{Zn}$ by anion exchange chromatography (Bio-

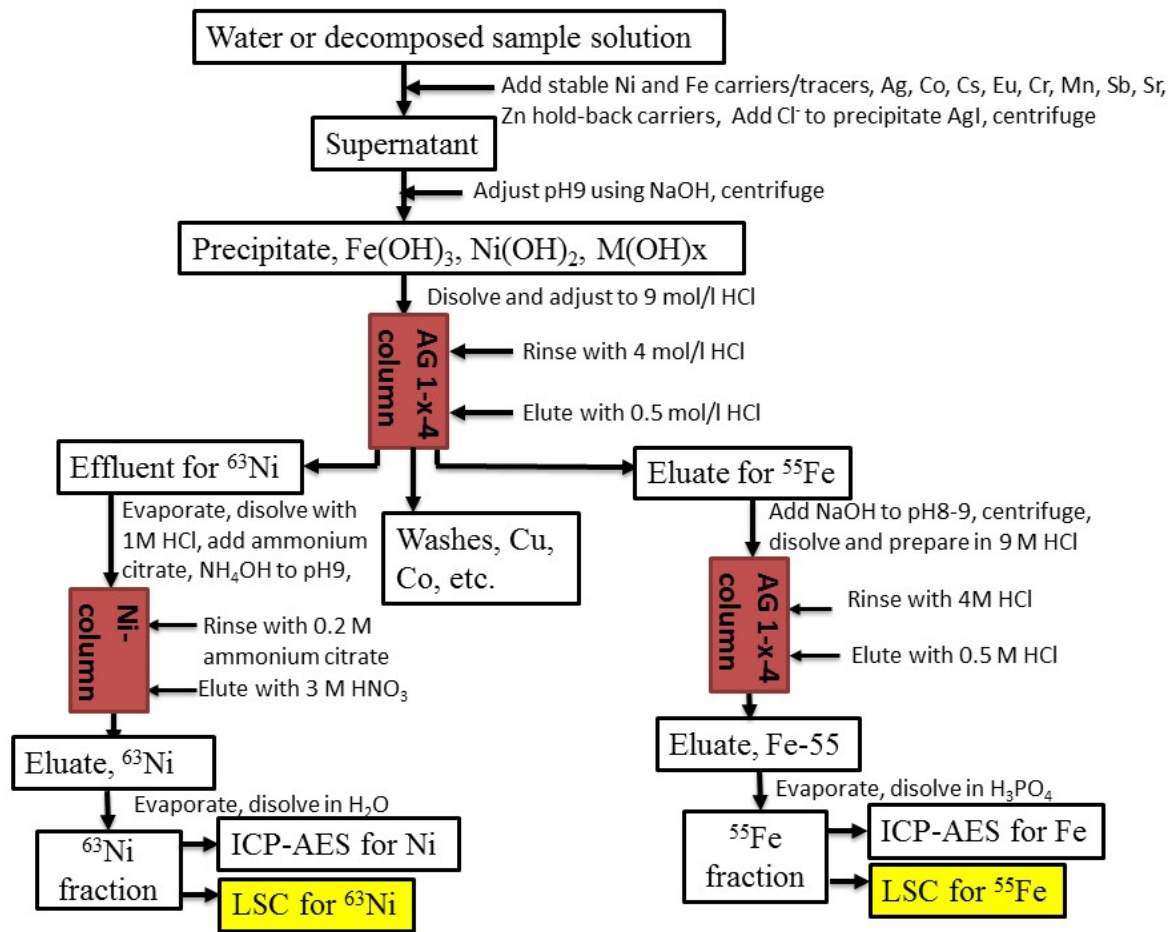

644 Fig. 5 Analytical procedure for ${ }^{55} \mathrm{Fe}$ and ${ }^{63} \mathrm{Ni}$ in environmental and waste samples. 
645 The distinct yellow color of $\mathrm{Fe}^{3+}$ can cause a very strong color quench, which 646 significantly reduces the counting efficiency of ${ }^{55} \mathrm{Fe}$ by LSC. Because the very low 647 energy of Auger electrons emitted by ${ }^{55} \mathrm{Fe}(5-6 \mathrm{keV})$ is measured by LSC, the high color 648 quench could reduce the counting efficiency to $<10 \%$, causing a worse detection limit. A 649 number of approaches have been adopted to reduce the color quenching of Fe, such as 650 solvent extraction to transfer iron to organic phase and reduction of $\mathrm{Fe}^{3+}$ to $\mathrm{Fe}^{2+}$ by 651 ascorbic acid. These approaches could not completely overcome the color quench of Fe. 652 In addition, the $\mathrm{Fe}^{2+}$ is not very stable and can be re-oxidized to $\mathrm{Fe}^{3+}$ slowly in air, 653 causing a gradually increased quench level and decreased counting efficiency. An 654 effective method for removing the yellow color of $\mathrm{Fe}^{3+}$ using $\mathrm{H}_{3} \mathrm{PO}_{4}$ has been proposed $655[12,84]$. By this method, a colorless $\mathrm{Fe}^{3+}$ solution is obtained and the counting efficiency 656 is significantly improved to more than $40 \%$. Since $\mathrm{H}_{3} \mathrm{PO}_{4}$ has less quench effect and high 657 compatibility with scintillation cocktail compared to other acids, and the amount of Fe 658 mixed with cocktail can thus be significantly increased. It has been confirmed that for 659 less than $10 \mathrm{mg}$ Fe carrier, $40 \%$ counting efficiency is obtained; and for $200 \mathrm{mg} \mathrm{Fe}$, the 660 counting efficiency is $15 \%$ [12].

662 Nickel-63

$663 \quad{ }^{63} \mathrm{Ni}\left(t_{1 / 2}=101.2 \mathrm{y}\right)$ is a neutron activation product formed by neutron capture of stable 664 nickel $\left({ }^{62} \mathrm{Ni}\right) .{ }^{63} \mathrm{Ni}$ in the environment was released through corrosion of steel components, 665 associated with the primary coolant system of nuclear power reactors. ${ }^{63} \mathrm{Ni}$ is pure beta 666 emitter with relative low energy $\left(E_{\max }=67 \mathrm{keV}\right)$, LSC is the most often used method for 667 its measurement. Another nickel isotope, ${ }^{59} \mathrm{Ni}\left(t_{1 / 2}=7.5 \times 10^{4} \mathrm{y}\right)$, is similarly formed from 668 stable ${ }^{58} \mathrm{Ni}$. The initial activity ratio of ${ }^{63} \mathrm{Ni} /{ }^{59} \mathrm{Ni}$ is around 100 or more, and ${ }^{59} \mathrm{Ni}$ decays 669 by electron capture with emission of X-rays. Given the low sensitivity of LSC to X-rays, $670{ }^{59} \mathrm{Ni}$ has very minor effect on the low-energy part of the beta spectrum of ${ }^{63} \mathrm{Ni}\left[89 .{ }^{63} \mathrm{Ni}\right.$ in 671 the environment originates from radioactive effluents from nuclear facilities and from 672 nuclear weapons tests and accidents. The principal requirement for the determination of $673{ }^{63} \mathrm{Ni}$ is to characterize nuclear waste for decommissioning and radioactive waste disposal.

674 The determination of ${ }^{63} \mathrm{Ni}$ in the environmental samples was also applied to evaluate the 675 impact of the nuclear facilities. 
676 Due to its low beta energy, the determination of ${ }^{63} \mathrm{Ni}$ requires chemical separation and 677 purification of nickel from coexisting elements and radionuclides. Methods for 678 determining ${ }^{63} \mathrm{Ni}$ have been reported for many sample matrices including liquid effluent, 679 sludge, ion exchange resin, graphite, heavy concrete, steel, copper, lead and aluminium 680 from nuclear power plants and environmental samples like soil, sediment, sea water, fish, 681 vegetation and urine [12, 84, 87, 88, 90-92].

682 The pre-treatment of samples containing organic matter is started by wet or dry ashing 683 and then continued by leaching the residue with concentrated $\mathrm{HCl}$ or $\mathrm{HNO}_{3}$ to dissolve 684 nickel and other elements. For concrete, graphite and metals, acid digestion or dissolution 685 is often used and confirm to be reliable. Graphite, concrete, soil and sediment do not have 686 to be completely dissolved using mixed acids and/or alkaline fusion following by acid 687 digestion. Stable nickel as carrier and other elements as holdback carriers are added 688 before chemical separation to determine chemical yield and to effectively removal 689 interfering radionuclides. Some methods are often applied for pre-concentration and 690 separation of $\mathrm{Ni}$ from interfering radionuclides, e.g. precipitation of $\mathrm{Fe}(\mathrm{OH})_{3}$ with 691 ammonia to remove many metals, while nickel remains in the supernatant; precipitation 692 of nickel using insoluble Ni-DMG complex; solvent extraction of Ni using DMG or tri-n693 octylphosphine (TOPO) as extractant; anion exchange chromatography, and extraction 694 chromatography using Ni resin. It was observed that large fraction of Ni can be also co695 precipitated with $\mathrm{Fe}(\mathrm{OH})_{3}$ when using ammonia, these might be attributed to the wrap of $696 \mathrm{Ni}$ in the $\mathrm{Fe}(\mathrm{OH})_{3}$ when high amount of iron presents in the solution. Hou et al. [12] 697 (2005) developed a chemical separation procedure for determination of ${ }^{63} \mathrm{Ni}$ in 698 decommissioning waste and environmental samples. Ni in the sample solution is first 699 separated using hydroxide precipitation by addition of $\mathrm{NaOH}$, most of anions, alkaline 700 elements (e.g. ${ }^{3} \mathrm{H},{ }^{137} \mathrm{Cs},{ }^{36} \mathrm{Cl},{ }^{90} \mathrm{Sr},{ }^{133} \mathrm{Ba}$ etc.) are removed. The precipitate is then 701 dissolved in $\mathrm{HCl}$ and prepared in high concentration of $\mathrm{HCl}(9 \mathrm{M})$, which is loaded to a 702 strong basic anion exchange resin column. $\mathrm{Ni}^{2+}$ passed through the column, but most of 703 transition metals (e.g. ${ }^{60} \mathrm{Co},{ }^{55} \mathrm{Fe},{ }^{65} \mathrm{Zn}$ ) are retained on the column. Thereafter Ni is 704 further purified using the Ni Resin extraction chromatography, to remove the remaining 705 interfering radionuclides (e.g. ${ }^{152,154} \mathrm{Eu},{ }^{60} \mathrm{Co},{ }^{54} \mathrm{Mn}$, etc.). They used this method for 706 determining ${ }^{63} \mathrm{Ni}$ in nuclear waste samples including heavy concrete, aluminium, lead 
707 and graphite, and achieved high decontamination factors $\left(>10^{5}\right)$ for all interfering 708 radionuclides. Chemical yields were over $90 \%$ and the detection limit of $0.014 \mathrm{~Bq}$ for $709{ }^{63} \mathrm{Ni}$ using a low-background LSA. This method has also been applied for environmental 710 samples [88] Warwick and Croudace [84] developed a method that was based on the 711 same separation steps as those of Hou et al. [12]; but the extraction chromatography 712 separation using Ni resin was performed prior to the anion exchange. It has also been 713 observed that ${ }^{60} \mathrm{Co}$ and ${ }^{58} \mathrm{Co}$ could not be sufficiently removed by using only Ni resin 714 extraction chromatography, making the method unreliable and a correction have to be 715 implemented to subtract the interference from ${ }^{58} \mathrm{Co}$ and ${ }^{60} \mathrm{Co}$. Two sequentially connected $716 \mathrm{Ni}$ resin extraction chromatography separation steps can reduce the contribution of 717 radioactive cobalt. Therefore, a separation step using anion exchange chromatography is 718 necessary for the samples with high radioactive cobalt isotopes $\left({ }^{58} \mathrm{Co},{ }^{60} \mathrm{Co}\right)$ [87]. Fig. 5 719 shows a combined procedure for separation of nickel and iron for the determination of $720 \quad{ }^{63} \mathrm{Ni}$ and ${ }^{55} \mathrm{Fe}$.

721 The sample preparation for measuring the ${ }^{63} \mathrm{Ni}$ activity by the LSC counter is quite 722 simple. The eluate containing the sample fraction is collected from the chromatographic 723 column at the end of separation procedure. The eluate is evaporated to near dryness and 724 the residue is dissolved in a few milliliters of dilute $\mathrm{HCl}$ or $\mathrm{HNO}_{3}$, which is placed in a 725 LSC vial for counting. Attention has to be given when evaporating the Ni eluate to 726 dryness, because nickel in the $\mathrm{HNO}_{3}(3-12 \mathrm{M})$ eluate presents as $\mathrm{Ni}\left(\mathrm{NO}_{3}\right)_{2}$, which has a 727 low boiling point $\left(136.7^{\circ} \mathrm{C}\right)$ and can be easily lost during evaporation at high temperature $728\left(>137^{\circ} \mathrm{C}\right)$. Therefore, the eluate of $\mathrm{Ni}$ is often evaporated to near dryness $(<0.5 \mathrm{ml})$ on a 729 hotplate with low temperature $\left(<120^{\circ} \mathrm{C}\right)$ in the end of the evaporation $(<3 \mathrm{ml})$.

730 The counting efficiencies of the prepared ${ }^{63} \mathrm{Ni}$ sample vary from $\sim 50 \%$ to $\sim 80 \%$ 731 depending on the sample composition. Quench corrections are applied in most cases. 732 Detection limits of $0.005-0.014 \mathrm{~Bq} /$ sample for ${ }^{63} \mathrm{Ni}$ has been reported by using a 733 combined chemical separation procedure and ultra-low background LSC instrument [12, 734 84].

735 Besides the radiometric techniques, ${ }^{63} \mathrm{Ni}$ can be also determined using AMS [93]. The 736 comparison by Hou and Roos [89] showed that the detection limits of $0.12-45 \mathrm{mBq}$ 737 achieved by the AMS methods. For both methods, chemical separation is necessary. 
738 Nevertheless, the ${ }^{63} \mathrm{Ni}$ assays are mostly performed using LSC, because of the 739 accessibility of the LSC counters in radiochemical laboratories.

\section{Strontium-89 and Strontium-90/Yttrium-90}

${ }^{90} \mathrm{Sr}\left(E_{\max }=546 \mathrm{keV}, t_{1 / 2}=28.8 \mathrm{y}\right)$ and ${ }^{89} \mathrm{Sr}\left(E_{\max }=1495 \mathrm{keV}, t_{1 / 2}=50.57 \mathrm{~d}\right)$ are

743 fission products, ${ }^{89} \mathrm{Sr}$ can be also produced by neutron activation of stable ${ }^{88} \mathrm{Sr}$. The main

744 sources of ${ }^{90} \mathrm{Sr}$ and ${ }^{89} \mathrm{Sr}$ in the environment are atmospheric nuclear weapons tests,

745 nuclear accidents and discharges from nuclear facilities. Fallout from nuclear weapons

746 testing is primarily responsible for the ${ }^{90} \mathrm{Sr} /{ }^{90} \mathrm{Y}$ concentrations found globally in the

747 environment. ${ }^{90} \mathrm{Sr}$ is important for environmental monitoring because of its relatively

748 high fission yield $\left(5.7 \%\right.$ for $\left.{ }^{235} \mathrm{U}\right)$, its long physical and biological half-lives, and its

749 transfer to food chains. It is highly toxic because it accumulates in bone tissue which is

750 exposed by high energy betas of ${ }^{90} \mathrm{Sr} /{ }^{90} \mathrm{Y} .{ }^{89} \mathrm{Sr}$ shares the same biological significance but

751 is less hazardous. It has a much shorter physical half-life and thus will not have a long-

752 term environmental impact.

753 Both ${ }^{90} \mathrm{Sr}$ and ${ }^{89} \mathrm{Sr}$ are pure beta emitter, and ${ }^{90} \mathrm{Sr}$ decays to short-lived pure beta emitter

$754{ }^{90} \mathrm{Y}\left(t_{1 / 2}=64.05 \mathrm{~h}\right), \mathrm{LSC}$ is the major method for their measurement. For quantitative

755 analysis of radiostrontium, strontium has to be separated from sample matrix and all other

756 radionuclides before measurement [94]. Strontium is one of alkaline earth elements; it

757 mimics calcium in its behaviour but much less abundance. The emphasis on the assay of

758 radiostrontium has been focused on the separation chemistry, especially its separation

759 from other alkaline earth elements and similar property radionuclides $\left({ }^{226,228} \mathrm{Ra},{ }^{133} \mathrm{Ba}\right.$,

$760{ }^{210} \mathrm{~Pb}$, etc.). These methods are mainly based on precipitation/co-precipitation, solvent

761 extraction, ion chromatography or ion exchange, extraction chromatography or 762 combination of these techniques [94].

763 The oldest method for radiostrontium determination is based on precipitation of $764 \mathrm{Sr}\left(\mathrm{NO}_{3}\right)_{2}$ in high concentration of $\mathrm{HNO}_{3}(72 \%)$ solution by using fumic nitric acid for 765 separation of strontium from most of elements including calcium, from yttrium and

766 fission products by the hydroxide precipitation, and from barium, radium and lead by 767 chromate precipitation. For pre-concentration of strontium, carbonate precipitation $768\left(\mathrm{SrCO}_{3}\right)$ is often used. In this step, calcium and many other elements including metals are 
769 also precipitated. The method is efficient but not selective for strontium although it is still

770 used in some labs. The main disadvantage of this procedure is its involvement of large

771 amount of fumic nitric acid and chromate, which are more dangerous and harmful for the

772 operators.

773 In the past decades, the extraction chromatography using the Sr•Spec resin has been

774 widely used for the determination of radiostrontium. In this resin, a crown ether [bis-

$7754,4^{\prime}\left(5^{\prime}\right)$-tert-butylcyclohexano-18-crown-6] in 1-octanol is grafted on an inert polymeric

776 resin (Amberlite XAD-7 or Amberchrom CG-71ms) and packed it into a

777 chromatographic column. The Sr Spec resin shows a high selectivity for strontium ions

778 over calcium, magnesium and most other metals and fission products. In this method, the

779 sample is first ashed or acid digested to transfer $\mathrm{Sr}$ to a solution, and then pre-

780 concentrated using $\mathrm{SrCO}_{3}$ or $\mathrm{Sr}_{3}\left(\mathrm{PO}_{4}\right)_{2}$ precipitation After dissolved and prepared in 2-8

$781 \mathrm{M} \mathrm{HNO}_{3}$ medium, the sample solution is loaded to the Sr Spec column. If phosphate

782 precipitation was applied, $\mathrm{Al}\left(\mathrm{NO}_{3}\right)_{3}$ should be added to the solution to remove the effect

783 of phosphate. The column is then rinsed using $8 \mathrm{M} \mathrm{HNO}_{3}$, and strontium adsorbed on the

784 column is finally eluted with $0.05 \mathrm{M} \mathrm{HNO}_{3}$ solution. Strontium is strongly adsorbed on

785 the Sr column, whereas most interfering elements, including yttrium, were removed with

786 the feed and rinse solutions. Barium, lead and tetravalent neptunium and plutonium are

787 also retained by the column, and an attention should be given to avoid these element enter

788 to the eluate of $\mathrm{Sr}$.

789 TRU column stacked with $\mathrm{Sr}$ resin column has been proposed to get a better 790 decontamination for $\mathrm{Ba}, \mathrm{Pb}, \mathrm{Pu}$, Th and $\mathrm{U}$ [20]. Sr resin method has been widely used for 791 determination of radiostronium in various matrices such as water, soil, sediment and diet 792 [95-98]. For rapid determination of radiostrontium in milk samples, $\mathrm{HCl}$ and 793 trichloroacetic acid were first added to the sample to flocculate the suspended fat and 794 proteins in milk after addition of stable strontium carrier. The strontium in the supernatant 795 was then precipitated as carbonate and used for further separation using Sr Spec column 796 [17]. For determination of radiostronium in steel and iron samples, a procedure was 797 reported by using $\mathrm{SrF}_{2} / \mathrm{CaF}_{2}$ precipitation for separation of $\mathrm{Sr}$ from large amount of iron, 798 following by Sr Spec column to purify strontium [96]. In general, the separations using $\mathrm{Sr}$ 799 resin is considered simple, rapid, economic and safe. 
800 Besides the Sr Spec resin provided by Triskem and Eichrom, other similar resins for 801 separation of strontium have also been developed. AnaLig®Sr01 (or SuperLig® 620) 802 resin is prepared by covalently bonding of ligand, most likely a variation of an 18-crown8036 (18C6) structure on silica gel [98]. Another one was prepared by grafting two 804 extractants, 4,40(50)-bis-t-butylcyclohexano-18-crown-6 and di(2-ethyl-hexyl) 805 phosphoric acid onto Amber chrom CG-71 [99]. These resins showed similar features in 806 the separation of radiostrontium for the determination of ${ }^{89} \mathrm{Sr}$ and ${ }^{90} \mathrm{Sr}$ using LSC. 807 However, they are not well commercialized and not easy to obtain. The most popular $\mathrm{Sr}$ 808 resin is still the Sr Spec resin from Triskem and Eichrom.

809 The main limitation on the application of $\mathrm{Sr} \mathrm{Spec}$ and similar resin in the 810 determination of radiostronium is its low capacity for $\mathrm{Sr}$ and the interferences of high 811 calcium and salt content in sample on the strontium separation. For a $1.5 \mathrm{~g}$ Sr Spec resin 812 column, loading of no more than $5 \mathrm{mg} \mathrm{Sr}$ should be followed. For analysis of high $\mathrm{Sr}$ and 813 Ca containing sample (e.g., bone ash), a big column or splitting sample into aliquots and 814 loading to more Sr Spec. columns are needed [42]. For low-level environmental samples, 815 large sample size is needed for determination of ultra-low level ${ }^{90} \mathrm{Sr}$, which often contain 816 large amount of stable $\mathrm{Sr}, \mathrm{Ca}, \mathrm{Ba}$, other interfering elements and radionuclides, the 817 simple extraction chromatography separation using Sr resin may not be suitable.

818 Chen et al. [100] reported a simple method for the determination of ${ }^{90} \mathrm{Sr}$ in environmental 819 samples containing high $\mathrm{Ca}$ and $\mathrm{Sr}$, such as in large volume of seawater samples (45 820 liters). In this method, strontium is first separated from seawater by co-precipitation of $821 \mathrm{CaCO}_{3}-\mathrm{SrCO}_{3}$ with the addition of stable strontium carrier of 0.3-0.5 g Sr and $\mathrm{Na}_{2} \mathrm{CO}_{3}$, 822 the sample was heated to $90-95{ }^{\circ} \mathrm{C}$ and kept for 2 hour. The precipitation is separated by 823 settling for overnight to remove the supernatant followed by centrifuging the remaining 824 sludge. After dissolution of the $\mathrm{CaCO}_{3}-\mathrm{SrCO}_{3}$ using $\mathrm{HCl}$, calcium is separated by 825 hydroxide precipitation by the addition of $\mathrm{NaOH}$ to a final concentration of $0.5 \mathrm{M} \mathrm{NaOH}$. 826 In this condition, $\mathrm{Ca}(\mathrm{OH})_{2}$ precipitate is formed, but strontium remains in the solution 827 and separated from large amount of calcium. Strontium in the supernatant is then 828 separated as $\mathrm{SrCO}_{3}$ precipitate by the addition of $\mathrm{Na}_{2} \mathrm{CO}_{3}$. The formed $\mathrm{SrCO}_{3}$ is dissolved 829 in $\mathrm{HNO}_{3}$ solution and kept for 2-3 weeks for ingrowth of ${ }^{90} \mathrm{Y}$ from ${ }^{90} \mathrm{Sr}$. To this solution, 830 yttrium carrier is added, and then strontium is separated by adding $\mathrm{H}_{2} \mathrm{SO}_{4}$ to form $\mathrm{SrSO}_{4}$ 
831 precipitate In this case, $\mathrm{Ba}$ and $\mathrm{Ra}$ remaining in the sample are precipitated and removed

832 from yttrium. ${ }^{90} \mathrm{Y}$ is then separated by adding oxalic acid to form yttrium oxalate 833 precipitate, and ${ }^{90} \mathrm{Y}$ in the precipitate is measured using low background gas flow G-M 834 counter (Risø detector) or LSC after dissolved in $\mathrm{HNO}_{3}$. The decontamination factors for 835 most of interfering elements/radionuclides $(\mathrm{Ca}, \mathrm{Ra}, \mathrm{Ba})$ are higher than $10^{3}$, and a 836 detection limit of $5 \mathrm{mBq}$ was achieved. The main feature of this method is its capacity to 837 handle high calcium samples. Besides water samples (seawater, ground, river and lake 838 water), this method has also been applied for the analysis of milk, bone and large size soil 839 samples for ${ }^{90} \mathrm{Sr}[101]$.

840 Due to the short half-life, ${ }^{90} \mathrm{Y}(64 \mathrm{~h})$ reaches equilibrium with ${ }^{90} \mathrm{Sr}$ in an only few weeks, 841 they are normally in equilibrium in the environmental samples. Direct separation and 842 measurement of ${ }^{90} \mathrm{Y}$ from the samples or separation of the ingrown ${ }^{90} \mathrm{Y}$ from the 843 separated ${ }^{90} \mathrm{Sr}$ can be used to measure ${ }^{90} \mathrm{Sr}$. Based on high adsorption of $\mathrm{Y}$ on an 844 extraction chromatographic resin DGA (Triskem International), it was applied for 845 separation of Y from the sample and separated strontium solution, the obtained Y solution 846 was measured for determination of ${ }^{90} \mathrm{Sr}$ in the samples [96].

847 In addition, solvent extraction and ion exchange chromatography are also used for 848 separating radiostrontium from various environmental matrices [94]. Tributyl phosphate 849 (TBP) and bis-2-etytlhexyl-phosphoric acid (HDEHP) have been the most commonly 850 used organic extractants to separate ${ }^{90} \mathrm{Y}$ from liquid samples, which is assumed to be in 851 equilibrium with ${ }^{90} \mathrm{Sr}$. Consequently, rapid assays of ${ }^{90} \mathrm{Sr}$ via ${ }^{90} \mathrm{Y}$.

852 Regardless of the separation method, the separated $\mathrm{Sr}$ is finally prepared for LSC or 853 Cerenkov counting. At the end of the separation procedure, strontium is precipitated as 854 the carbonate or the oxalate, then dissolved in dilute $\mathrm{HCl}$ or $\mathrm{HNO}_{3}$ acid and mixed with 855 the LSC cocktail. The organic eluates/phase from the chromatographic columns or 856 solvent extraction can be used for LSC measurement. Chemical yields of strontium and 857 yttrium can be determined by gravimetric methods or atomic absorption 858 spectrophotometry, flame photometry or using ${ }^{85} \mathrm{Sr}$ as a yield tracer. Stable $\mathrm{Sr}$ and Y 859 originally present in the samples have to be considered in the measurement of the 860 chemical yield, especially for the environmental samples which might contain significant 861 amount of stable Sr and Y. 
862 In the samples, especially shortly collected from a nuclear facilities or its surrounding 863 environment, both ${ }^{89} \mathrm{Sr}$ and ${ }^{90} \mathrm{Sr}$ might present, the simultaneous determination of ${ }^{90} \mathrm{Sr}$ and

$864{ }^{89} \mathrm{Sr}$ by LSC is possible using several approaches. The separated strontium sample can be 865 measured merely by LSC after mixing with scintillation cocktail or directly by Cerenkov 866 counting or by measuring the sample first by Cerenkov counting followed by adding 867 scintillation cocktail for LSC. Because the overlap of the beta spectra of ${ }^{90} \mathrm{Sr}$ and ${ }^{89} \mathrm{Sr}$, the 868 strontium sample is often measured twice at various times during the ${ }^{90} \mathrm{Y}$ ingrowth. 869 Thereafter ${ }^{90} \mathrm{Sr}$ and ${ }^{89} \mathrm{Sr}$ activities can be calculated from the two independent counts in 870 consideration of the contribution of ${ }^{90} \mathrm{Sr},{ }^{90} \mathrm{Y}$ and ${ }^{89} \mathrm{Sr}$ on the counts in different counting 871 windows. The different counting efficiency for ${ }^{90} \mathrm{Sr},{ }^{90} \mathrm{Y}$ and ${ }^{89} \mathrm{Sr}$ and the time for ${ }^{90} \mathrm{Y}$ 872 ingrowth and the ${ }^{89} \mathrm{Sr}$ decay have to be considered and corrected. When ${ }^{90} \mathrm{Y}$ is separated, 873 its activity is often measured by Cerenkov counting immediately after the separation. If 874 only ${ }^{90} \mathrm{Sr}$ is to be determined, this measurement is sufficient; but in the occurrence of ${ }^{89} \mathrm{Sr}$, 875 the combined ${ }^{89} \mathrm{Sr}$ and ${ }^{90} \mathrm{Sr}$ activity should be measured in the separated strontium sample. 876 For low activity samples with high ${ }^{89} \mathrm{Sr} /{ }^{90} \mathrm{Sr}$ activity ratios, accurate determination of $877{ }^{90} \mathrm{Sr}$ is better to be measured by separation and measurement of the ingrown ${ }^{90} \mathrm{Y}$ using 878 Cerenkov counting or G-M counter. In this method, strontium in the sample solution is 879 first adsorbed onto the Sr Spec column, then waiting for 1-2 days to allow ingrowth of $880{ }^{90} \mathrm{Y}$ on the column. The ingrown ${ }^{90} \mathrm{Y}$ is then elated from the column using $8 \mathrm{M} \mathrm{HNO}_{3}$ and 881 used for Cerenkov counting. ${ }^{89} \mathrm{Sr}$ and ${ }^{90} \mathrm{Sr}$ are elated afterwards in the normal way using 882 water or diluted $\mathrm{HNO}_{3}$ (i.e., $0.05 \mathrm{M} \mathrm{HNO}_{3}$ ) and measured by LSA. Fig. 6 shows the 883 spectra of ${ }^{89} \mathrm{Sr},{ }^{90} \mathrm{Sr}$ and ${ }^{90} \mathrm{Y}$ in the application where the measurement is based using two 884 LSC windows. The detection limits by the current low-background LSA are typically less 885 than $0.1 \mathrm{~Bq}(1-2$ hours count time).

886 Determination of ${ }^{89} \mathrm{Sr}$ and ${ }^{90} \mathrm{Sr}$ by Cerenkov counting is based on the fact that both ${ }^{89} \mathrm{Sr}$ 887 and ${ }^{90} \mathrm{Y}$ can be detected by measuring the Cerenkov radiation (photons) in colourless 888 aqueous solutions with about $40 \%$ and $60 \%$ counting efficiency, respectively, while the 889 counting efficiency of ${ }^{90} \mathrm{Sr}$ is less than $1.4 \%$ because of the low energy of its beta 890 particles. The ${ }^{89} \mathrm{Sr}$ activity is determined almost exclusively from the freshly separated 891 strontium sample. Recounting is performed after some ingrowth of ${ }^{90} \mathrm{Y}$ from ${ }^{90} \mathrm{Sr}$ and the 892 calculation of the concentrations of ${ }^{89} \mathrm{Sr}$ and ${ }^{90} \mathrm{Sr}$ is possible from these two counts. 
893 Alternatively, ${ }^{90} \mathrm{Y}$ can be separated from the purified strontium sample after its ingrowth 894 and counted separately. Although the efficiency of Cerenkov counting of ${ }^{89} \mathrm{Sr}$ and ${ }^{90} \mathrm{Y}$ is 895 lower than that of LSC, the detection limits of Cerenkov counting for them are similar as 896 the LSC because of the lower background in the Cerenkov counting. The Cerenkov 897 counting techniques allow the use of ${ }^{85} \mathrm{Sr}$ as a yield tracer because it decays through 898 electron capture, could not produce Cerenkov radiation; therefore, it is not detected by 899 this counting.

900

901

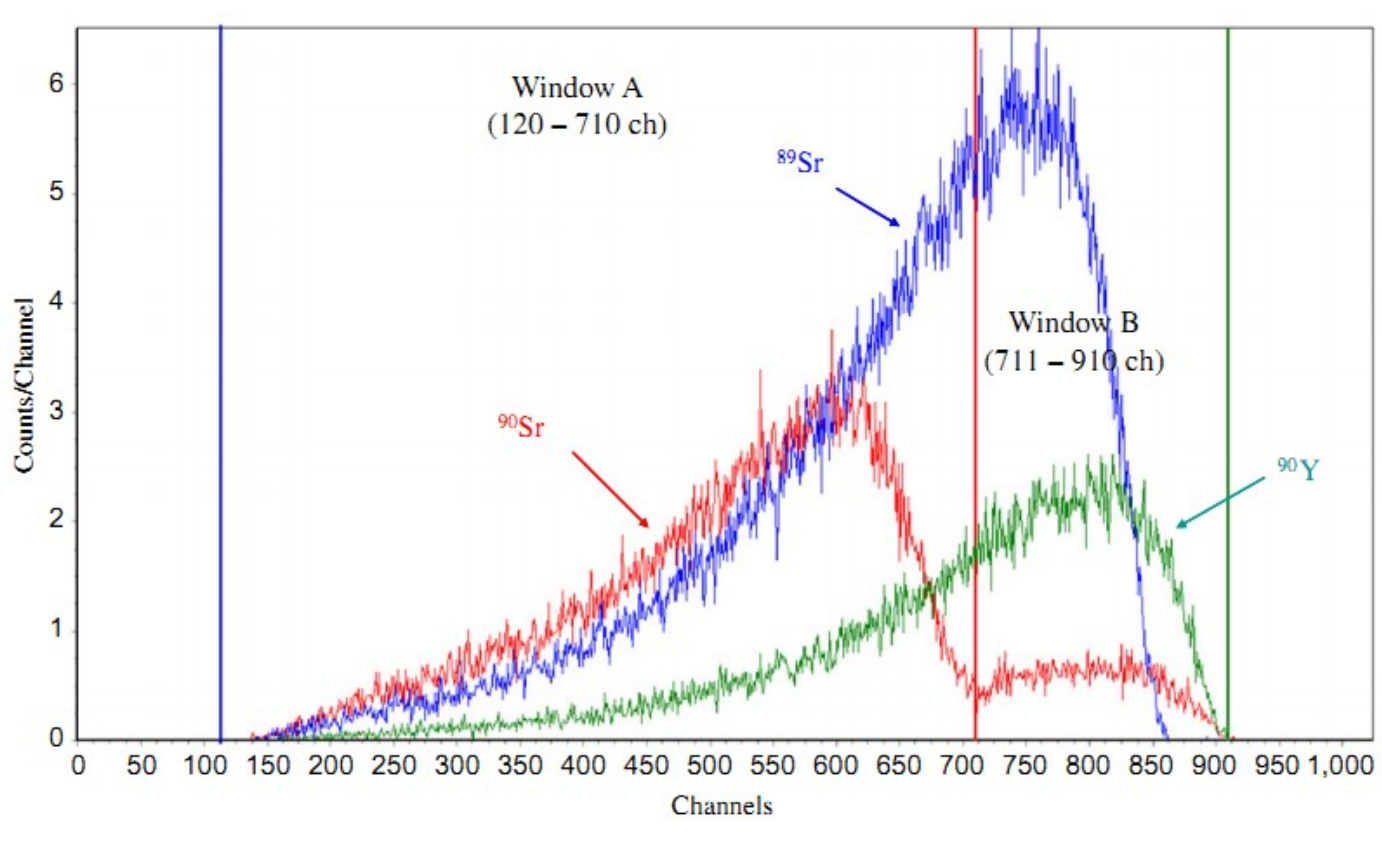

Fig. 6 LSC spectra of ${ }^{89} \mathrm{Sr},{ }^{90} \mathrm{Sr}$ and ${ }^{90} \mathrm{Y}$. The spectrum of ${ }^{90} \mathrm{Sr}$ include small contribution of its daughter radionuclides of ${ }^{90} \mathrm{Y}$.

\section{Technetium-99}

$904 \quad{ }^{99} \mathrm{Tc}$ is a fission product of ${ }^{235} \mathrm{U}$ and ${ }^{239} \mathrm{Pu}$ with relatively high fission yields $(6.1 \%$ 905 from $\left.{ }^{235} \mathrm{U}\right) .{ }^{99} \mathrm{Tc}$ in the environment mainly originates from nuclear weapons tests and 906 nuclear fuel cycle operations, especially the releases from spent fuel reprocessing plants 907 in Sellfield (UK) and La Hague (France) [102]. The principal reasons for the high interest 
908 in the analysis of ${ }^{99} \mathrm{Tc}$ in environmental samples are its very long half-life, high mobility 909 and solubility as the pertechnetate ion $\left(\mathrm{TcO}_{4}^{-}\right)$in oxidative conditions, and consequently 910 its high transfer rate from soil to edible vegetation and from seawater to seaweeds. Under 911 reducing condition, it can be reduced to $\mathrm{Tc}^{4+}$ and strongly bound to sediments. Studies on

$912{ }^{99} \mathrm{Tc}$ have focused on marine and coastal environments owing to discharges from nuclear 913 reprocessing plants $[6,103-113] .{ }^{99} \mathrm{Tc}$ is one of the most significant components in the 914 disposal of nuclear wastes. In nuclear medicine, ${ }^{99 \mathrm{~m}} \mathrm{Tc}\left(t_{1 / 2}=6 \mathrm{~h}\right)$ is used in high-activity 915 amounts, which decay to ${ }^{99} \mathrm{Tc}$, and becomes another source of ${ }^{99} \mathrm{Tc}$ in the environment. $916{ }^{99} \mathrm{Tc}$ is a long-lived $\left(t_{1 / 2}=2.11 \cdot 10^{5} \mathrm{y}\right)$ pure beta emitter $\left(E_{\max }=293.5 \mathrm{keV}\right)$, and therefore 917 can be measured by LSC after separation from sample matrices and all other 918 radionuclides. It can be also measured by ICP-MS, in this case the chemical separation 919 from the isobaric interference is the main challenge because of serious interference of the 920 isobars $\left({ }^{99} \mathrm{Ru}\right.$ and $\left.{ }^{98} \mathrm{Mo} 1 \mathrm{H}\right)$ of stable isotopes.

921 Chemical separation techniques including anion exchange, solvent extraction, 922 selective precipitation, extraction chromatography and even a combustion technique have 923 been used to assay ${ }^{99} \mathrm{Tc}$ in various environmental samples, nuclear effluent and waste 924 samples. Technetium is a volatile element when presents as heptoxide, loss of technetium 925 might also occur during sample preparation and separation, a caution has to be taken 926 during evaporation or ashing. Shi et al. [105] investigated the stability of technetium in 927 various chemical treatment steps including ashing of solid materials and evaporation of 928 aqueous solution. It was found that no significant loss of technetium occurs in ashing of 929 seaweed under $800^{\circ} \mathrm{C}$ for less than 6 hours and under $500{ }^{\circ} \mathrm{C}$ for soil and sediment 930 samples. Evaporation of a solution in different concentration of $\mathrm{HNO}_{3}$ to dryness at less 931 than $100{ }^{\circ} \mathrm{C}$ does not cause obvious loss of technetium, while significant loss of 932 technetium happens in $\mathrm{HCl}$ media, especially in high concentration of $\mathrm{HCl}$. However, if a 933 small volume of solution (more than $0.5 \mathrm{~mL}$ ) remained after evaporation, the loss of 934 technetium can be highly reduced. Salt presenting in the solution can reduce the loss of 935 technetium during evaporation.

$936{ }^{99} \mathrm{Tc}$ has no stable isotope to use as a carrier or for chemical yield monitoring. 937 Although the analytical behaviour of rhenium is quite similar to that of Tc, these elements 938 can behave quite differently under certain conditions; precautions need to be taken if 
939 rhenium is used as a tracer. ${ }^{99 \mathrm{~m}} \mathrm{Tc}$, obtained from a ${ }^{99} \mathrm{Mo}-{ }^{99 \mathrm{~m}} \mathrm{Tc}$ generator has been used 940 widely as a yield tracer in the radiochemical separation of ${ }^{99} \mathrm{Tc}$ for environmental samples, 941 because it is readily available and its emission of gamma rays. The disadvantage of the $942{ }^{99 \mathrm{~m}} \mathrm{Tc}$ tracer is that it may contain ${ }^{99} \mathrm{Tc},{ }^{99} \mathrm{Mo}$ and ${ }^{103} \mathrm{Ru}$ as impurities, which may cause 943 serious interference in the measurement of ${ }^{99} \mathrm{Tc}$ at low level, requiring correction for each 944 tracer solution used [114]. Hou et al. [115] has developed a simple method to produce the $945{ }^{99} \mathrm{~m}$ Tc tracer solution that is pure enough to be utilized in the analysis of low-level 946 environmental samples. The ${ }^{99 \mathrm{~m}} \mathrm{Tc}-{ }^{99} \mathrm{Mo}$ generator was first eluted using saline water $947(0.9 \% \mathrm{NaCl})$ for $3-5$ times to remove the accumulated ${ }^{99} \mathrm{Tc}$ in the generator through decay 948 of ${ }^{99 \mathrm{~m}} \mathrm{Tc}$ and ${ }^{99} \mathrm{Mo}$, the new ingrown ${ }^{99 \mathrm{~m}} \mathrm{Tc}$ is then eluted after a suitable ingrowth time (1 $949 \mathrm{~min}-3$ hours). The obtained ${ }^{99 \mathrm{~m}} \mathrm{Tc}$ solution is then purified by passing through an 950 activated alumina cartridge to remove any ${ }^{99} \mathrm{Mo}$ and ${ }^{103} \mathrm{Ru}$ leaked from the column. The $951{ }^{99} \mathrm{~m}$ Tc activity is measured with a gamma spectrometer before preparing the sample for 952 the LSC. Thereafter, the sample is stored for a week to allow ${ }^{99 \mathrm{~m}} \mathrm{Tc}$ to decay completely 953 before measuring the ${ }^{99} \mathrm{Tc}$ activity by LSC. Another possibility for a yield tracer would be 954 to use ${ }^{95 \mathrm{~m}} \mathrm{Tc}$ (half-life $=61 \mathrm{~d}$ ). ${ }^{95 \mathrm{~m}} \mathrm{Tc}$ decays through electron capture with emission of 955 gamma rays, and can be measured through counting the low-energy auger electrons using 956 LSC. Therefore, ${ }^{99} \mathrm{Tc}$ and ${ }^{95 \mathrm{~m}} \mathrm{Tc}$ can be discriminated and measured by LSA.

957 Chemical separation methods are mainly based on a combination of selective 958 precipitations, ion exchange and solvent extraction using different extractants like DB18959 C6 crown ether (dibenzo-18-crown-6), tri-n-octylamine (TnOA) and tri- $n$-butyl 960 phosphate (TBP). Separation of technetium using anion exchange chromatography is 961 based on the very high affinity of $\mathrm{TcO}_{4}{ }^{-}$on the strong basic anion exchange resin in either 962 diluted acid, alkaline or neutral media. Chen et al. [116] has reported a method for 963 determination of ${ }^{99} \mathrm{Tc}$ in seawater and other environment samples. ${ }^{99} \mathrm{Tc}$ is first pre964 concentrated from large volume of seawater samples (up to $200 \mathrm{~L}$ ) using anion exchange 965 chromatography. The filtered seawater is spiked with ${ }^{99 \mathrm{~m}} \mathrm{Tc}$ tracer, and then loaded to a 966 big anion exchange column $\left(2.5 \mathrm{~cm}\right.$ in diameter and $40 \mathrm{~cm}$ in length, $\mathrm{AG} 1 \times-4 \mathrm{resin}, \mathrm{Cl}^{-}$ 967 form). After rinsing with diluted $\mathrm{NaOH}$ and diluted $\mathrm{HNO}_{3}$ solution, ${ }^{99} \mathrm{Tc}$ is eluted from 968 the column using 8-10 $\mathrm{M} \mathrm{HNO}_{3}$. The eluate is evaporated to small volume $(<10 \mathrm{ml})$, and 969 treated with $\mathrm{H}_{2} \mathrm{O}_{2}$ and $\mathrm{NaClO}$ with heating to remove $\mathrm{Ru}$. Afterwards, the solution is 
970 converted to $1 \mathrm{M} \mathrm{HSO}_{4}$ medium, ${ }^{99} \mathrm{Tc}$ in the solution is further purified by solvent 971 extraction using 5\% triisooctylamine (TIOA) in xylene. The overall recovery of ${ }^{99} \mathrm{Tc}$ is 972 more than $75 \%$ and the most interference can be removed to be able to measure 973 background level ${ }^{99} \mathrm{Tc}$ in seawater samples $(0.003 \mathrm{mBq} / \mathrm{L})$ using up to $500 \mathrm{~L}$ seawater.

$974 \mathrm{Fe}(\mathrm{OH})_{3}$ precipitation has been used to remove the radionuclides of transition metals, 975 actinide and lanthanides, while $\mathrm{Tc}$ as water soluble $\mathrm{TcO}_{4}{ }^{-}$remained in the supernatant. In 976 this case, the sample solution is better treated with oxidizing reagents (e.g. $\mathrm{K}_{2} \mathrm{~S}_{2} \mathrm{O}_{8}, \mathrm{H}_{2} \mathrm{O}_{2}$, 977 etc.) to ensure all technetium is converted to $\mathrm{TcO}_{4}^{-}$. Technetium extracted into tri-n978 octylamine (TnOA) in xylene from $\mathrm{H}_{2} \mathrm{SO}_{4}$ medium was used to purify $\mathrm{Tc}$ from $\mathrm{Ru}$, and 979 the extracted ${ }^{99} \mathrm{Tc}$ in TnOA-xylene can be mixed with the scintillation cocktail for LSC 980 measurement of ${ }^{99} \mathrm{Tc}$ [117].

981 Selective extraction chromatographic methods using TEVA•Spec resin (Triskem 982 International) has become the most popular method for the determination of ${ }^{99} \mathrm{Tc}$ in 983 environmental samples [103-105, 112]. The function group on TEVA resin is similar as 984 anion exchange resin; $\mathrm{TcO}_{4}^{-}$also shows a high affinity to TEVA resin. The sample is 985 normally loaded in a neutral solution or in $0.1 \mathrm{M} \mathrm{HNO}_{3}$ solution to a TEVA column, $\mathrm{Tc}$ is 986 retained, while most of other elements pass through the column. ${ }^{99} \mathrm{Tc}$ is finally eluted 987 with 4-8 $\mathrm{M} \mathrm{HNO}_{3}$. Shi et al. [105] has reported a method for removing Ru from ${ }^{99} \mathrm{Tc}$ by 988 pretreatment of the loading solution with $30 \% \mathrm{H}_{2} \mathrm{O}_{2}$ in alkaline media, and found a 989 significantly improvement in the removal of ruthenium in chromatographic separation 990 using TEVA column. This might be attributed to the reduction of ruthenium in this 991 process. In addition, TEVA also show a better removal of Mo from Tc. With two 992 sequential TEVA column, Mo and Tc can be remove with a high decontamination factor 993 [105].

994 Quantitative measurement of ${ }^{99} \mathrm{Tc}$ by LSC is viewed as a practical but also as the main 995 approach, because of the more widespread accessibility of the LSAs, meanwhile it is also 996 tolerance of isobaric ions interference $\left({ }^{99} \mathrm{Ru}\right.$ and $\left.{ }^{98} \mathrm{Mo}{ }^{1} \mathrm{H}\right)$, which is the major challenge in 997 the ICP-MS measurement of ${ }^{99} \mathrm{Tc}$. The LSC efficiencies of ${ }^{99} \mathrm{Tc}$ are typically in the range 998 of $70-80 \%$ depending on sample composition and quenching. The backgrounds using 999 low-background LSA (e.g. Quantulus LSA) are between 1.6-3.3 cpm and the detection 1000 limits of $17 \mathrm{mBq}$ (2 hours count) can be achieved [89]. 
1001 Tarancon et al. [5] has proposed concept to combine the chromatographic separation 1002 with scintillation for the determination of radionuclides using LSC. In this method, a 1003 plastic scintillation resin is synthesized, in which extraction reagent and scintillator are 1004 grafted on plastic beads. The plastic scintillation resin behaves as both extraction 1005 chromatographic resin and scintillator. The resin is prepared and uploaded to a column, 1006 the sample solution is loaded to the column, the target radionuclide is adsorbed on the 1007 resin, and the matrix and interfering radionuclides are removed by rinsing. The 1008 scintillation resin with the analyte radionuclide in the column is directly measured by 1009 ordinary LSC. This research group has reported a method for the determination of ${ }^{99} \mathrm{Tc}$ in 1010 environmental and waste samples [6]. A specific plastic scintillation resin was 1011 synthesized by drafting Aliquat 336 (trioctylmethylammonium chloride) as extractant to 1012 plastic scintillation microsphere. Here, the plastic scintillation microsphere (PSm) 1013 behaves like liquid scintillation cocktail but in a solid phase. PSm consists of a polymeric 1014 solvent and both primary and secondary scintillators, such as the classical PPO, POPOP, 1015 p-T or bis-MSB. Fluor molecules remain encapsulated inside the PS solid. Fig. 7 shows 1016 schematic diagram of the determination of ${ }^{99} \mathrm{Tc}$ using the plastic scintillation resin.

1017

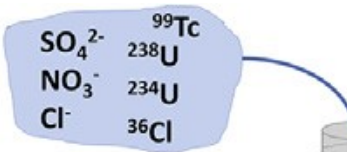

1019

Fig. 7 Schematic diagram of plastic scintillation for determination of ${ }^{99} \mathrm{Tc}[6]$ 
$1023{ }^{129}$ I decays by beta emission with the maximum beta energy of $150 \mathrm{keV}$, accompanied 1024 with emission of low intensity (7.5\%) $39.6 \mathrm{keV}$ gamma ray and some $29.46 \mathrm{keV}(20.4 \%)$ 1025 and $29.78 \mathrm{keV}(37.7 \%)$ X-rays. It can be therefore measured by LSC and $\gamma$ spectrometry, 1026 while LSC is more sensitive.

$1027{ }^{129} \mathrm{I}$ is naturally present in the environment, generated mainly in the atmosphere from 1028 xenon by nuclear reactions induced by cosmic radiation. The concentration of natural ${ }^{129} \mathrm{I}$ 1029 in the environment is so low that it is not usually expressed as activity concentration but 1030 in proportion to the only stable isotope of iodine as ${ }^{129} \mathrm{I} /{ }^{127} \mathrm{I}$ atomic ratio. Before the 1031 nuclear age, the ${ }^{129} \mathrm{I} /{ }^{127} \mathrm{I}$ atomic ratio was about $10^{-12}$ in the sea and somewhat higher in 1032 terrestrial environment. ${ }^{129} \mathrm{I}$ in the present environment is mainly released from the 1033 human nuclear activities, including nuclear weapons tests, nuclear accidents, and 1034 emissions from nuclear facilities, the level of ${ }^{129} \mathrm{I}$ in the environment has risen, and the $1035{ }^{129} \mathrm{I} /{ }^{127} \mathrm{I}$ ratio has increased by several orders of magnitude, up to as much as $10^{-4}$ in the 1036 surrounding location of nuclear fuel reprocessing plants. The most extensive releases of $1037{ }^{129} \mathrm{I}$ to the environment occurred at the spent nuclear fuel reprocessing facilities at 1038 Sellafield (UK) and La Hague (France) since the early 1990s [118-120].

1039 The very long half-life of ${ }^{129} \mathrm{I}\left(1.6 \times 10^{7} \mathrm{y}\right)$ means that its specific activity is very low $1040\left(6.5 \times 10^{6} \mathrm{~Bq} / \mathrm{g}\right)$. Thus, radiometric methods including LSC are suitable only for samples 1041 in which the ${ }^{129}$ I activity is high. Such samples are found in nuclear power plants and fuel 1042 reprocessing facilities, or environmental samples around the reprocessing plants. 1043 Radiometric methods are not sensitive enough for measuring the very low activity 1044 concentrations of ${ }^{129} \mathrm{I}$ in the environment. More sensitive methods are neutron activation 1045 analysis and especially accelerator mass spectrometry [118, 121].

1046 Measurement of ${ }^{129} \mathrm{I}$ using LSC is mainly used for the analysis of nuclear waste or 1047 environmental samples collected in the contaminated site by nuclear activities (e.g. 1048 reprocessing plants or nuclear accident sites) [122-123]. For determination of ${ }^{129} \mathrm{I}$ in the 1049 ion exchange resin used in the purification of the primary circuit of nuclear power plants, 1050 the iodine in the resin is first extracted using $\mathrm{NaOCl}$. In this case, iodide adsorbed on the 1051 exchange resin is oxidized to iodate, which has low affinity to the resin and eluted from 1052 the resin. After addition of $\mathrm{KIO}_{3}$ solution as carrier, the iodate is reduced to $\mathrm{I}_{2}$ using 1053 hydroxylamine hydrochloride in acidic media and extracted into $\mathrm{CCl}_{4}$ phase. Afterwards, 
1054 iodine is back extracted into water with $\mathrm{NaHSO}_{3}$, which reduces $\mathrm{I}_{2}$ to $\mathrm{I}^{-}$. The iodide is 1055 then oxidized to $\mathrm{I}_{2}$ with $\mathrm{NaNO}_{2}$ in acid condition, which is extracted with toluene or $1056 \mathrm{CHCl}_{3}$. The iodine in the toluene is back extracted into aqueous solution with $0.01 \mathrm{M}$

$1057 \mathrm{NaHSO}_{3}$. Scintillation cocktail is added to the aqueous solution and the activity of ${ }^{129} \mathrm{I}$ is 1058 measured by liquid scintillation counting. The detection limit of $0.6 \mathrm{~Bq} / \mathrm{L}$ was achieved.

1059 For solid samples, such as soil, sediment, vegetation, air particles, ${ }^{129} \mathrm{I}$ has to be separated 1060 from the sample matrix and then purified for its measurement using LSC or other 1061 techniques. Based on its volatility, iodine is often separated from solid samples by 1062 combustion to release iodine as gaseous form [124-126]. The released iodine is trapped in $1063 \mathrm{NaOH}$ solution, which is then used to separate iodine by extraction with $\mathrm{CCl}_{4}$ as 1064 described above for its measurement. In addition, alkali fusion can be also used to 1065 separate iodine from environmental samples, such as soil, sediment, air particles, 1066 vegetation and animal tissues $[121,127]$. In this case, $\mathrm{NaOH}$ is then mixed with the 1067 sample. After dried, the mixture is ashed/fussed at $500-550{ }^{\circ} \mathrm{C}$ for $3-4$ hours. The 1068 ashed/fused sample is leached with hot water, and the leachate is separated from residue 1069 by filtration. Iodine in the leachate is finally separated by $\mathrm{CCl}_{4}$ extraction as described 1070 above [121, 127]. Fig. 3 shows a combined procedure for determination of ${ }^{129} \mathrm{I}$ and ${ }^{36} \mathrm{Cl}$ 1071 in soil samples, in which alkaline fusion or acid digestion were applied for decomposition 1072 of samples and solvent extraction was applied for separation of ${ }^{129}$ I from sample matrices 1073 and interference radionuclides. For the separation of iodine from water, milk and urine 1074 samples, especially large volume of seawater (30-50 liters), an anion exchange 1075 chromatographic method has been reported by Hou et al. [119, 120]. In this method, 1076 iodine in the water or other liquid samples is first reduced to iodide using $\mathrm{KHSO}_{3}$ at $1077 \mathrm{pH}<2$, the sample is loaded to an anion exchange column (AG1 $\times-4, \mathrm{NO}_{3}{ }^{-}$form), the 1078 adsorbed iodine is then eluted with $2 \mathrm{M}$ of $\mathrm{NaNO}_{3}$ solution. The iodine in the eluate is 1079 separated by $\mathrm{CCl}_{4}$ extraction. Iodine is finally obtained in a small volume of back 1080 extraction solution, which is used for LSC measurement or prepared in suitable target for 1081 neutron activation analysis or AMS measurement for ${ }^{129} \mathrm{I}$.

1082

1083 Plutonium-241

1084 Plutonium was released to the environment from nuclear weapons tests and nuclear 
1085 fuel cycle operations particularly from reprocessing plants [89, 128]. There are mainly 1086 four isotopes of plutonium, ${ }^{238} \mathrm{Pu}\left(t_{1 / 2}=87.74 \mathrm{y}\right),{ }^{239} \mathrm{Pu}\left(t_{1 / 2}=2.41 \times 10^{4} \mathrm{y}\right),{ }^{240} \mathrm{Pu}\left(t_{1 / 2}=\right.$ $10876563 \mathrm{y})$ and ${ }^{241} \mathrm{Pu}\left(t_{1 / 2}=14.4 \mathrm{y}\right)$, present in the environment. Among them, only ${ }^{241} \mathrm{Pu}$ is a 1088 beta emitter with emission of low-energy $\beta$-particles $\left(E_{\max }=21 \mathrm{keV}\right)$. Although it is less 1089 radiotoxic than other alpha-emitting plutonium isotopes, ${ }^{241} \mathrm{Pu}$ decays to more toxic $\alpha$ 1090 emitting ${ }^{241} \mathrm{Am}$, makes it also an important radionuclides in the radiation protection. 1091 Meanwhile, the differences in the $\mathrm{Pu}$ isotopic ratios are good fingerprint to trace the 1092 origin of the environmental contamination and for nuclear forensics [89, 129, and 130]. 1093 Environmental monitoring of ${ }^{241} \mathrm{Pu}$ around nuclear facilities is needed and its 1094 determination in activity waste in nuclear fuel reprocessing cycles is important, as it will 1095 influence the method of final disposal.

1096 Liquid scintillation is the major method for the measurement of ${ }^{241} \mathrm{Pu}$, although mass 1097 spectrometry (ICP-MS) has also been used for its determination $[38,131] .{ }^{241} \mathrm{Am}$ is the 1098 direct decay daughter of ${ }^{241} \mathrm{Pu}$, therefore measurement of the ingrown ${ }^{241} \mathrm{Am}$ from ${ }^{241} \mathrm{Pu}$ 1099 using alpha spectrometry has also been used for determination of ${ }^{241} \mathrm{Pu}$.

1100 Many methods have been developed for the determination plutonium in environmental 1101 and nuclear samples, as summarized in four comprehensive reviews by [89, 128, and 1102 132]. The chemical separation schemes of ${ }^{241} \mathrm{Pu}$ are normally complicated, because the 1103 concentrations of ${ }^{241} \mathrm{Pu}$ is normally very low, its oxidation states have to be considered 1104 during the separation, and plutonium has to be purified completely from other 1105 radionuclides in advance to avoid the interference. Fig. 8 shows an often used analytical 1106 procedure for determination of plutonium isotopes. In general, plutonium is first released 1107 from the solid sample matrix by acid digestion or alkaline fusion followed by acid 1108 dissolution. The released plutonium in the sample solution or in liquid samples (water 1109 sample) is then pre-concentrated by co-precipitation of hydroxide, florid or phosphate. 1110 The precipitate is dissolved and plutonium is converted to $\mathrm{Pu}^{4+}$ valence state, which can 1111 be implemented by first reduced all plutonium to $\mathrm{Pu}^{3+}$ using strong reductant such as $1112 \mathrm{KHSO}_{3}$, and then oxidize $\mathrm{Pu}^{3+}$ to $\mathrm{Pu}^{4+}$ using $\mathrm{NaNO}_{2}$, concentrated $\mathrm{HNO}_{3}$ containing $1113 \mathrm{HNO}_{2}$ can be also used for this purpose. The prepared sample solution is loaded to an 1114 anion exchange column (e.g. AG 1x-4, or Dowex 1x-4) or TEVA extraction 1115 chromatographic column, followed by rinsing with $\mathrm{HNO}_{3}$ to remove uranium and all 
1116 transition elements and $\mathrm{HCl}$ for Th removal. Plutonium absorbed on the column is finally 1117 eluted by reducing it to $\mathrm{Pu}^{3+}$ using $\mathrm{NH}_{2} \cdot \mathrm{OH}-\mathrm{HCl}$ or using diluted $\mathrm{HCl}$ or diluted $\mathrm{HF}$. The 1118 plutonium eluate is evaporated to dryness and dissolved in a small volume of diluted $\mathrm{HCl}$ 1119 for LSC measurement of ${ }^{241} \mathrm{Pu}$.

Fig. 8 Diagram of chemical separation procedure for determination of plutonium anion exchange or TEVA cloumn

Washing the preciptiate with $2 \mathrm{M} \mathrm{NaOH}$ Dissolve with $\mathrm{HCl}$, reduce $\mathrm{Pu}$ to $\mathrm{Pu}^{3+}$, Copreciptiate $\mathrm{Pu}(\mathrm{OH})_{3}$ with $\mathrm{Fe}(\mathrm{OH})_{2}$, dissolve with conc. $\mathrm{HNO}_{3}$ and adjust to $8 \mathrm{M} \mathrm{HNO3}$ media

\section{Water sample or leachate, with tracer ${ }^{242} \mathrm{Pu}$ \\ $\downarrow \quad$ Add $\mathrm{NaOH}$}

\section{Coprecipitate of $\mathrm{Pu}$ hydroxides with $\mathrm{Fe}(\mathrm{OH})_{3}$}

$$
\begin{aligned}
& \text { Wash with } \mathrm{HNO}_{3} \text { and } \mathrm{HCl} \text { to remove } \mathrm{Am}, \mathrm{Th}, \mathrm{U}, \mathrm{Np} \text { etc. } \\
& \text { Elute } \mathrm{Pu} \text { with } \mathrm{NH}_{2} \mathrm{OH} \text { in } \mathrm{HCl} \text { by reducing } \mathrm{Pu} \text { to } \mathrm{Pu}^{3+} \\
& \text { Eluate of } \mathrm{Pu} \longrightarrow \text { sSC measurement for }{ }^{241} \mathrm{Pu} \text {.ectrodeposition of } \mathrm{Pu}
\end{aligned}
$$

$1134 \quad{ }^{241} \mathrm{Pu}$ is a low-energy $\beta$-emitter, and LSC is the ideal measurement technique for 1135 determining its activity. While, other plutonium isotopes are alpha emitters, and often 1136 measured using alpha spectrometry. Therefore, ${ }^{241} \mathrm{Pu}$ and other alpha emitting plutonium 1137 isotopes are usually measured separately. This is often implemented that the separated 1138 plutonium is first electro-deposited on metal disc or micro-precipitated as $\mathrm{NdF}_{3}$ co1139 precipitate on membrane filter and measured for alpha emitting plutonium isotopes $\left({ }^{238} \mathrm{Pu}\right.$, $1140{ }^{239,240 \mathrm{Pu}}$ and ${ }^{242} \mathrm{Pu}$ as chemical yield tracer) [132]. Afterwards, the Pu sample on the disk 
1141 or filter paper is dissolved and measured using LSC for determining the ${ }^{241} \mathrm{Pu}$ activity.

1142 The all alpha emitting plutonium isotopes measured by alpha spectrometry can be used as

1143 the chemical yield for the ${ }^{241} \mathrm{Pu}$ determination in LSC, which can be measured by using

1144 alpha-beta discrimination feature equipped in most of LSA. The Pu on the stainless steel

1145 is dissolved in concentrated $\mathrm{HNO}_{3}$ and then purified by solvent extraction or ion

1146 exchange, which is necessary if some interfering elements like Fe and Pt are present in

1147 the solution with $\mathrm{Pu}$ [131]. They cause quenching and decrease the counting efficiency of

$1148{ }^{241} \mathrm{Pu}$ and increase misclassification. The $\mathrm{Pu}$ alpha source prepared as co-precipitation of

$1149 \mathrm{NdF}_{3}$ can be treated by dissolving $\mathrm{Pu}$ in a solution of $\mathrm{H}_{3} \mathrm{BO}_{3} / \mathrm{HNO}_{3}$ and ethanol for LSC

1150 measurement of ${ }^{241} \mathrm{Pu}$. The application of $\alpha / \beta$ discrimination feature in the LSC can also

1151 reduce interferences and background in the low-energy $\beta$-region of the ${ }^{241} \mathrm{Pu}$. A typical $\beta$ -

1152 spectrum of ${ }^{241} \mathrm{Pu}$ with $\alpha$-peak of other $\mathrm{Pu}$-isotopes is shown in Fig. 9. The detection

1153 limits for ${ }^{241} \mathrm{Pu}$ are of the order of $10-100 \mathrm{mBq}$ per sample based on a $100-600$ minute

1154 count time [89].

1155

1156

1157

1158

1159

1160

1161

1162

1163

1164

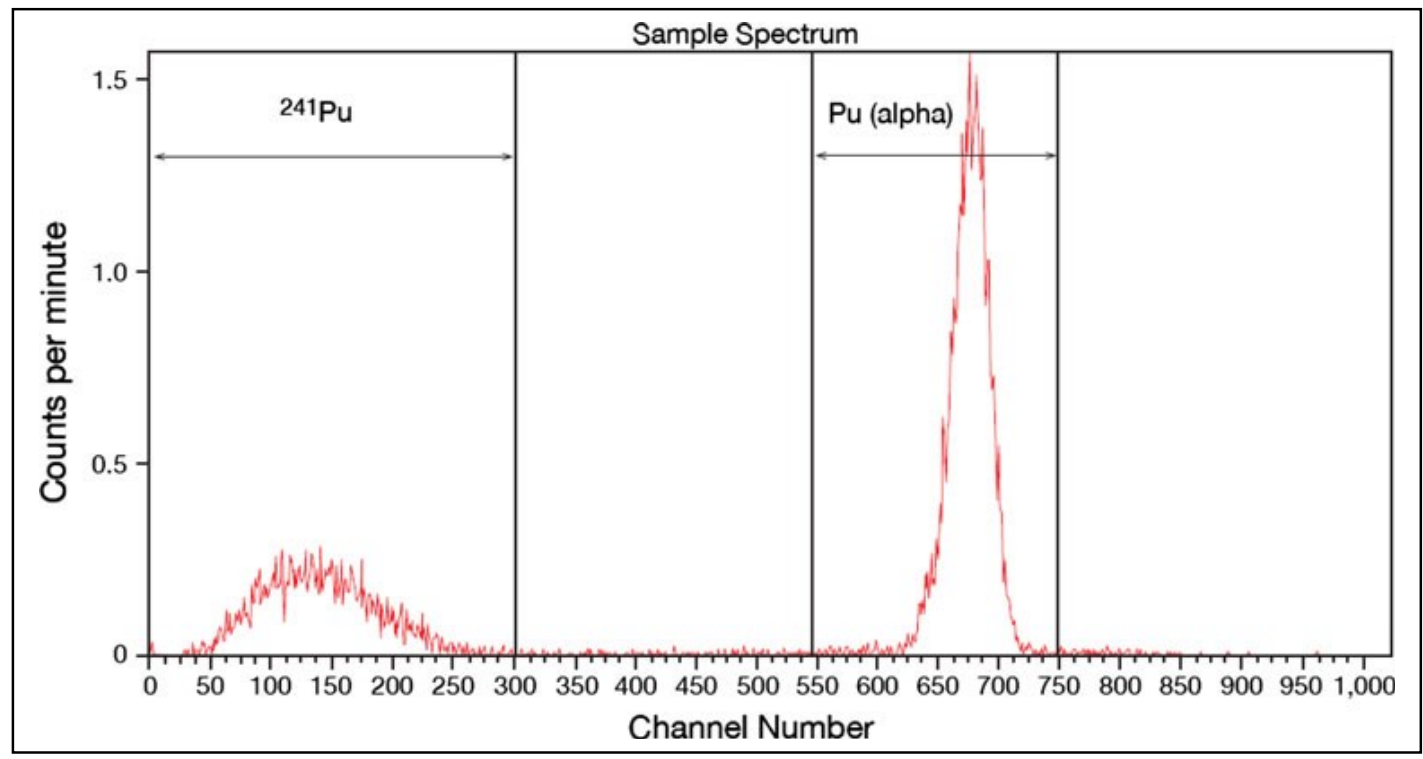

Fig. 9 LSC spectra of a plutonium sample measured by Quantulus [131] 


\section{Analysis for nature occurred radionuclides}

1168 Naturally occurred radionuclides are mainly decay chain radionuclides of ${ }^{235} \mathrm{U},{ }^{238} \mathrm{U}$ 1169 and ${ }^{232} \mathrm{Th},{ }^{40} \mathrm{~K}$ and some cosmogonic radionuclides. However, the radionuclides 1170 measured using LSC are mainly those decay chain radionuclides of uranium and thorium, 1171 especially isotopes of $\mathrm{Ra}, \mathrm{Rn}$ and $\mathrm{Pb}$. In the past decades, LSC is becoming a popular 1172 method for measurement of gross alpha and gross beta in water samples for screen 1173 purpose.

\section{Radon}

1176 There are three natural radon isotopes, ${ }^{219} \mathrm{Rn},{ }^{220} \mathrm{Rn}$ and ${ }^{222} \mathrm{Rn}$, all are alpha emitter. 1177 The short-lived ${ }^{220} \mathrm{Rn}\left(t_{1 / 2}=55.6 \mathrm{~s}\right)$ and ${ }^{219} \mathrm{Rn}\left(t_{1 / 2}=3.96 \mathrm{~s}\right)$ are decay products of ${ }^{232} \mathrm{Th}$ 1178 and ${ }^{235} \mathrm{U}$, respectively. ${ }^{222} \mathrm{Rn}\left(t_{1 / 2}=3.82 \mathrm{~d}\right)$ is the immediate daughter of ${ }^{226} \mathrm{Ra}$ in the ${ }^{238} \mathrm{U}$ 1179 decay series. Uranium and thorium occur in all rocks and soils at varying concentrations, 1180 the produced ${ }^{222} \mathrm{Rn}$ and ${ }^{220} \mathrm{Rn}$ in the rock and soil can diffuse from mineral grains into 1181 pore spaces and thereafter escape to air and dissolve in water. Because of very short half1182 life, ${ }^{220} \mathrm{Rn}$ moves much shorter distances before decaying, it is of concern only where the 1183 concentration of ${ }^{232} \mathrm{Th}$ is high. ${ }^{219} \mathrm{Rn}$ is not of significant concern for radiation exposure 1184 owing to its short half-life and to the low abundance of ${ }^{235} \mathrm{U}$ in natural uranium. Radon1185222 is the most significant radon isotope; it presents in air, ground and surface waters. 1186 The most important mechanism of exposure is the inhalation of radon and its short-lived 1187 decay products with indoor air; ${ }^{222} \mathrm{Rn}$ also accounts for the majority of the human

1188 exposure to radiation and presents the largest risk to human health from all natural 1189 sources of radiation by increasing the risk of lung cancer [133]. Besides the diffusion 1190 from the ground and construction material, releases from radon-rich household water 1191 might be also an important reason of high radon in indoor air. Radon in drinking water 1192 presents an important risk by radiation exposure of cells in the gastrointestinal tract and 1193 in other organs. Radon concentrations in surface waters are typically less than $4 \mathrm{~Bq} / \mathrm{L}$, 1194 while in ground waters the concentrations vary over a wide range up to $10,000 \mathrm{~Bq} / \mathrm{L}$.

1195 As an inert gas, radon is an excellent tracer either alone or together with radium for 
1196 studying geochemical, hydrogeological and oceanic processes like groundwater discharge 1197 rates, groundwater seepage, vertical turbulent mixing, gas exchange across the air-water 1198 interface, mixing processes between ground- and seawater and submarine groundwater 1199 discharges [134-137]. In these studies, the radon concentration is determined in the field 1200 using an extraction method and a portable LSA or by bringing the sample into the 1201 laboratory for measurement with a low-background LSA.

1202 For measurement of Ra in air using LSC, radon is first adsorbed on activated charcoal in 1203 a small vial during a few days. Afterwards, radon is extracted from the charcoal into 1204 toluene or directly into an organic scintillation cocktail to be measured using LSC [1381205 139]. Radon emanation rates from soil can be also measured by LSC [140-141]. In this 1206 case, dried soil is weighed into a glass vial, and wetted with distilled water; an organic 1207 scintillation cocktail is then added. The vial is closed tightly and stored for a month to 1208 attain the constant radon level emanated from soil before the measurement. Alternatively, 1209 radon can be trapped from the dried soil sample directly into the scintillation cocktail in a 1210 glass vial for measurement. This is performed in a tightly closed glass bottle where the 1211 soil is located at the bottom and the vial is hanging from a hook fixed into the stopper of 1212 the glass bottle [141]. The in situ measurement is performed by hanging an open LSC 1213 vial containing the cocktail inside a test hole or tube sunk into the soil [142].

1214 Radon in water originates from the decay of ${ }^{226} \mathrm{Ra}$, which is either dissolved in water 1215 or localized in rock or soil minerals in contact with water. Most of the radon in water 1216 originates from ${ }^{226} \mathrm{Ra}$ in minerals from where radon gas diffuses into pore spaces and 1217 dissolves in soil or ground water. Hence, most of radon in water is unsupported and 1218 therefore its concentration in water is often orders of magnitude higher than that of ${ }^{226} \mathrm{Ra}$ 1219 dissolved in the same water. However, radon will not be transported far from its place of 1220 birth owing to its short half-life. Special attention should be paid to sample collection and 1221 its transport when undertaking radon measurements. Radon can easily escape from water 1222 during the sampling as well the sample transport and storage if the sampling vials are not 1223 gas-tight, because radon is not highly soluble in water. Samples should also be collected 1224 into glass bottles, because some radon will be lost by adsorption onto the surface of 1225 polyethylene bottles and escaped from the bottle by migration through the polyethylene 1226 wall. The bottle caps should be equipped with rubber or Teflon ${ }^{\mathrm{TM}}$ septum to prevent 
1227 radon leakage from the bottle. As a noble gas, ${ }^{222} \mathrm{Rn}$ is therefore difficult to be measured 1228 by alpha spectrometry. The most widely used methods for determining radon in water are 1229 radon emanation, gamma counting and LSC. Among these methods, the detection limit of 1230 gamma spectrometry $(1-9 \mathrm{~Bq} / \mathrm{L})$ is quite high [143], a lower detection limit of 0.04-1.0 $1231 \mathrm{mBq} \mathrm{L}{ }^{-1}$ can be reached by emanation method when using a big sample up to $19 \mathrm{~L}$ [144]. 1232 LSC is a popular method for measurement of ${ }^{222} \mathrm{Rn}$ in water; it is based on the detection 1233 of radon gas and its short-lived $\alpha$-emitting daughters, whose decay properties are shown 1234 in Table 1.

1235 Table 1 . Members of ${ }^{226} \mathrm{Ra}$ subseries and their most significant decay properties.

\begin{tabular}{|l|l|l|l|l|}
\hline $\begin{array}{l}\text { Radio- } \\
\text { nuclide }\end{array}$ & Half-life & $\begin{array}{l}\alpha-\text { decay energy } \\
(\mathrm{MeV}) \text { and } \\
\text { intensity }(\%)\end{array}$ & $\begin{array}{l}\beta \text {-decay energy }(\mathrm{MeV}) \text { and } \\
\text { intensity }(\%)\end{array}$ & $\begin{array}{l}\text {-emission energy }(\mathrm{keV}) \text { and intensity } \\
\%)\end{array}$ \\
\hline${ }^{226 \mathrm{Ra}}$ & $1600 \mathrm{y}$ & $\begin{array}{l}4.784(93.8), \\
4.601(6.2)\end{array}$ & - & $186.2(3.64)$ \\
\hline${ }^{222} \mathrm{Rn}$ & $3.82 \mathrm{~d}$ & $\begin{array}{l}5.489(99.9), \\
4.986(0.1)\end{array}$ & - & $510(0.076)$ \\
\hline${ }^{218} \mathrm{Po}$ & $3.11 \mathrm{~min}$ & $6.002(100)$ & - & \\
\hline${ }^{214} \mathrm{~Pb}$ & $26.8 \mathrm{~min}$ & - & $0.667(45.9), 0.724(40.2)$, & $351.9(35.6), 295.2(18.4)$, \\
& & & $1.019(11.0)$ & $(7.3)$ \\
\hline${ }^{214} \mathrm{Bi}$ & $19.9 \mathrm{~min}$ & & $3.270(19.1), 1.540(17.6)$, & $609.3(45.5), 1764,5(15.3), 1120.3$ \\
& & & $1.505(17.0)$ & $(14.9), 1238.1(5.8), 2204.1(4.9), 768.4$ \\
& & & $(4.4)$ & $(4.9)$ \\
\hline${ }^{214} \mathrm{Po}$ & $164.3 \mu \mathrm{s}$ & $7.687(100)$ & - & \\
\hline
\end{tabular}

1237 The LSC methods for measurement of ${ }^{222} \mathrm{Rn}$ are based on the high solubility of radon 1238 in organic solvents such as toluene and xylene or organic scintillation cocktail. Water 1239 samples can be prepared by introducing a small amount of water $(10-12 \mathrm{ml})$ directly into 1240 the LSC vial containing the organic scintillation cocktail $(8-10 \mathrm{ml})$. A low detection limit 1241 of $\left(0.04-0.2 \mathrm{~Bq} \mathrm{~L}^{-1}\right)$ can be achieved by direct LSC methods by applying more than 60 1242 minutes counting time and $\alpha / \beta$ discrimination [145]. This is because the counting 1243 efficiency of radon with its daughters $\left({ }^{218} \mathrm{Po},{ }^{214} \mathrm{Po}\right)$ in equilibrium can be as high as 
$1244270 \%$ and $\alpha$ backgrounds using $\alpha / \beta$ discrimination is also very low $(<0.1 \mathrm{cmp})$ in a 1245 narrow energy alpha window. The main advantages of the LSC methods are their simple 1246 methodology, high sensitivity and automatic sample counting. If higher sensitivities are 1247 required, radon can be extracted from a larger water volume directly into the LSC 1248 scintillation cocktail or into toluene to be mixed with the cocktail. In this case, ${ }^{222} \mathrm{Rn}$ is 1249 usually extracted from $0.5-1 \mathrm{~L}$ water sample with $20-40 \mathrm{~mL}$ of extractant. After shaking 1250 and allowing the layers to separate, a known proportion of the extractant is transferred 1251 into the scintillation vial for the measurement. The detection limits obtained by these 1252 methods are $0.0015-0.02 \mathrm{~Bq} \mathrm{~L}^{-1}$ depending mainly on the count time and the sample 1253 volume.

1254 Emulsifying cocktail (e.g. Ultima Gold XR) can be also used for the measurement of $1255{ }^{222} \mathrm{Rn}$. In this case, two alpha $\left({ }^{218} \mathrm{Po},{ }^{214} \mathrm{Po}\right)$ and two beta decay daughters $\left({ }^{214} \mathrm{Bi}\right.$ and $\left.{ }^{214} \mathrm{~Pb}\right)$ 1256 with ${ }^{222} \mathrm{Rn}$ are measured, a counting efficiency up to $500 \%$ can be obtained. However, 1257 due to the increased background level, the detection limit of ${ }^{222} \mathrm{Rn}$ by this method is not 1258 better than by using organic scintillation cocktail and alpha-beta discrimination method.

1259 The glass vials equipped with urea screw caps and Al foil liners is often used in this 1260 measurement to be radon gastight. Low diffusion polyethylene vial with Teflon lined and 1261 Al lined cap was also used for this work. However, a long time storage should be avoid, 1262 otherwise a slow diffusion of Ra into the Teflon lined wall of the vial might be happened 1263 and cause a high analytical uncertainty.

\section{Radium}

1266 Radium has four naturally occurred isotopes, ${ }^{226} \mathrm{Ra}\left(t_{1 / 2}=1600 \mathrm{y}\right)$, which belongs to 1267 the ${ }^{238} \mathrm{U}$ decay series, ${ }^{228} \mathrm{Ra}\left(t_{1 / 2}=5.75 \mathrm{y}\right)$ and ${ }^{224} \mathrm{Ra}\left(t_{1 / 2}=3.66 \mathrm{~d}\right)$, which belong to the $1268{ }^{232} \mathrm{Th}$ decay series and ${ }^{223} \mathrm{Ra}\left(t_{1 / 2}=11.43 \mathrm{~d}\right)$, which belongs to the ${ }^{235} \mathrm{U}$ decay series.

1269 Among these isotopes, ${ }^{228} \mathrm{Ra}$ is a beta emitter with maximum energy of only $39.6 \mathrm{keV}$, 1270 while other three are alpha emitters. Radium is widespread in soil, minerals, foodstuffs, 1271 surface and ground waters and many common materials. Radium-226 is considered as 1272 one of the most hazardous long-lived $\alpha$ emitters in the environment with respect to 1273 internal radiation exposure. As an alkaline earth element, radium is accumulated in the 
1274 skeleton through a process similar to calcium. Food consumption is the main source of

$1275{ }^{226} \mathrm{Ra}$ to man, but the radiation exposure through drinking water can be also an important 1276 source, or even be extremely high, if the drinking water originates from ground water 1277 sources in contact with uranium rich minerals like granites or phosphates. The regulations 1278 limit the maximum contaminant level in public water supplies for combined ${ }^{226} \mathrm{Ra}$ and $1279{ }^{228} \mathrm{Ra}$ to $0.19 \mathrm{~Bq} \mathrm{~L}^{-1}$ in the USA [146].The primary health concerns of radium have been 1280 directed to ${ }^{226} \mathrm{Ra}$ and ${ }^{228} \mathrm{Ra}$ and little attention has been given to the short-lived ${ }^{224} \mathrm{Ra}$ and $1281 \quad{ }^{223} \mathrm{Ra}$. However, ${ }^{224} \mathrm{Ra}$ can make a significant contribution to elevated measurements of 1282 gross $\alpha$-activities in some case. ${ }^{226} \mathrm{Ra},{ }^{228} \mathrm{Ra},{ }^{224} \mathrm{Ra}$ and ${ }^{223} \mathrm{Ra}$ in ground and surface 1283 waters have proven useful as natural tracers to study geochemical processes, particularly 1284 in the marine environment [135].

1285 There are a variety of methods for determining one or more radium isotopes in 1286 environmental and food samples using different chemical separation and measurement 1287 methods [27, 146-147].

1288 Radium isotopes can be determined by LSC, radon emanation, alpha and gamma 1289 spectrometry. The chemical separation methods are mainly based on precipitation, cation 1290 exchange, extraction, adsorption or a combination of these techniques. Several 1291 comparison studies have been made on the commonly used methods for determination of $1292 \quad{ }^{226} \mathrm{Ra}$ and ${ }^{228} \mathrm{Ra}[89,148]$.

1293 Alpha spectrometry is the most sensitive radiometric method because of its low 1294 background. In this method, radium must be separated carefully from the sample matrix 1295 and from other elements, including barium. Thereafter, radium is electrodeposited as a 1296 thin layer on a stainless steel disk or co-precipitated with $\mathrm{BaSO}_{4}$ and/or $\mathrm{PbSO}_{4}$, which is 1297 collected on a membrane filter, in order to avoid impairing the resolution and chemical 1298 yield, [86, 149]. The high resolution of alpha spectroscopy for low mass samples is 1299 enable to directly measure the concentrations of ${ }^{226} \mathrm{Ra},{ }^{224} \mathrm{Ra}$ and ${ }^{223} \mathrm{Ra} .{ }^{228} \mathrm{Ra}$ can be 1300 measured directly from the same disk either by gamma spectrometry via the $\gamma$-emitting 1301 daughter, ${ }^{228} \mathrm{Ac}$, after 2 days ingrowth or by alpha spectrometry via its $\alpha$-emitting grand1302 daughter, ${ }^{228} \mathrm{Th}$, after 6-12 months of ingrowth. The detection limits of ${ }^{226} \mathrm{Ra}$ and ${ }^{228} \mathrm{Ra}$ in 1303 environmental samples by alpha spectrometric methods are $0.1-0.5 \mathrm{mBq}$ and $0.2-0.3$ $1304 \mathrm{mBq}$, respectively, and $0.1-1 \mathrm{~Bq}$ and $0.1-0.3 \mathrm{~Bq}$, respectively, by gamma spectrometry 
$[89,150-151]$.

1306 Radon emanation method is based on the separation and measurement of the radon

1307 and its daughters from radium isotopes. For large volume of water samples, radium

1308 isotopes can be first pre-concentrated on $\mathrm{MnO}_{2}$ resin, followed by the emanation of their 1309 radon daughters $\left({ }^{219} \mathrm{Rn},{ }^{220} \mathrm{Rn},{ }^{222} \mathrm{Rn}\right)$ and measurement of these radon isotopes. A low

1310 detection limit can be obtained if a large size of sample is analysed.

1311 Low background LSA with $\alpha / \beta$ discrimination is the most popular technique for 1312 determining ${ }^{226} \mathrm{Ra}$ activity. This is due to the high counting efficiency, easy sample 1313 preparation and automatic sample counting. The typical detection limits are between $13140.3-1.4 \mathrm{mBq}$ for a 6 hours count [89]. ${ }^{226} \mathrm{Ra}$ is generally determined indirectly through $1315{ }^{222} \mathrm{Rn}$ and its short-lived daughters or together with them by LSC. In this method, radium 1316 has to be separated from the sample matrices and concentrated. Ashing, acid digestion are 1317 the often applied method for pre-treatment of solid samples. The conventional method to 1318 separate ${ }^{226} \mathrm{Ra}$ from a sample matrix is the so-called barium sulphate method. The $\mathrm{Pb}$ - and 1319 Ba-carriers are first added into the water or sample solution to co-precipitate radium with $1320 \mathrm{BaSO}_{4}$ and $\mathrm{PbSO}_{4}$ at $\mathrm{pH} 1$ with $\mathrm{H}_{2} \mathrm{SO}_{4}$. The precipitate is washed a few times with $\mathrm{HNO}_{3}$ 1321 and then dissolved in alkaline EDTA. For further purification and separating radium from 1322 lead, radium is precipitated again as sulphate using an acetic acid solution at $\mathrm{pH} 4.5$ while 1323 lead remains in solution to be removed. The nitric acid wash and the re-precipitation of $1324 \mathrm{RaSO}_{4}$ in EDTA solution ensure high purification of radium from most interfering 1325 radionuclides. The chemical yield can be determined gravimetrically or by using ${ }^{133} \mathrm{Ba}$ (if 1326 only ${ }^{226} \mathrm{Ra}$ is measured) as a yield tracer. The $\mathrm{Ra}-\mathrm{BaSO}_{4}$ precipitates are prepared for the 1327 LSC measurement by suspending fine precipitates into a scintillation gel or by dissolving 1328 the precipitates in warm alkaline EDTA solution. $\mathrm{BaSO}_{4}$ precipitate can be also converted 1329 to the more soluble $\mathrm{BaCO}_{3}$, which is dissolved in $\mathrm{HNO}_{3}$ and then mixed with the LSC 1330 cocktail. Measurement of the samples shortly after the separation using its own alpha 1331 peak can obtain the results rapidly after the sampling. In that case, the ${ }^{228}$ Ra activity can 1332 be calculated from the $\beta$-counts with the least amount of corrections owing to minor 1333 ingrowth of ${ }^{214} \mathrm{~Pb}$ and ${ }^{214} \mathrm{Bi}$. The detection limits for ${ }^{226} \mathrm{Ra},{ }^{228} \mathrm{Ra}$ and ${ }^{210} \mathrm{~Pb}$ are $0.5-2 \mathrm{mBq}$, $13344 \mathrm{mBq}$, and $2-5.2 \mathrm{mBq}$, respectively. A better detection limit for ${ }^{226} \mathrm{Ra}$ can be obtained by 1335 using organic scintillation cocktail. In this case, the separated Ba-RaSO4 precipitate is 
1336 dissolved in EDTA solution, which is transferred to LSC vial and filled with organic 1337 scintillation cocktail (e.g. Opti-Flour O). After 3-10 days ingrowth of ${ }^{222} \mathrm{Rn}$, the vial was 1338 shaken to extract Rn to organic phase, and then measured by LSC using alpha-beta 1339 discrimination by counting its three alpha daughters $\left({ }^{222} \mathrm{Rn},{ }^{218} \mathrm{Po}\right.$ and $\left.{ }^{214} \mathrm{Po}\right)$.

1340 Selective adsorption is also used for radium separation. One of them is the Empore ${ }^{\mathrm{TM}}$ 1341 Radium Rad Disk, which selectively adsorb radium from water with recoveries ranging 1342 from $90-100 \%$ for 1-3 L sample. In this method, water samples are first acidified with $1343 \mathrm{HNO}_{3}$ to a $2 \mathrm{M}$ and then passed through the disk. After washing the disk with $2 \mathrm{M} \mathrm{HNO}_{3}$, 1344 radium is eluted from the disk with $0.25 \mathrm{M}$ EDTA solution, which can be concentrated 1345 prior to mixing with the LSC cocktail. Lead, strontium and barium are co-separated with 1346 radium. High barium in the samples will reduce radium recovery considerably, and the 1347 interfering ${ }^{210} \mathrm{~Pb}$ should be separated from radium either before or after the elution. The 1348 detection limits reported for the Empore ${ }^{\mathrm{TM}}$ Radium Rad Disk extraction method vary 1349 between $1-2 \mathrm{mBq}, 4-8 \mathrm{mBq}$ and $2-6 \mathrm{mBq}$ for ${ }^{226} \mathrm{Ra},{ }^{228} \mathrm{Ra}$ and ${ }^{210} \mathrm{~Pb}$, respectively.

$1350 \quad \mathrm{MnO}_{2}$-impregnated acrylic fibre cartridge and $\mathrm{MnO}_{2}$ resin (impregnated $\mathrm{MnO}_{2}$ on a 1351 modified polyacrylonitrile (PAN) supporting material) column are also used to 1352 concentrate radium from large volume of water samples. The sorption of Ra was 1353 especially favourable for low-salinity waters; it is also highly dependent on $\mathrm{pH}$, with the 1354 best range of $\mathrm{pH} 4$ to 8 . At higher salinities, other alkaline earth elements $(\mathrm{Mg}, \mathrm{Ca}$, and $\mathrm{Sr})$ 1355 compete with $\mathrm{Ra}$ for the free sorption sites in the $\mathrm{MnO}_{2}$ resin. For determination of low1356 level ${ }^{226} \mathrm{Ra}$ in large volume saline water (seawater) samples, a $\mathrm{MnO}_{2}$ co-precipitation 1357 method can be used. Water sample $(>10 \mathrm{~L})$ is first acidified using $\mathrm{HCl}$ to $\mathrm{pH}<2$, followed 1358 by addition of $\mathrm{KMnO}_{4}$ solution. After adjusting the $\mathrm{pH}$ to 9.0 using ammonia, $\mathrm{MnCl}_{2}$ is 1359 added during stirring for forming $\mathrm{MnO}_{2} \cdot \mathrm{MnO}_{2}$ precipitate which adsorbed radium is 1360 separated by settling and centrifuge. After washing with water, $\mathrm{MnO}_{2}$ is then dissolved by 1361 addition of $\mathrm{HCl}$ and $\mathrm{H}_{2} \mathrm{O}_{2}$ [152]. Radium in the solution can be further purified by $1362 \mathrm{Ba}(\mathrm{Ra}) \mathrm{SO}_{4}$ precipitation for the measurement of ${ }^{226} \mathrm{Ra}$ by LSC.

1363 Solvent extraction method was also applied for determination of radium. A 1364 commercial extractive scintillation cocktail RADAEX ${ }^{\circledR}$ was developed specifically for 1365 LSC measurement of radium [153]. The extraction of radium with RADAEX needs to be 1366 carried at alkaline media ( $\mathrm{pH} 10-12)$, large amount of metals in high salt content water 
1367 will be precipitated in this condition. Therefore, this method cannot be directly applied 1368 for analysis of high saline water samples.

$1369{ }^{228} \mathrm{Ra}$ is a low-energy beta emitter $(39.6 \mathrm{keV})$, it is often measured indirectly through its 1370 daughter, ${ }^{228} \mathrm{Ac}$ and ${ }^{228} \mathrm{Th}$. For high-level samples, ${ }^{228} \mathrm{Ra}$ can be simply measured through 1371 the gamma lines of ${ }^{228}$ Ac by gamma spectrometry, or the beta spectrum of ${ }^{228} \mathrm{Ac}$ using 1372 LSC. While for the low-level samples with relative high ${ }^{226} \mathrm{Ra}$, the daughters of ${ }^{226} \mathrm{Ra}$ $1373\left({ }^{214} \mathrm{Bi},{ }^{214} \mathrm{~Pb}\right)$ presented in the samples might seriously interferes with the measurement of $1374{ }^{228}$ Ac due to the low resolution of LSC. A method for pre-concentration and separation of $1375{ }^{228} \mathrm{Ac}$ was reported for reliable determination of low-level ${ }^{228} \mathrm{Ra}$ [154]. In this method, 1376 radium is first separated from the sample matrices by co-precipitation of radium with $1377 \mathrm{MnO}_{2}$, and then $\mathrm{Ra}$ is separated from other radionuclides (U, Th, etc.) by extraction 1378 chromatography using Diphonix resin, which effectively retains actinides and lanthanides 1379 while divalent cations like Ra and Ba pass through. Radium presented in the effluent and 1380 wash solutions from the Diphonic column are set aside for ingrowth of ${ }^{228}$ Ac. Thereafter 1381 the solution is loaded to the second Diphonix resin column, the ingrown ${ }^{228} \mathrm{Ac}$ is retained 1382 on the column and separated from radium, which is then eluted using 1 M HEDPA (11383 hydroxyethane-1,1 diphosphonic acid) directly into a plastic LS vial and mixed with LSC 1384 cocktail for measurement. The detection limit of $23.2 \mathrm{mBq}$ was reported for $60 \mathrm{~min}$ 1385 counting time. The separated ${ }^{228}$ Ac can be also measured by Cerenkov counting due to 1386 the high beta energy of ${ }^{228} \mathrm{Ac}(2.07 \mathrm{MeV})$

1388 Lead-210 [Bismuth-210 and Polonium-210]

$1389{ }^{210} \mathrm{~Pb}\left(t_{1 / 2}=22.2 \mathrm{y}\right)$ decays by emitting $\beta$ particles $\left(E_{\max }=63.5 \mathrm{keV}\right)$ with $\gamma$ emission $\left(E_{\gamma}\right.$

$1390=46.5 \mathrm{keV})$ and internal conversion to the $\beta$-emitting ${ }^{210} \mathrm{Bi}\left(t_{1 / 2}=5.01 \mathrm{~d}, E_{\max }=1161.5\right.$

$1391 \mathrm{keV})$ which decays to the $\alpha$-emitting ${ }^{210} \mathrm{Po}\left(t_{1 / 2}=138.4 \mathrm{~d}, E_{\alpha}=5.3 \mathrm{MeV}\right)$ (Fig. 10). As

1392 radionuclides of ${ }^{238} \mathrm{U}$ decay series ${ }^{210} \mathrm{~Pb},{ }^{210} \mathrm{Bi}$ and ${ }^{210} \mathrm{Po}$ exist widely in rock, soil,

1393 atmosphere, waters, and food. ${ }^{210} \mathrm{~Pb}$ and ${ }^{210} \mathrm{Po}$ belong to the most toxic radionuclides. The 1394 toxicity of ${ }^{210} \mathrm{Po}$ is mainly due to its two alpha-daughters ${ }^{210} \mathrm{Bi}$ and ${ }^{210} \mathrm{Po}, 79 \%$ of the 1395 internal dose following ingestion of uranium and thorium series radionuclides is caused 1396 by ${ }^{210} \mathrm{~Pb}$ and ${ }^{210} \mathrm{Po}$. The main intake of ${ }^{210} \mathrm{~Pb}$ and ${ }^{210} \mathrm{Po}$ is derived from the food, the ${ }^{210} \mathrm{Po}$ 1397 concentrations are high in seafood like fish, molluscs and crabs, and high ${ }^{210} \mathrm{~Pb}$ and ${ }^{210} \mathrm{Po}$ 
1398 concentrations were found in reindeer and caribou meat. Drinking water usually

1399 constitutes a minor contribution to the normal intake of ${ }^{210} \mathrm{~Pb}$ and ${ }^{210} \mathrm{Po}$; but it can be

1400 significant for some population groups consuming ground water enrich with radon. The

1401 guideline value of WHO for ${ }^{210} \mathrm{~Pb}$ and ${ }^{210} \mathrm{Po}$ in drinking water is $0.1 \mathrm{~Bq} \mathrm{~L}^{-1}$ [155],

1402 therefore, much effort is paid to analyses of ${ }^{210} \mathrm{~Pb}$ and ${ }^{210} \mathrm{Po}$ in drinking waters. ${ }^{210} \mathrm{~Pb}$ is

1403 widely used to date sediments in seas, lakes and estuaries, and most of determinations of

$1404{ }^{210} \mathrm{~Pb}$ in environmental studies are used for this purpose.

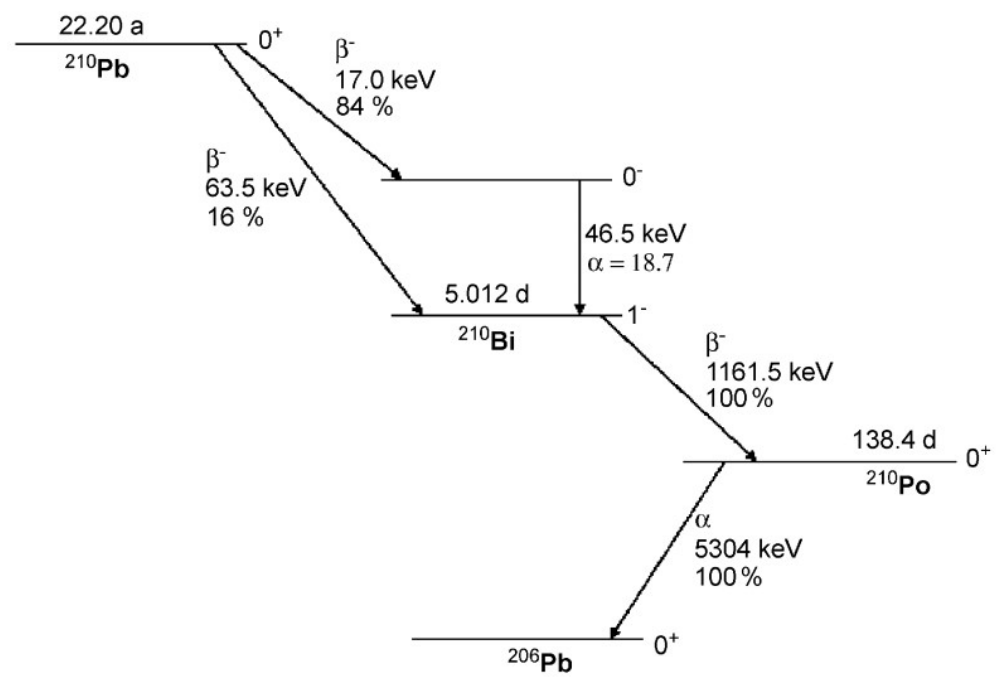

Fig. 10 Decay scheme for the ${ }^{210} \mathrm{~Pb}$ subseries [156]

${ }^{210} \mathrm{~Pb}$ can be directly measured by gamma spectrometry and LSC or beta counting (e.g. proportional counter), or indirectly measured by $\alpha$-spectrometry through counting its decay daughter, ${ }^{210} \mathrm{Po}$. Due to short half-life of ${ }^{210} \mathrm{Bi}(5.0 \mathrm{~d})$, it is not often determined separately. The methods based on $\alpha$ and $\beta$ counting require ${ }^{210} \mathrm{~Pb}$ to be separated from the matrix and from other radionuclides. Because ${ }^{210} \mathrm{~Pb}$ and ${ }^{210} \mathrm{Po}$ are found often in disequilibrium in biological and most environmental samples, they have to be analysed individually.

Due to the low intensity (4.25\%) of low energy (46.5 keV) gamma ray of ${ }^{210} \mathrm{~Pb}$, the direct gamma spectrometric method requires to analyse large size of samples, long counting time, corrections for self-absorption and interference from other $\gamma$ - and X-rays. The detection limit for ${ }^{210} \mathrm{~Pb}$ was reported to be up to $0.4 \mathrm{~Bq} / \mathrm{sample}$ for a $1000 \mathrm{~min}$ counting time, therefore not suitable for determination of ${ }^{210} \mathrm{~Pb}$ in low-level samples. 
Alpha spectrometric measurement of ${ }^{210} \mathrm{~Pb}$ and ${ }^{210} \mathrm{Po}$ is based on two spontaneous depositions of ${ }^{210} \mathrm{Po}$ onto a silver (also $\mathrm{Ni}, \mathrm{Cu}$, steel) disc and on measuring the ${ }^{210} \mathrm{Po}$ activity, and the second deposition is implemented after a few months ingrowth of ${ }^{210} \mathrm{Po}$ from ${ }^{210} \mathrm{~Pb}$. Although the detection limit $(0.1-0.2 \mathrm{mBq})$ is quite low, but a long analytical period is needed.

1405 The energy of beta particles of ${ }^{210} \mathrm{~Pb}(17.0 \mathrm{keV}(84 \%)$ and $63.5 \mathrm{keV}(16 \%))$ is very low, 1406 the counting efficiency of LSC is low for directly counting the beta emission of ${ }^{210} \mathrm{~Pb}$, 1407 and sensitive to sample quenching. LSC measurement of ${ }^{210} \mathrm{~Pb}$ is often carried out via its 1408 high beta energy daughter, ${ }^{210} \mathrm{Bi}(1161.5 \mathrm{keV})$ after some days ingrowth. However, $\mathrm{Pb}$ has 1409 to be separated form sample matrices and other radionuclides before LSC measurement. 1410 Precipitation of $\mathrm{Pb}$ as the sulphate, extraction chromatography and solvent extraction are 1411 the often used method for its separation.

1412 The separation of ${ }^{210} \mathrm{~Pb}$ by co-precipitation as $\mathrm{Ba}(\mathrm{Ra}, \mathrm{Pb}) \mathrm{SO}_{4}$ is a traditional method, 1413 by which radium isotopes and ${ }^{210} \mathrm{~Pb}$ can be separated simultaneously. After the sample 1414 pre-treatments by ashing, acid digestion or alkali fusion, the chemical separation is 1415 started by adding stable $\mathrm{Pb}$ and $\mathrm{Ba}$ carriers as the yield tracers, followed by precipitation 1416 as the sulphate, the formed sulphate is then dissolved in alkaline EDTA. The separation 1417 of $\mathrm{Pb}$ from $\mathrm{Ra}$ is achieved by adjusting the EDTA solution of sample to $\mathrm{pH} 4.2-4.5$ of 1418 with acetic acid. The $\mathrm{Ra}$ precipitates with $\mathrm{BaSO}_{4}$, while $\mathrm{Pb}$ remains in the solution. 1419 Afterward, the solution is further acidified to precipitate $\mathrm{Pb}$ as $\mathrm{PbSO}_{4}$. The precipitate is 1420 washed with distilled water to remove other interfering radionuclides. The ${ }^{210} \mathrm{PbSO}_{4}$ can 1421 be prepared for LSC counting by suspending it in a scintillation gel or dissolving it in 1422 alkaline EDTA solution and then mixing with the LSC cocktail. The sample is often 1423 counted using LSC with $\alpha / \beta$-discrimination, ${ }^{210} \mathrm{~Pb}$ is determined from the spectrum of $1424{ }^{210} \mathrm{~Pb}$ or the ingrown ${ }^{210} \mathrm{Bi}$. ${ }^{210} \mathrm{~Pb}$ can be also measured by Cerenkov counting of the 1425 ingrown ${ }^{210} \mathrm{Bi}$, the potential interferences from alpha and soft beta emitters can be 1426 eliminated in this case, but the counting efficiency of Cerenkov counting is 1427 comparatively low (20\%). An increased Cerenkov counting efficiency up to $75 \%$ was 1428 achieved through the use of Triton X-100 and sodium salicylate as enhancers. Under 1429 these conditions, ${ }^{210}$ Po caused some interference, which was not present in the absence of 1430 the enhancers. When Cerenkov counting was used for measurement of ${ }^{210} \mathrm{~Pb}$ through 
$1431{ }^{210} \mathrm{Bi}$, no scintillation cocktail is needed; the EDTA dissolution of $\mathrm{PbSO}_{4}$ is directly 1432 applied for measurement.

1433 Extraction chromatography using Sr Spec resin have been applied for separation of

$1434{ }^{210} \mathrm{~Pb}$ and ${ }^{210} \mathrm{Po}$ for their determination in various environmental and biological samples

1435 [157-159]. This is based on the high adsorption of $\mathrm{Pb}$ and $\mathrm{Po}$ on this resin in diluted $\mathrm{HCl}$

1436 solution, while ${ }^{210} \mathrm{Bi}$ does not retain on the column. In this method, the decomposed and

1437 pre-concentrated sample is prepared in $2 \mathrm{M} \mathrm{HCl}$ and loaded to a $\mathrm{Sr} \mathrm{Spec}$ column; ${ }^{210} \mathrm{Po}$

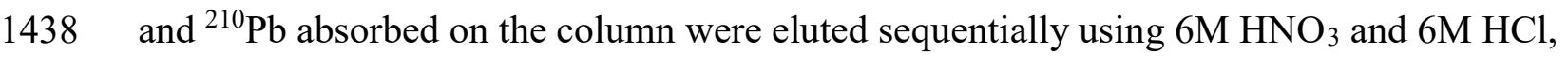

1439 respectively. The $\mathrm{HCl}$ elute was evaporated to dryness followed by converting lead from

1440 chloride to nitrate and by precipitating it as the oxalate for the yield determination. ${ }^{210} \mathrm{Po}$

1441 was determined by alpha spectrometry using ${ }^{208} \mathrm{Po}$ as the yield tracer after spontaneous

1442 deposition on a metal disc. The separated ${ }^{210} \mathrm{~Pb}$ was determined by LSC after dissolving

$1443 \mathrm{PbC}_{2} \mathrm{O}_{4}$ into $1 \mathrm{~mL}$ of $6 \mathrm{M} \mathrm{HNO}_{3}$ and mixing with scintillation cocktail. In this method,

$1444{ }^{210} \mathrm{Po}$ and ${ }^{210} \mathrm{~Pb}$ were efficiently separated from other elements and interfering

1445 radionuclides [157].

1446

\section{Gross alpha and gross beta measurements}

1448 Gross alpha and gross beta activity measurement is often used for screening analysis in 1449 monitoring of environment, diet and contamination. Particularly, drinking water supplies

1450 are screened by the gross alpha and beta analysis method, which is a highly useful control 1451 measure for the radiological characterization of water and as a factor in the decision as to 1452 whether further analyses by radionuclide-specific methods will be required. Urine 1453 samples from the workers who potentially exposed to radioactive contamination is also 1454 often screened by gross alpha and gross beta measurement to obtain an overview on 1455 internal exposure of radiation. The guideline activity concentrations of water by WHO $1456[155]$ are $0.5 \mathrm{~Bq} \mathrm{~L}^{-1}$ for gross alpha and $1 \mathrm{~Bq} \mathrm{~L}^{-1}$ for gross beta, respectively. Whereas the 1457 European Union [160] has set the screening values of $0.1 \mathrm{~Bq} \mathrm{~L}^{-1}$ for gross alpha and $1 \mathrm{~Bq}$ $1458 \mathrm{~L}^{-1}$ for gross beta.

1459 Some volatile radionuclides are easily lost during the sample preparation, e.g. ${ }^{3} \mathrm{H},{ }^{14} \mathrm{C}$ and 1460 radon, these nuclides, as well as short-lived daughters of radon, are excluded from the 1461 gross alpha and gross beta screening analyses, which have to be determined by specific 
1462 methods. In the normal situation, most important radionuclides to be screened by gross 1463 alpha and beta analyses in drinking water sources are the long-lived radionuclides, ${ }^{234} \mathrm{U}$, $1464{ }^{238} \mathrm{U},{ }^{226} \mathrm{Ra},{ }^{228} \mathrm{Ra}$ and ${ }^{210} \mathrm{~Pb}$ and ${ }^{210} \mathrm{Po}$, from uranium and thorium decay series. ${ }^{40} \mathrm{~K}$ occurs 1465 in variable amounts in all natural waters; and its contribution to the gross beta counts can 1466 be significant. However, its determination is not important, because potassium is under 1467 homeostatic control in the body and its amount remains constant in healthy people. Gross 1468 alpha and beta measurements are also used to screen transuranic elements and gross beta 1469 for fission products in the case related to the nuclear faculties and exposures.

1470 The commonly used methods for gross alpha and beta analysis in drinking water are 1471 based either on the gas proportional counting (GPC) or on LSC techniques. In the GPC 1472 method, water sample is evaporated to near dryness, and then quantitatively transfer the 1473 residue to a planchet for measurement. The GPC method is tedious and labor-intensive, 1474 and the results are not precise owing to the inherent variability of the sample preparation 1475 technique and water composition. Meanwhile sample size is strongly limited due to the 1476 total dissolved solids (TDS) in the sample, which cause self-absorption of $\alpha$-and $\beta$ 1477 particles, and the counting efficiency is affected by TDS and the chemical composition of 1478 water. The small sample size combined with the relatively low counting efficiency of the 1479 GPC makes it difficult to attain low detection limits even by applying very long counting 1480 times. The reported detection limits of the GPC methods are $0.8 \mathrm{~Bq} \mathrm{~L}^{-1}$ for the gross alpha 1481 and $3 \mathrm{~Bq} \mathrm{~L}^{-1}$ for gross beta using a $22 \mathrm{~h}$ counting time [161], which could not meet the 1482 requirement of the regulation for screening of the gross alpha in drinking water (0.1-0.5 $1483 \mathrm{~Bq} / \mathrm{L}$ ). In the LSC method, the water sample is directly or after some pre-concentration 1484 taken to a LSC vial, and mixed with the scintillation cocktail for LSC counting using $\alpha / \beta$ 1485 discrimination. This avoids most of the difficulties typically in the GPC methods, 1486 although dissolved minerals or organics in water may cause variable quenching, which 1487 must be considered in the calibrations [161]. If the sample is pre-concentrated, the residue 1488 is often dissolved into a few $\mathrm{mL}$ of dilute $\mathrm{HCl}, \mathrm{HNO}_{3}$ or $\mathrm{H}_{3} \mathrm{PO}_{4}$ prior to the addition of the 1489 LS cocktail.

1490 The calibrations of gross alpha and beta analyses include the optimization of the $\alpha / \beta$ 1491 discrimination performance and the determination of $\alpha$ - and $\beta$-counting efficiencies and 1492 spillovers in the selected $\alpha$ - and $\beta$-windows. The calibrations become more complicated if 
1493 variable quenching is corrected, because the optimum pulse decay setting (optimal PSA

1494 value), as well as efficiencies, backgrounds and spillovers, depend on quenching. Hence,

1495 each sample should be measured at its optimum SPA setting, which is not a practical 1496 approach in routine measurements. Another drawback for performing precise calibrations

1497 is because the optimum SPA setting and alpha and beta spillovers depend on particle 1498 energies. The real samples may contain several $\alpha$ - and $\beta$-emitters with largely variable 1499 particle energies compared to those used for calibrations including the setting of the 1500 optimum SPA. The optimum SPA setting is highly effected for higher-energy $\alpha$ - and $\beta$ 1501 emitters than for lower-energy emitters. The $\beta$-spillover increases with $\beta$-particle energy 1502 while $\alpha$-spillover decreases with $\alpha$-particle energy. With increasing quench, the higher 1503 energy $\beta$-particle produces a higher spillover compared to the lower-energy particles, 1504 while the higher-energy $\alpha$-particle produces a lower spillover compared to the low-energy 1505 particles at the same PSA level. In summary, the calibrations with appropriate quench 1506 corrections are necessary, although they would not provide accurate results for variably 1507 quenched samples with variable radionuclide composition. The calibrations would be 1508 simplest if the samples were unquenched and as similar as possible to the nuclides used 1509 for SPA instrument calibration. It is preferable to perform the calibrations with $\alpha$ - and $\beta$ 1510 emitters with the energies equal to the averages of the nuclides expected to be in actual 1511 samples to be analysed.

1512 In a similar manner, gross alpha and gross beta activities may be determined for a 1513 range of other environmental matrices. A filter sample is simply placed in the LSC vial 1514 with the scintillation cocktail [162] for LSC measurement. Urine samples have been 1515 prepared by mixing urine directly with the cocktail [163] or after some processing which 1516 involves oxidation of organic substances, co-precipitation of actinides as phosphate, wet 1517 ashing using $\mathrm{HNO}_{3}$ and $\mathrm{H}_{2} \mathrm{O}_{2}$, conversion of the nitrates to the chlorides, dissolution of 1518 the white residue in $0.2 \mathrm{M} \mathrm{HCl}$ followed by the addition of the cocktail [164].

\section{Conclusion and perspectives}

1520 As a conventional radiometric method, LSC has been widely used for measurement of 1521 various radionuclides for different applications. Although this method has been used for 
1522 more than 60 years, a continuous development and new applications still progress. The 1523 major progresses discussed in this paper with the perspective challenges are summarized 1524 below:

1525 1) Communization of TDCR based LSA instrument makes this technique one of the 1526 popular LSC methods, and used in many radiochemical and environmental laboratory 1527 for the determination of radionuclides of beta emission, electron capture and alpha 1528 emitters, and in alpha/beta discrimination model and Cerenkov counting model as 1529 those in ordinary LSC.

1530 2) With the rapid increased requirement in the decommissioning of nuclear facilities, a 1531 number of analytical methods for determination of radionuclides mainly occurred in 1532 decommissioning waste have been developed using LSC as measurement technique. This includes the methods for the determination of ${ }^{36} \mathrm{Cl},{ }^{41} \mathrm{Ca},{ }^{55} \mathrm{Fe},{ }^{63} \mathrm{Ni},{ }^{99} \mathrm{Tc},{ }^{129} \mathrm{I}$, ${ }^{241} \mathrm{Pu}$ in various types of samples.

3) LSC is still a competitive method for the determination of pure beta emitting radionuclides including those decay by electron capture, especially for the short-lived ( $\mathrm{t}^{1 / 2}<100$ years) radionuclides, e.g. ${ }^{3} \mathrm{H},{ }^{241} \mathrm{Pu},{ }^{89} \mathrm{Sr}$ and ${ }^{90} \mathrm{Sr}$. It can provide relative rapid and precise measurement compared to other methods,

4) LSC has been well used for determination of naturally occurred radionuclides, and still an attractive method for the determination of ${ }^{222} \mathrm{Rn},{ }^{228} \mathrm{Ra}$ and ${ }^{210} \mathrm{~Pb}$ because of its easy operation, short analytical time, and reliable analytical results. LSC has also becoming more popular method for the determination of gross alpha and gross beta activity for screening purpose.

5) More LSC methods are still needed for the determination of other uncommon radionuclides for the decommissioning of nuclear facilities, e.g. ${ }^{93} \mathrm{Mo},{ }^{93} \mathrm{Zr},{ }^{79} \mathrm{Se}$, ${ }^{126} \mathrm{Sn},{ }^{151} \mathrm{Sm}$, etc. A challenge in this aspect will be the calibration and standardization of the LSC for the measurement of these radionuclides, because of luck of standard solution of these radionuclides, and not well established decay properties of these radionuclides.

1550 6) Although an increased number of TDCR based LSA instruments have been installed 
in many laboratories, the analytical methodology is still limited, and more method developments are still needed. With the introduction of the low background TDCR based LSA instrument, it is expected that this method will become a more popular LSC method in many application fields, e.g. environmental radioactivity and trace studies.

7) Plastic scintillation resins based LSC method has been proposed in the past years, and a number of such resins have been synthesized and tested for determination of the separation procedure and avoid the utilization of scintillation cocktail, and consequently reduce the organic waste. However, such scintillation resins are still limited and the methods need to be further validated for analysis of real environmental and nuclear samples with complicated components and matrices.

1. Kossert K, Capogni M, Nähle OL (2014) Bilateral comparison between PTB and ENEA to check the performance of a commercial TDCR system for activity measurements. Appl Radiat Iso 93:38-44

2. Kossert K (2010) Activity standardization by means of a new TDCR-Čerenkov counting technique. App. Radia. Isot 68:1116-1120.

3. Eikenberg J, Beer H, Jaggi M (2014) Determination of $210 \mathrm{~Pb}$ and $226 \mathrm{Ra} / 228 \mathrm{Ra}$ in continental water using HIDEX 300SL LS-spectrometer with TDCR efficiency tracing and optimized alpha-beta discrimination. Appl Radiat Iso 93:64-69

4. Priya S, Gopalakrishnan RK, Goswami A (2014) TDCR measurement of H-3, Ni-63 and Fe-55 using Hidex 300SL LSC device. J Radioanl Nucl Chem 302:353-359

5. Tarancon A, Bagan H, Garcia JF (2017) Plastic scintillators and related analytical procedures for radionuclide analysis. J Radioanal Nucl Chem 314:555-572

6. Barrera J, Tarancon A, Bagan H, Garcia F (2016) A new plastic scintillation resin for single-step separation, concentration and measurement of technetium-99. Anal Chim Acta 936:259-266 
Journal of Radioanalytical and Nuclear Chemistry

1580

1581

1582

1583

1584

1585

1586

1587

1588

1589

1590

1591

1592

1593

1594

1595

1596

1597

1598

1599

1600

1601

1602

1603

1604

1605

1606

1607

1608

1609

1610

7. Bagan H, Tarancon A, Rauret G, Carcia JF (2011) Radiostronium separation and measurement in a single step using plastic scintillators plus selective extractants. Application to aqueous sample analysis. Anal. Chim Acta 686(1-2):50-56

8. Lluch E, Barrera J, Tarancon A, Bagan H, Carcia JF (2016) Analysis of Pb-210 in water samples with plastic scintillation resin. Anal. Chim Acta 940:38-45

9. Hou XL (2005) Radiochemical determination of ${ }^{41} \mathrm{Ca}$ in reactor concrete for decommissioning. Radiochim Acta 93:611-617

10. Hou XL (2007) Radiochemical analysis of radionuclides difficult to measure or waste characterization in decommissioning of nuclear facilities. J Radioanal Nucl Chem 273:43-48

11. Hou XL, Frøsig L, Nielsen SP (2007) Determination of ${ }^{36} \mathrm{Cl}$ in nuclear waste from reactor decommissioning, Anal Chem 79:3126-3134

12. Hou XL, Østergaard LF, Nielsen SP (2005) Determination of ${ }^{63} \mathrm{Ni}$ and ${ }^{55} \mathrm{Fe}$ in nuclear waste samples using radiochemical separation and liquid scintillation counting. Anal Chim Acta 535:297-307

13. Choi KC, Park SK, Han SH, Choi KS, Jee KY (2005) Determination of 129I in radioactive waste from Korea NPPs. Proceedings of 10th International Conference on Environmental Remediation and Radioactive Waste Management, 2005:1446-1449

14. Osvath S, Vajda N, Molnar Z, Kovaca-Szeles E, Braun M, Halasz M (2017) Determination of $93 \mathrm{Zr}$ in nuclear power plant wastes. J Radioanal Nucl Chem 314:31-38

15. Guerin N, Gagne A, Kramer-Tremblay S (2017) A rapid method for the routine monitoring of Tc-99 by liquid scintillation counting. J Radioanal Nucl Chem 314:2009-2017

16. Vesely A, Trombitas H, Lindauer H (2008) Determination of beta emitters in materials from research reactor decomissioning. In "Advances in Liquid Scintillation Spectrometry, 2008" (J. Eikenberg, M. Jäggi, H. Beer, and H. Baehrle, Eds.), pp. 435-441. Radiocarbon Publishers, University of Arizona, Tucson.

17. Guerin N, Riopel R, Rao R, Kramer-Tremblay S, Dai X (2017a) An improved method for the rapid determination of ${ }^{90} \mathrm{Sr}$ in cow's milk. J Environ Radioact 175:115-119 18. Tayeb M, Dai X, Corcoran EC, Kelly DG (2014) Evaluation of interferences on 
Journal of Radioanalytical and Nuclear Chemistry

1611

1612

1613

1614

1615

1616

1617

1618

1619

1620

1621

1622

1623

1624

1625

1626

1627

1628

1629

1630

1631

1632

1633

1634

1635

1636

1637

1638

1639

1640

1641

measurements of ${ }^{90} \mathrm{Sr} /{ }^{90} \mathrm{Y}$ by TDCR Cherenkov counting technique. J Radioanal Nucl Chem 300:409-414

19. Tayeb M, Dai X, Sdraulig S (2016) Rapid and simultaneous determination of strontium-90 and strontium-89 in seawater in emergency situations. J Environ Radioact 153:214-221

20. Dai X, Cui Y, Kramer-Tremblay S (2013) A rapid method for determining strontium90 in urine samples. $J$ Radioanal Nucl Chem 296:363-368

21. Anand SS, Rengarajan R, Sarma VVSS (2018) ${ }^{234}$ Th based carbon export flux along the Indian Geotraces G102 section in the Arabian Sea and the Indian Ocean. Global Bioerochemcial Cycles 32:417-436.

22. Graven HD (2015) Impact of fossil fuel emissions on atmospheric radiocarbon and various applications of radiocarbon over this century. PNAS 112(31):9542-9545

23. Keller ED, Turnbull JC, Norris MW (2016) Detecting long-term change in point source fossil $\mathrm{CO}_{2}$ emissions with tree ring archives. Atom Chem Phys DOI:10.5194/acp-2015-919

24. Pates, J.M., Cook, G.T., MacKenzie, A.B., Anderson, R., and Bury, S.J. (1996). Determination of ${ }^{234} \mathrm{Th}$ in marine samples by liquid scintillation spectrometry. Anal. Chem. 68, 3783-3788

25. Biggin, C.D., Cook, G.T., MacKenzie, A.B., and Pates, J.M. (2002). Time-efficient method for the determination of ${ }^{210} \mathrm{~Pb},{ }^{210} \mathrm{Bi}$ and ${ }^{210} \mathrm{Po}$ activities in seawater using liquid scintillation spectrometry. Anal. Chem. 74, 671-677.

27. Fons-Castells J, Oliva J, Tent-Petrus J, Llaurado M (2017) Simultaneous determination of Ra-226, $\mathrm{Ra}-228$ and $\mathrm{Pb}-210$ in drinking water using 3M Empore (TM) RAD disk by LSC-PLS. Appl Radiat Iso 124:83-89

28. Mikalauskiene R, Maeika J, Petroaius R, Szwarczewski P (2018) Comparison of beta (LSC) and gamma (HPGe) spectrometric methods for lead-210 in chronological study. Geochronometria 45:38-50

29. Stanley P (2012) Liquid scintillation counting: Recent development. Elsevier, Amsterdam, pp510

30. L'Annunziata MF (2012) Handbook of radioactivity analysis, 3rd edition, Academic press, Amsterdam. 
Journal of Radioanalytical and Nuclear Chemistry

1642 31. Cassette P, Bouchard J (2003) The design of a liquid scintillation counter based on the 1643 triple to double coincidence ratio method. Nucl. Instr. Method Phys Res. A505:72-75

1644 32. Cassette P, Vatin R (1992) Experimental evaluation of TDCR models for 3 PM liquid 1645 scintillation countor. Nucl. Instr. Method Phys Res. A312:95-99

1646 33. Malonda AG, Coursey BM (1988) Calculation of beta counting efficiency for liquid 1647 scintillation system with three phototubes. Appl. Radat Iso 39: 1191-1196

1648 34. Zimmerman BE, Colle R, Cessna JT (2004) Construction and implementation of the 1649 NIST triple-to-double coincidence ratio spectrometer. Appl. Radiat. Iso 60:433-438 1650 35. Hwang HY, Kwak SI, Lee HY, Lee KB, Park TS (2004) Development of 3 PM liquid 1651 scintillation counting system with geometrical efficiency variation. Appl Radiat Iso $1652 \quad 60: 469-473$

1653 36. Ivan C, Cassette P, Sahagia M (2008) A new TDCR-LS counter using channel 1654 photomultiplier tubes. Appl Radiat Iso 66:1006-1011

1655 37. Qin MJ, Mo L, Alexiev D, Cassette P (2008) Construction and implementation of a 1656 TDCR system at ANSTO. Appl Radiat Iso 66:1033-1037

1657 38. Jäggi M, Eikenberg J (2014) Camparison of TriCarb and Hidex 300SL techniques 1658 using measurement of ${ }^{241} \mathrm{Pu}$ and ${ }^{90} \mathrm{Sr}$ on various samples. Appl Radiat Iso 93:120-125 1659 39. Atkinson R, Eddy T, Kuhne W, Jannik T, Brandl A (2014) Measurement of the tritium 1660 concentration in the fractionated distillate from environmental water samples. $J$ 1661 Environ Radioact 135:113-119

1662 40. Dai X, Kramer-Tremblay S (2014) Five-Column Chromatography Separation for 1663 Simultaneous Determination of Hard-to-Detect Radionuclides in Water and Swipe 1664 Samples. Anal Chem 86:5441-5447.

1665 41. Priya S, Murali MS, Mary G, Radhakrishnan K, Gopalakrishnan RK, Goswami A 1666 (2013) Validation of chemical separation method for the determination of ${ }^{63} \mathrm{Ni}$ using 1667 TDCR technique in steel samples of APSARA reactor. J Radioanl Nucl Chem $1668 \quad 298: 1551-1557$

1669 42. Miura T, Minai Y (2017) Radiometric analysis of ${ }^{90} \mathrm{Sr}$ in fish bone ash samples by 1670 liquid scintillation counting after separation by extraction chromatographic resin. $\mathrm{J}$ $1671 \quad$ Radioanal Nucl Chem 313: 343-351

1672 43. Oropesa Verdecia P, Carcia Rodriguez L, Serra Aguila RA, Moreno Leon Y, Jenez 
Journal of Radioanalytical and Nuclear Chemistry

1673

1674

1675

1676

1677

1678

1679

1680

1681

1682

1683

1684

1685

1686

1687

1688

1689

1690

1691

1692

1693

1694

1695

1696

1697

1698

1699

1700

1701

1702

1703

Magana Y, Cassette P (2018) Ga-68 activity calibrations for nuclear medicine application in Cuba. Appl Radiat Iso 134: 112-116

44. Krapiec M, Walanus A (2011) Application of the triple photomultiplier liquid spectrometer Hidex 300SL in radiocarbon dating. Radiocarbon, 53:543-550

45. Wisser, S., Frenzel, E., and Dittmer, M. (2006). Innovative procedure for the determination of gross-alpha/gross-beta activities in drinking water. Appl. Radiat. Isot. 64, 368-372.

46. Broda R (2003) A review of the triple-to-double coincidence ratio (TDCR) method for standardizing radionuclides. Appl Radiat Isot 58(5): 585-594

47. Guerin N, Dai X (2015) Determination of ${ }^{55} \mathrm{Fe}$ in urine by liquid scintillation counting. J. Radioanal. Nucl. Chem. 304:1059-1069.

48. Taddei MHT, Macacini JF, Vicente R, Marumo JT, Sakata SK, Terremoto LAA (2013) A comparison study using liquid scintillation counting and X-ray spectrometry to determine ${ }^{55} \mathrm{Fe}$ in radioactive waste. J Radioanal Nucl Chem 295:2267-2272

49. Kossert K, Carles AG, Nahle O (2014) Improved Cerenkov counting techniques based on a free parameter model. Appl Radiat Isot 86:7-12

50. Bobin C, Thiam C, Bouchard J, Jaubert F (2010) Application of a stochastic TDCR model based on Geant 4 for Cherenkov primary measurements. Appl Radiat Isot 68:2366-2371

51. Kossert K, Bokeloh K, Ehlers M, Nahle O, Scheibe O, Schwarz U, Thieme K (2016) Comparison of ${ }^{90} \mathrm{Y}$ activity measurements in nuclear medicine in Germany. Appl Radiat Isot 109:247-249

52. Olfert J M, Dai X, Kramer-Tremblay S (2014) Rapid determination of ${ }^{90} \mathrm{Sr} /{ }^{90} \mathrm{Y}$ in water samples by liquid scintillation and Cherenkov counting. J Radioanal Nucl Chem 300:263-267

53. Coha I, Neufuss S, Grahek Ž, Němec M, Nodilo M, John J. (2016) The effect of counting conditions on pure beta emitter determination by Cherenkov counting. $J$ Radioanal Nucl Chem 310:891-903

54. Amano H, Sakamoto H, Shigal N, Suzuki K (2016) Method for rapid analysis of Sr90 in edible plant samples collected near Fukushima, Japan. Appl Radiat Iso 112:131135 
1704

1705

1706

1707

1708

1709

1710

1711

1712

1713

1714

1715

1716

1717

1718

1719

1720

1721

1722

1723

1724

1725

1726

1727

1728

1729

1730

1731

1732

1733

1734

55. Yang Y, Song L, Luo M, Dai X, Guo X (2017) A rapid method for determining ${ }^{90} \mathrm{Sr}$ in leaching solution from cement solidification of low and intermediate level radioactive wastes. J Radioanal Nucl Chem 314:477-482

56. Kumabe I, Koori N, Matsuki Y, Sugisaki M, Ichigi T (1988) On-line measurement system for low level tritium gas by use of proportional counter. Journal of Atomic Energy Society of Japan 30:526-530

57. Jean-Baptiste P, Cassette P; Fourra E, Tartas I, Dapoigny A (2014) Measurement of French national tritiated water standard by helium-3 mass spectrometry. Appl Radiat Iso. $87: 157-161$

58. Huang YJ, Fan ZB, Chen CF, Qin HJ, Wu LS, Guo GY, Yang LT, Shang-Guan ZH (2014) Method validation and uncertainty evaluation of organic bound tritium analysis in environmental sample. J Environ Radioact 134:83-88

59. Croudace IW, Warwick PE, Morris JE (2012) Evidence for the preservation of technogenic tritium organic compounds in an estuarine sedimentary environment. Environ Sci Technol 46(1):5704-5712

60. Croudace IW, Warwick PE, Kim D (2014) Using thermal evolution profiles to infer tritium speciation in nuclear site metals: An aid to decommissioning. Anal Chem 86(18):9177-9185

61. Warwick PE, Kim D, Croudace IW (2010) Effective desorption of tritium diverse solid matrices and its application to routine analysis of decommissioning materials. Anal Chim Acta 676:93-102

62. Enachescu M, Stan-Sion C, Petre AR, Postolache C, Fugaru V (2018) H-3 and C-14 measurement of the irradiated graphite from the decommissioning VVR-S reactor in NIPNE Bucharest. J Anal At Spectrom 33:431-436

62. Hou XL (2005) Rapid analysis of ${ }^{14} \mathrm{C}$ and ${ }^{3} \mathrm{H}$ in graphite and concrete for decommissioning of nuclear reactor. Appl Radiat Isot 62:871-882

63. Kim DJ, Warwick PE, Croudace IW (2008) Tritium speciation in nuclear reactor bioshield concrete and its impact on accurate analysis. Anal Chem 80:5476-5480

64. Oh JS, Warwick PE, Croudace IW, Lee SH (2014) Rapid determination of tritium in urine samples using a combustion technique. J Radioanal Nucl Chem 299:187-191

65. Croudace IW, Warwick PE, Marsh R (2017) A suite of robust radioanalytical 
Journal of Radioanalytical and Nuclear Chemistry

1735 techniques for the determination of tritium and other volatile radionuclides in

1736 decommissioning wastes and environmental matrices. Fusion Science and Technology,

$1737 \quad 71: 290-295$

1738 66. UNSCEAR (2008) Sources and effects of ionizing radiation, Report to the General

1739 Assembly with scientific annexes Vol I. United Nations Scientific Committee on the

1740 Effects of Atomic Radiation, New York. 2010.

1741 67. Hou XL (2018) Tritium and ${ }^{14} \mathrm{C}$ in the Environment and Nuclear Facilities: Sources

1742 and Analytical Methods. J Nucl Fuel Cycle Waste Technol. 16:11-39

1743 68. Magnusson $\AA$, Stenström K, Aronsson PO (2008) C-14 in spent ion-exchange resins

1744 and process water from nuclear reactors: A method for quantitative determination of

1745 organic and inorganic fractions. J Radioanal Nucl Chem 275:261-273

1746 69. Canducci C, Bartolomei P, Magnani G, Rizzo A, Piccoli A, Tositti L, Esposito M

1747 (2013) Upgraded of the $\mathrm{CO}_{2}$ direct absorption method for low-level ${ }^{14} \mathrm{C}$ liquid

1748 scintillation counting. Radiocarcon 55(2-3):260-267.

1749 70. Shaw GD, Conklin MH, Nimz GJ, Liu FJ (2014) Groundwater and surface water flow

1750 to the Merced River, Yosemite Valley, California: ${ }^{36} \mathrm{Cl}$ and $\mathrm{Cl}-$ evidence. Water

1751 Resources Res. 50:1943-1959

1752 71. Muensterer C, Fohlmeister J, Christl M, Schroeder-Ritzrau A, Alfimov V, Ivy-Ochs S,

1753 Wackerbarth A, Mangini A (2012) Cosmogenic Cl-36 in karst waters from Bunker

1754 Cave North Western Germany - A tool to derive local evapotranspiration? Geochim

1755 Cosmochim Acta 86:138-149

1756 72. Fehn U (2012) Tracing crustal fluids: Application of natural I-129 and Cl-36. Annual

1757 Review of Earth and Planetary Sciences 40:45-67.

1758 73. Tolmachyov S, Ura S, Momoshima N, Yamamoto M, Maeda Y (2001) Determination

1759 of Cl-36 by liquid scintillation counting from soil collected at the Semipalatinsk

$1760 \quad$ Nuclear Test Site. J Radioanal Nucl Chem 249:541-545

1761 74. Itoh M, Watanabe,K, Hatakeyama M, Tachibana M (2002) Determination of ${ }^{36} \mathrm{Cl}$ in

1762 biological shield concrete using pyrohydrolysis and liquid scintillation counting.

1763 Analyst 127:964-966

1764 75. Fréchou C, Degros JP (2005) Measurement of ${ }^{36} \mathrm{Cl}$ in nuclear wastes and effluents:

1765 validation of a radiochemical protocol with an in-house reference sample. J Radioanal 
Journal of Radioanalytical and Nuclear Chemistry

1766

1767

1768

1769

1770

1771

1772

1773

1774

1775

1776

1777

1778

1779

1780

1781

1782

1783

1784

1785

1786

1787

1788

1789

1790

1791

1792

1793

1794

1795

1796

Nucl Chem 263(2):333-339.

76. Hammer-Rotzler B, Neuhausen J, Vockenhuber C, Boutellier V, Wohlmuther M, Tuerler A, Schumann D (2015) Radiochemical determination of I-129 and Cl-36 in MEGAPIE, a proton irradiated lead-bismuth eutectic spallation target. Radiochim Acta 103:745-758.

77. Suárez JA, Rodriguez M, Espartero AG, Piña G (2000) Radiochemical analysis of ${ }^{41} \mathrm{Ca}$ and ${ }^{45} \mathrm{Ca}$. Appl Radiat Isot 52:407-412

78. Itoh M, Watanabe K, Hatakeyama M, Tachibana M (2002) Determination of ${ }^{41} \mathrm{Ca}$ in biological-shield concrete by low-energy X-ray spectrometry. Anal Bioanal Chem 372:532-538

79. Warwick PE, Croudace IW, Hilegonds DJ (2009) Effective Determination of the Long-lived Nuclide Ca-41 in Nuclear Reactor Bioshield Concretes: Comparison of Liquid Scintillation Counting and Accelerator Mass Spectrometry. Anal Chem 81:1901-1906

80. Hampe D, Gleisberg B, Akhmadaliev S, Rugel G, Merchel S (2013) Determination of Ca-41 with LSC and AMS: method development, modifications and applications. J Radioanal Nucl Chem 296:617-624

81. Fink D, Klein J, Middleton R (1990) Ca-41 -past, present and future, Nucl Instr Method Phys Res B52:572-576

82. Müller P, Blaum K, Bushaw BA, Die S, Geppert,Ch, Nähler A, Nötershäuser W, Trautmann N, Wendt K (2000) Trace detection of ${ }^{41} \mathrm{Ca}$ in nuclear reactor concrete by diode-laser based resonance ionization mass spectrometry. Radiochim Acta,88:487492

83. Konig W, Schupfner R, Schuttelkopf H (1995) A fast and very sensitive LSC procedure to determine Fe-55 in stell and concrete. J Radioanal Nucl Chem Articles 193:127-131

84. Warwick PE, Croudace IW (2002) Separation of Fe-55/59 from fission and activation products using a di isobutylketon based extraction chromatographic materials, In: Warwick P (ed.) Proceedings of International symposium on environmental radiochemical analysis, Maidstone (GB), 18-20 Sep 2002. (Royal Society of Chemistry, Cambridge). 
1797

1798

1799

1800

1801

1802

1803

1804

1805

1806

1807

1808

1809

1810

1811

1812

1813

1814

1815

1816

1817

1818

1819

1820

1821

1822

1823

1824

1825

1826

1827

84. Warwick PE, Croudace IW (2006) Isolation and quantification of ${ }^{63} \mathrm{Ni}$ and ${ }^{55} \mathrm{Fe}$ in reactor effluents using extraction chromatography and liquid scintillation analysis. Anal Chim Acta 567:277-285

86. Dai X, Kramer-Tremblay S, Li C (2012c) Rapid determination of ${ }^{226}$ Ra in urine samples. Radiat Prot Dosim 151:30-35

87. Hou XL, Togneri L, Olsson M, Englund S, Gottfridsson O, Forsstrom M, Hirvonen H (2015) Standardization of Radioanalytical Methods for Determination of ${ }^{63} \mathrm{Ni}$ and ${ }^{55} \mathrm{Fe}$ in Waste and Environmental Samples, NKS-356, Nordic Nuclear Safty Research. http://www.nks.org/en/nks_reports/view_document.htm?id=111010213336225

88. Gudelis A, Druteikiené R, Luksiené B, Gvozdaité R, Nielsen SP, Hou XL, Mazeika J, Petrosius R (2010) Assessing deposition levels of ${ }^{55} \mathrm{Fe},{ }^{60} \mathrm{Co}$ and ${ }^{63} \mathrm{Ni}$ in the Ignalina NPP environment. J Environ Radioact 101:464-467

89. Hou XL, Roos P (2008) Critical comparison of radiometric and mass spectrometric methods for the determination of radionuclides in environmental, biological and nuclear waste samples. Anal Chim Acta 606:105-139

90. Holm E, Oregioni B, Vas D, Petterson H, Rioseco J, Nilsson U (1990) Nickel-63:

Radiochemical separation and measurement with an on implanted silicon detector. $J$ Radioanal NuclChem 138:111-118

91. Huang FYJ, Su TY, Tsai TL, Chao JH (2017) Analysis of Ni-63 in radwastes by extraction chromatography and radiometric techniques. J Radioanal Nucl Chem 314:979-886

92. Gautier C, Colin C, Garcia C (2016) A comparative study using liquid scintillation counting to determine $\mathrm{Ni}-63$ in low and intermediate level radioactive waste. $\mathrm{J}$ RadioanalNucl. Chem 308:261-270

93. Wang XM, He M, Ruan XD, Xu YN, Shen HZ, Du L, Xiao CJ, Dong KX, Jiang S, Yang XR, Lan XX, Wu SY, Zhao QZ, Cai L, Pang FF (2015) Measurement of ${ }^{59} \mathrm{Ni}$ and ${ }^{63} \mathrm{Ni}$ by accelerator mass spectrometry at CIAE. Nucl Instr Method B 361:34-38

94. Vajda N, Kim C-K (2010) Determination of radiostrontium isotopes: A review of analytical methodology. Appl Radiat Isot 68:2306-2326

95. Vajda N, Ghods-Esphahani A, Cooper E, Danesi PR (1992) Determination of radiostrontium in soil samples using crown ether. J Radioanal Nucl Chem 162:307- 
Journal of Radioanalytical and Nuclear Chemistry

323

96. Maxwell SL, Culligan B, Hutchison JB, Utsey RC, Sudowe R, McAlister DR (2017) Rapid method to determination ${ }^{89 / 90} \mathrm{Sr}$ in steel samples. J Radioanal Nucl Chem $314: 439-450$

97. Hou XL (2017) Determination of radionuclidic impurities in ${ }^{99 \mathrm{~m}} \mathrm{Tc}$ eluate from ${ }^{99 \mathrm{~m}} \mathrm{Tc} /{ }^{99}$ Mo generator for quality control. J Radioanal Nucl Chem 314:659-668

98. Grahek Z, Dulanska S, Karanovic G, Coha I, Tucakovic I, Nodilo M, Matel L (2018) Comparison of different methodologies for the ${ }^{90} \mathrm{Sr}$ determination in environmental samples, J Environ Radioact, 181:18-31

99. Surman JJ; Pates JM, Zhang H, Happel S (2014) Development and characterization of a new $\mathrm{Sr}$ selective resin for the rapid determination of ${ }^{90} \mathrm{Sr}$ in environmental water samples, Talanta, 129:623-628

100. Chen QJ, Hou XL, Yu YX, Dahlgaard H, Nielsen SP (2002) Separation of Sr from $\mathrm{Ca}, \mathrm{Ba}$ and $\mathrm{Ra}$ by means of $\mathrm{Ca}(\mathrm{OH})_{2}$ and $\mathrm{Ba}(\mathrm{Ra}) \mathrm{Cl}_{2}$ or $\mathrm{Ba}(\mathrm{Ra}) \mathrm{SO}_{4}$ for the determination of radiostrontium. Anal Chim Acta 466:109-1

101. Popov L, Hou XL, Nielsen SP, Yu Y, Djingova R, Kuleff I (2006) Determination of radiostrontium in environmental samples using sodium hydroxide for separation of strontium from calcium. J Radioanal Nucl Chem 269:161-173

102. Shi KL, Hou XL, Roos P, Wu WS (2011) Determination of Technetium-99 in environmental samples: a review. Anal Chim Acta 709:1-20

103. Ikäheimonen TK, Vartti VP, Ilus E, Mattila J (2002) Technetium-99 in Fucus and seawater samples in the Finnish coastal area of the Baltic Sea, 1999. J Radioanal Nucl Chem 252:309-313

1034. Marshall TA, Morris K, Law GTW, Mosselmans JFW, Bots P, Parry SA, Shaw S (2014) Incorporation and Retention of 99-Tc(IV) in Magnetite under High pH Conditions. Environ Sci Technol 48:11853-11862

1045. Oliver LR, Perkins WT, Mudge SM (2006) Detection of technetium-99 in Ascophyllum nodosum from around the Welsh coast. Chemosphere 65:2297-2303 1066. Hou XL, Jensen M, Nielsen SP (2007) Use of ${ }^{99 \mathrm{~m}} \mathrm{Tc}$ from a commercial ${ }^{99} \mathrm{Mo} /{ }^{99 \mathrm{~m}} \mathrm{Tc}$ generator as yield tracer for the determination of ${ }^{99} \mathrm{Tc}$ at low levels. Appl Radiat Isot $1858 \quad 65: 610-618$ 
1859 1860

1861

1057. Shi KL, Hou XL, Roos P, Wu WS (2012) Stability of technetium and decontamination of $\mathrm{Ru}$ and Mo in determination of ${ }^{99} \mathrm{Tc}$ in environmental soid samples by ICP-MS. Anal Chem 84: 2009-2016

106․ Shi KL, Qiao JX, Roos P, Wu WS Hou XL (2012) Rapid determination of technetium-99 in large volume seawater samples using sequential injection extraction chromatographic separation and ICP-MS measurement. Anal Chem.84:6783-6789.

1079. Shi KL, Hou XL, Roos P, Nielsen SP (2013) Seasonal variation of technetium-99 in Fucus vesiculosus and its application as an oceanographic tracer. Estuarine Coastal and shelf Science, 127:24-28.

11008. Shi KL, Hou XL, Qiao JX, Sun XJ, Roos P, Wu WS (2016) Analytical of technitium species and fractions in natural seaweed using biochemical separation and ICP-MS measurement. Anal Chem 88:11931-11937

11109. Kolacinska K, Samczynski Z, Dudek J, Bojanowska-Czajka A, Trojanowicz M (2018) A comparison study on the use of Dowex 1 and TEVA-resin in determination of Tc-99 in environmental and nuclear coolant samples in a SIA system with ICP-MS detection. Talanta. 184:527-536

1120. Guerin N, Riopel R, Kramer-Tremblay S, de Sillva N, Cornett J, Dai XX (2017c) Determination of Tc-99 in fresh water using TRU resin by ICP-MS. Anal Chim Acta 988:114-120

11느. Jenkinson SB, McCubbin D, Kennedy PHW, Dewar A, Bonfield R, Leonard KS (2014) An estimate of the inventory of technetium-99 in the sub-tidal sediments of the Irish Sea. J Environ Radioact 133:SI 40-47.

11z․ Rodriguez R, Leal L, Mianda S, Ferrer L, Avivar J, Carcia A, Cerda V (2015). Automation of Tc-99 extraction by LOV prior ICP-MS detection: Application to environmental samples. Talanta 133: SI 88-93.

11⒋ Dowdall, M., Selnæs, Ø.G., Gwynn JP, Lind B (2004) On the Use of ${ }^{99} \mathrm{Mo} /{ }^{99 \mathrm{~m}} \mathrm{Tc}$ Generators in the Analysis of Low Levels of ${ }^{99} \mathrm{Tc}$ in Environmental Samples by Radiochemical Methods. Water Air Soil Pollu. 156:287-297

116. Chen QJ, Dahlgaard H, Nielsen SP (1994) Determination of ${ }^{99} \mathrm{Tc}$ in seawater at ultra-low levels. Anal Chim Acta 285:177-180 
117. Wigley F, Warwick PE, Croudace IW, Caborn J, Sanchez AL (1999) Optimised method for the routine determination of technetium-99 in environmental samples by liquid scintillation counting. Anal Chim Acta 380:73-82.

1892 118. Hou XL, Hansen V, Aldahan A, Possnert G, Lind OC, Lujaniene G (2009)

1893 Speciation of Iodine-129 in the Environment. Anal Chim Acta 632:181-196.

1894 119. Hou XL, Dahlgaard H, Nielsen SP (2001) Chemical speciation analysis of ${ }^{129}$ I in

1895 seawater and a prliminary investigation to use it as a tracer for geochemical cycle

1896 study of stable iodine. Mar Chem 74:145-155.

120. Hou XL, Dahlgaard H, Nielsen SP (2002) Level and origin of iodine-129 in the

1898 Baltic Sea. J Environ Radioact 61:331-343

121. Hou XL, Dahlgaard H, Rietz B, Jacobsen U, Nielsen SP, Aarkrog A (1999) Determination of iodine-129 in seawater and some environmental materials by neutron activation analysis. Analyst 124:1109-1114

1902 122. Zulauf A, Happel S, Mokili MB, Bombard A, Jungclas H (2010) Characterization of 1903 an extraction chromatographic resin for the separation and determination of Cl-36 1904 and I-129. J Radioanal Nucl Chem 286:539-546

1905 123. Osman AAA, Bister S, Riebe B, Daraoui A, Vockenhuber C, Wacker L, Walther C 1906 (2016) Radioecological investigation of H-3, C-14, and I-129 in natural waters from 1907 Fuhrberger Feld catchment, Northern Germany. J Environ Radioact 165:243-252.

1908 124. Muramatsu Y, Uchida S, Sumiya M, Ohmomo Y (1995) Iodine separation procedure 1909 for the determination of ${ }^{129} \mathrm{I}$ and ${ }^{127} \mathrm{I}$ in soil by neutron activation analysis. J

$1910 \quad$ Radioanal Nucl Chem Lett 94:329-338

1911 125. Hou XL, Wang YY (2016) Determination of ultra-low level ${ }^{129}$ I in vegetation using 1912 pyrolysis for iodine separation and accelerator mass spectrometry measurement. $J$

1913 Anal At Spectrom 31:1298-1310

1914 126. Hou XL, Zhang DX (2018) Determination of ${ }^{129}$ I in environmental solid samples

1915 using pyrolysis separation and accelerator mass spectrometry measurement. J

1916 Radioanal Nucl Chem 317:487-499

1917 127. Zhang LY, Hou XL, Xu S (2015) Speciation analysis of ${ }^{129} \mathrm{I}$ and ${ }^{127} \mathrm{I}$ in aerosol using 1918 sequential extraction and mass spectrometry detection. Anal Chem 87(13):6937-6944 
Journal of Radioanalytical and Nuclear Chemistry

1919

1920

1921

1922

1923

1924

1925

1926

1927

1928

1929

1930

1931

1932

1933

1934

1935

1936

1937

1938

1939

1940

1941

1942

1943

1944

1945

1946

1947

1948

1949

128. Qiao JX, Hou XL, Miró M, Roos P (2009) Determination of plutonium isotopes in waters and environmental solids: A review. Anal Chimi Acta 652:66-84.

129. Alamalu, D.; Aggarwal, S.K. (2016). Determining the age and history of plutonium using isotope correlations and experimentally determined data on isotopic abundances of plutonium and Am-241. J. Radioanal. Nucl. Chem. 307, 277-284.

130. Varga Z, Nicholl A, Zsigrai Z, Wallenius M, Mayer K (2018) Methodology for the Preparation and Validation of Plutonium Age Dating Materials. Anal Chem 90:40194024.

131. Oh JS, Warwick PE, Croudace IW, Lee SH (2013) Rapid measurement of ${ }^{241} \mathrm{Pu}$ activity at environment level using low-level liquid scintillation analysis. J Radioanal Nucl Chem 298:353-359.

132. Vajda N, Kim CK (2010) Determination of Pu isotopes by alpha spectrometry: a review of analytical methodology. J Radioanal Nucl Chem 283:203-223

133. UNSCEAR (2006) Annex E: Sources-to-effects assessment for radon in homes and workplaces, In "Effects of Ionizing Radiation". United Nations Scientific Committee on the Effects of Atomic Radiation UNSCEAR 2006 Report to the General Assembly. Volume 2, United Nations, New York

134. Purkl S, Eisenhauer A (2004) Determination of radium isotopes and ${ }^{222} \mathrm{Rn}$ in a groundwater affected coastal area of the Baltic Sea and the underlying sub-sea floor aquifer. Marine Chem 87:137-149

135. Lamontagne S, Le Gal La Salle C, Hancock GJ, Webster IT, Craig T, Simmons CT, Love AJ, Julianne James-Smith J, Smith AJ, Kämpf J, Fallowfield HJ (2008) Radium and radon radioisotopes in regional groundwater, intertidal groundwater, and seawater in the Adelaide Coastal Waters Study area: Implications for the evaluation of submarine groundwater discharge. Marine Chem 109:318-336

136. Cook PG, Wood C, White T, Simmons CT, Fass T, Brunner P (2008) Groundwater inflow to a shallow, poorly-mixed wetland estimated from a mass balance of radon. $J$ Hydrol 354:213-226

137. Murad A, Alshamsi D, Hou XL, Al Shidi F, Al Kendi R, Aldahan A (2014) Radioactivity in groundwater along the borders of Oman and UAE. J Radioanal Nucl Chem 299:1653-1660 
Journal of Radioanalytical and Nuclear Chemistry

1950 138. Schönhofer F, Pock K, Friedmann H (1995) Radon surveys with charcoal and liquid

1951 scintillation counting. Field experience and comparison to other techniques. $J$

1952 Radioanal Nucl Chem 193:337-346

1953 139. Iimoto T, Akasaka Y, Koike Y, Kosako T (2008) Development of a technique for

1954 the measurement of the radon exhalation rate using an activated charcoal collector. $J$

1955 Environ Radioact 99:587-595

1956 140. Wadach JB, Hess CT (1985) Radon-222 concentration measurements in soil using

1957 liquid scintillation and Track Etch. Health Phys 48:805-808

1958 141. Turtiainen T (2009) Measurement of radon emanation of drainage layer media by

1959 liquid scintillation counting. J Radioanal Nucl Chem 279:325-331

1960 142. Horiuchi K, Murakami Y (1983) A new method for the determination of radon in

1961 soil air by the "open vial" and integral counting with a liquid scintillation counter. $J$

1962 Radioanal Nucl Chem 80:153-163

1963 143. Talha SA, Lindsay R, Newman RT, de Meijer RJ, Maleka PP, Hlatshwayo IN,

1964 Mlwilo NA, Mohanty AK (2008) $\gamma$-Ray spectrometry of radon in water and the role

1965 of radon to representatively sample aquifers. Appl Radiat Isot 66:1623-1626

1966 144. Stringer CE, Burnett WC (2004) Sample bottle design improvements for radon

1967 emanation analysis of natural waters. Health Phys 87:642-646

1968 145. EPA (2009) 2009 Edition of the Drinking Water Standards and Health Advisories,

1969 EPA 822-R-09-011. Office of Water, U.S. Environmental Protection Agency,

1970 Washington, DC.

1971 14도. Galán-López M, Martín-Sánchez A (2008) Present status of ${ }^{222} \mathrm{Rn}$ in groundwater

1972 in Extremadura. J Environ Radioact 99:1539-1543

1973 1476. Dinh CN, Rajchel L, Van HD, Nowak J (2017) Ra-224 and the Ra-224/Ra-228

1974 activity ratio in selected mineral waters from the Polish Carpathians. Geological

1975 Quarterly 61:771-778

1976 14즈. Kim H, Jung Y, Ji YY, Lim JM, Chung KH, Kang MJ (2017) Validation of a

1977 procedure for the analysis of Ra-226 in naturally occurring radioactive materials

1978 using a liquid scintillation counter. J Environ Radioact 166:188-194 
1979 14ำ. Vasile M, Benedik L, Altzitzoglou T, Spasova Y, Wätjen U, González de Orduña $\mathrm{R}$, Hult M, Beyermann M, Mihalcea I (2010) ${ }^{226} \mathrm{Ra}$ and ${ }^{228} \mathrm{Ra}$ determination in

1981 mineral waters - comparison of methods. Appl Radiat Iso. 68:1236-1239

1982 15049. Song L, Yang Y, Luo M, Ma Y, Dai X (2017) Rapid determination of radium$1983224 / 226$ in seawater sample by alpha spectrometry. J Radioanal Nucl Chem 171:169$1984 \quad 175$

1985 1510. Eikenberg J, Tricca A, Vezzu G, Bajo S, Ruethi M, Surbeck H (2001) coated discs. J Environ Radioact 54:109-131.

1521. van Beek P, M Souhaut M, Reyss JL (2010) Measuring the radium quartet $\left({ }^{228} \mathrm{Ra}\right.$, ${ }^{226} \mathrm{Ra},{ }^{224} \mathrm{Ra},{ }^{223} \mathrm{Ra}$ ) in seawater samples using gamma spectrometry. J Environ Radioact 101:521-529

153ㅡ. IAEA (2010) Analytical methodology for the determination of radium isotopes in environmental samples. IAEA/AQ/19, International Atomic Energy Agency, Vienna 1543. Case GN, McDowell WJ (1990) Separation of radium and its determination by photon-electron-rejecting alpha liquid scintillation (PERALS) spectrometry. Radioact Radiochem 1:58-69

15느. Nour S, El-Sharkawy A, Burnett WC, Horwitz EP (2004) Radium-228 determination of natural waters via concentration on manganese dioxide and separation using Diphonix ion exchange resin. Appl Radiat Isot 61:1173-1178 15호. WHO (2011) Guidelines for drinking-water quality, 4th edition. World Health Organization, Geneva, 541 pp.

1576. Laureano-Pérez L, Collé R, Fitzgerald R, Outola I, Pibida L (2007) A liquidscintillation-based primary standardization of ${ }^{210} \mathrm{~Pb}$. Appl Radiat Isot 65:1368-1380.

15⒎ Vajda N, La Rosa J, Zeisler R, Danesi P, Kis Benedek G (1997) A novel technique for the simultaneous determination of ${ }^{210} \mathrm{~Pb}$ and ${ }^{210} \mathrm{Po}$ using a crown ether. $J$ Environ Radioact 37:355-372

1598. Sirelkhatim DA, Sam AK, Hassona RK (2008) Distribution of ${ }^{226} \mathrm{Ra}-{ }^{210} \mathrm{~Pb}-{ }^{210} \mathrm{Po}$ in marine biota and surface sediments of the Red Sea, Sudan. J Environ Radioact 99:1825-1828 
2009

16059. Outola I, Nour S, Kurosaki H, Inn K, La Rosa J, Lucas L, Volkovitsky P, Koepenick K (2008) Investigation of radioactivity in selected drinking water samples from Maryland. J Radioanal Nucl Chem 277:155-159

1610. European Union (1998) Council Directive 98/83/EC of 3 November 1998 on the quality of water intended for human consumption. Official Journal of the European Communities, L 330/32, 05/12/1998. The Council of the European Union, Brussels.

1621. Jobbágy V, Wätjen U, Meresova J (2010) Current status of gross alpha/beta activity analysis in water samples: a short overview of methods. J Radioanal Nucl Chem 286:393-399

163z. Cooper EL, Cox JM, Workman WJ (1998) Analysis of Sr-90 and Alpha-Particle Emitters on Air Filters and Swipe Samples Using a Liquid Scintillation Counter with Alpha/Beta Discrimination. Radioact Radiochem 9:25-40

1643. Piraner O, Jones RL (2009) Urine gross alpha/beta analysis by liquid scintillation counting for terrorism preparedness. In "Advances in Liquid Scintillation Spectrometry, 2008" (J. Eikenberg, M. Jäggi, H. Beer, and H. Baehrle, Eds.), pp. 4146. Radiocarbon Publishers, University of Arizona, Tucson.

165⒋ Eikenberg J, Fiechtner A, Rüthi M, Zumsteg I (1996) A rapid screening method for determining gross alpha activity in urine using $\alpha / \beta$ LSC. In "Advances in Liquid Scintillation Spectrometry, 1994"' (G.T. Cook, D.D. Harkness, A.B. MacKenzie, B.F. Miller, and E.M. Scott, Eds.), pp. 283-292. Radiocarbon Publishers, University of Arizona,Tucson. 